\title{
Smoking prevention : comparing in-school, tailored out-of-school, and booster interventions
}

Citation for published version (APA):

Ausems, E. M. G. T. (2003). Smoking prevention : comparing in-school, tailored out-of-school, and booster interventions. [Doctoral Thesis, Maastricht University]. Universiteit Maastricht. https://doi.org/10.26481/dis.20031010ea

Document status and date:

Published: 01/01/2003

DOI:

10.26481/dis.20031010ea

Document Version:

Publisher's PDF, also known as Version of record

\section{Please check the document version of this publication:}

- A submitted manuscript is the version of the article upon submission and before peer-review. There can be important differences between the submitted version and the official published version of record.

People interested in the research are advised to contact the author for the final version of the publication, or visit the DOI to the publisher's website.

- The final author version and the galley proof are versions of the publication after peer review.

- The final published version features the final layout of the paper including the volume, issue and page numbers.

Link to publication

\footnotetext{
General rights rights.

- You may freely distribute the URL identifying the publication in the public portal. please follow below link for the End User Agreement:

www.umlib.nl/taverne-license

Take down policy

If you believe that this document breaches copyright please contact us at:

repository@maastrichtuniversity.nl

providing details and we will investigate your claim.
}

Copyright and moral rights for the publications made accessible in the public portal are retained by the authors and/or other copyright owners and it is a condition of accessing publications that users recognise and abide by the legal requirements associated with these

- Users may download and print one copy of any publication from the public portal for the purpose of private study or research.

- You may not further distribute the material or use it for any profit-making activity or commercial gain

If the publication is distributed under the terms of Article $25 \mathrm{fa}$ of the Dutch Copyright Act, indicated by the "Taverne" license above, 


\section{SMOKING PREVENTION}

Comparing in-school, tailored out-of-school, and booster interventions 


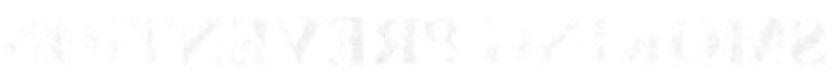

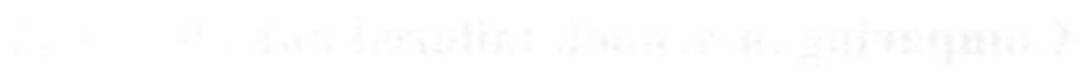

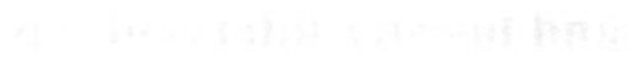




\section{SMOKING PREVENTION}

\section{Comparing in-school, tailored out-of-school, and booster interventions}

\section{Proefschrift}

ter verkrijging van de graad van doctor

aan de Universiteit Maastricht, op gezag van de Rector Magnificus,

Prof.dr. A.C. Nieuwenhuijzen Kruseman, volgens het besluit van het College van Decanen, in het openbaar te verdedigen op vrijdag 10 oktober 2003 om 12.00 uur

door

Elisabeth Maria Gertrudis Theresia Ausems 


\section{Promotor:}

Prof.dr. H. de Vries

\section{Co-promotor:}

Dr. I. Mesters

\section{Beoordelingscommissie:}

Prof.dr. N.K. de Vries (voorzitter)

Prof.dr. R.C.M.E. Engels (Katholieke Universiteit Nijmegen)

Prof.dr. R.A. Knibbe

Dr. R. Meertens

Dr. A.N. Mudde (Open Universiteit, Nederland)

ISBN: 90-9017337-4

Cover design: Kaspar Guyaux

Printed by Datawyse, Maastricht

The studies presented in this thesis were conducted at the Care and Public Health Research Institute (CAPHRI), part of the Netherlands School of Primary Care Research (CARE). The research was funded by grants from the European Commission (grants SOC 9620056805 F02, SOC 9720249105 F02) and the Dutch Cancer Foundation (99 UM 2094). 


\section{Contents}

$\begin{array}{lll}\text { Chapter } 1 \quad \text { General introduction } & 7\end{array}$

Chapter 2 Short-term effects of a randomized computer-based out-ofschool smoking prevention trial aimed at elemetary school children

Chapter 3 In-school and out-of-school smoking prevention aimed at Dutch elementary school children: Behavioral and mediating follow-up results of a randomized controlled trial

Chapter $4 \quad$ In-school and tailored out-of-school smoking prevention: Long-term effects of a Dutch randomized controlled trial using different strategies for handling missing data

Chapter 5 Do boosters contribute to tailored out-of-school smoking prevention?

Chapter 6 Effects of in-school and tailored out-of-school smoking prevention among Dutch vocational school students

Chapter 7 Do Dutch 11-12 years olds who never smoke, smoke experimentally or smoke regularly have different demographic backgrounds and perceptions of smoking?

Chapter 8 Prediction of smoking among Dutch elementary schoolchildren: Do girls need a specific prevention approach?

Chapter 9 General discussion

References

Summary

Samenvatting

Dankwoord 


\section{1}

\section{General introduction}

Despite all prevention efforts, the prevalence of smoking amongst youngsters remains a cause for concern all over the world for many authorities, including the World Health Organization (Brundtland, 1998), Unicef (Bellamy, 1998), the Group of Eight Ministers of the Environment (G8 ministers of the Environment, 1997), the ministers responsible for youth (Ministers responsible for youth, 1998), many local health agencies and -not least- the youngsters' parents.

Today, several areas of special attention related to smoking prevention can be identified: smoking prevention interventions for youngsters; smoking prevention programs for at-risk groups; smoking prevention programs in out-of-school settings and smoking prevention interventions supplemented with effective booster sessions.

Since at least one-third of the Dutch twelve-years-olds do have some smoking experience, it seems justifiable to start smoking prevention as early as elementary school. In the Netherlands as well as in other industrialized countries, most research on smoking prevention has been conducted among adolescents, analyzing their determinants of smoking as well as the effectiveness of prevention programs among this population. The few elementary school-based smoking prevention programs that have been developed, which were based on a blueprint of secondary school programs, have so far either not proved very successful in reducing tobacco use (Ary et al., 1990; Elder et al., 1996; Flay et al., 1989; Murray et al., 1992; Nutbeam, Macaskill, Smith, Simpson, \& Catford, 1993; Price, Beach, Everett, Telljohann, \& Lewis, 1998; Ringwalt, Ennett, \& Holt, 1991) or have not been evaluated at all. Hence, effective smoking prevention programs for elementary school students need to be further developed and/or tested. Therefore, the first question that the research project reported on in this thesis dealt with 
concerned the development and evaluation of smoking prevention programs for elementary schools.

It has also been found that smoking rates are higher among youngsters with a lower SES background. Dutch vocational schools tend to accommodate more students from lower income families than high schools (De Vries et al., 1994). Data on smoking rates confirm that, compared with students from other secondary school types, smoking rates among Dutch vocational school students are indeed highest (Stivoro, 1998). Therefore, vocational school students are a specific risk group in terms of smoking behavior. Focusing on high-risk groups might improve the public health impact of smoking prevention programs. The second research question discussed in this thesis therefore concerned the development and evaluation of target-group specific smoking prevention programs for high-risk Dutch vocational school students.

A number of smoking prevention programs have been developed in the last decade, the most promising of which focus on the development of social skills to resist influences that encourage smoking (US Department of Health and Human Services, 2000). So far, most of these programs have been run in school settings, which is an obvious choice, since school-based smoking prevention programs can reach wide audiences. However, a potential drawback of these programs is that their implementation depends on limited time and untrained personnel (Murray et al., 1992). In addition, those not regularly attending school are difficult to reach (Bullock, De Vries, Lopez, Thomas, \& Charlton, 1996). Out-of-school approaches might improve access to such high-risk adolescents. Traditionally, mass media methods are used to try and change knowledge and attitudes among youngsters in out-of-school settings, but mass media approaches are hardly able to include information that is fine-tuned to each individual youngster. Consequently, these approaches have not been very effective in changing smoking behavior. An innovative mass media-like strategy, namely computerized tailored interventions, may overcome these fine-tuning limitations. Hence, the third research question discussed in this thesis deals with the development and evaluation of a tailored smoking prevention program.

Another point of special attention is that, although some adolescent smoking prevention studies have reported short-term effects, these effects tend to dissipate over time (Ellickson, Bell, \& McGuigan, 1993; Flay et al., 1989; Lantz et al., 2000; US Department of Health and Human Services, 1994, 2000). The lack of booster sessions is suggested in the literature to be an important reason for this dissipation of effects. The fourth research question discussed in this thesis therefore concerned the development and evaluation of a smoking prevention booster program.

Finally, our understanding of reasons for smoking initiation and continuation among elementary school students is limited. It is, for instance, unclear whether smoking prevention programs for elementary school students should make a distinction between smoking initiation and continuation, or whether girls and boys in this group should be treated separately. The fifth research question therefore dealt with determinants (including gender-specific determinants) of smoking initiation and continuation among elementary school students.

In sum, the present thesis emphasizes the five points of interest described above. It focuses on the development and evaluation of a tailored out-of-school smoking prevention program and the evaluation of existing in-school programs directed at elementary school students and vocational students. Next, it reports on the development 
and evaluation of a booster program, which was added to the tailored out-of-school program for elementary school students. The thesis then focuses on the assessment of smoking determinants among Dutch elementary school students, because this information has hardly been available so far.

The remaining sections of this chapter describe smoking among youngsters, followed by a brief discussion of the health effects of smoking, the development of smoking prevention strategies, a theoretical explanation of smoking onset, a review of existing smoke prevention programs developed for adolescents, and finally, a short outline of the research project.

\section{Adolescence smoking behavior}

Between 1982 and 2000, statistics on smoking by Dutch adolescents aged 10 to 19 years remained rather stable (Stivoro, 2001). Table 1.1 presents data on smoking by Dutch youngsters of various age categories and attending various types of education for the year 1996, the year in which the smoking prevention programs described in this thesis were started. In the Netherlands, primary education lasts eight years and is intended for the general population between the ages of 4 and 12 years. From the age of 12, secondary education normally takes four to six years, depending on the school type chosen. The first year of secondary education is a transitional year between primary school and the various types of secondary education. Until 1999, two main types of secondary school were distinguished: the junior secondary vocational school (VBO, four years), which prepared pupils for specific vocations, and high school, which prepared students for further and higher education. High school was subdivided into three categories, at different levels: 1. Pre-university education (VWO, six years); 2. Senior general education (HAVO, five years); and 3. Junior general education (MAVO, four years).'

Smoking prevalence is known to rise sharply after students transfer from elementary to secondary education. This relation between smoking prevalence and school transition does not apply exclusively to the Dutch situation, where it occurs when students are 12 years old, but has also been identified by researchers in other countries (US Department of Health and Human Services, 1994). In 1996, the lifetime prevalence of smoking among 10- to 12 -year-old Dutch children was $19 \%$ for girls and $27 \%$ for boys. At the age of $13-14$, figures for girls $(47 \%)$ start to overtake those for boys $(46 \%)$. Four percent of 10- to 12-year-old girls and seven percent of 10- to 12-year-old boys indicate having smoked in the past four weeks, while at the age of 13-14, $25 \%$ of the girls and $18 \%$ of the boys report having done so (Stivoro, 1997). The greater rate of smoking initiation by female adolescents has been found in many developed countries and is of great concern, in view of the implications of smoking for, for instance, reproductive functions (US Department of Health and Human Services, 1994). Furthermore, table 1.1

\footnotetext{
'Recently (1999) the Dutch school system was restructured, MAVO and VBO being combined into a new school type called VMBO.
} 
shows that among secondary school students, the prevalence rates are highest in vocational schools students.

In sum, experimenting with smoking often starts earlier than the age of 14 years, the age category on which most current prevention programs focus. At least a third of the population of twelve-year-olds have experimented with smoking. Since experimentation often leads to regular smoking, prevention activities at an earlier age than the age of 14 are likely to be needed. Moreover, the data confirm that vocational school students are at particularly high risk of initiating smoking behavior.

Table 1.1 Smoking among Dutch youngsters, 1996

\begin{tabular}{|c|c|c|c|c|}
\hline \multirow{5}{*}{ 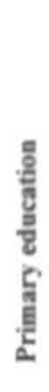 } & & $\begin{array}{l}\text { Ever } \\
\text { smoking }\end{array}$ & $\begin{array}{l}\text { Smoking } \\
\text { in the past } 4 \text { weeks }\end{array}$ & $\begin{array}{l}\text { Daily } \\
\text { smoking }\end{array}$ \\
\hline & 10 years old & $20 \%$ & $2 \%$ & - \\
\hline & 11 years old & $27 \%$ & $4 \%$ & $1 \%$ \\
\hline & 12 years old & $36 \%$ & $7 \%$ & $1 \%$ \\
\hline & Elementary school & $24 \%$ & $3 \%$ & - \\
\hline \multirow{5}{*}{ 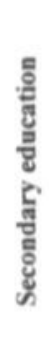 } & $\mathrm{VBO}^{\prime}$ & $72 \%$ & $47 \%$ & $39 \%$ \\
\hline & $\mathrm{MAVO}^{2}$ & $64 \%$ & $40 \%$ & $26 \%$ \\
\hline & HAVO' & $62 \%$ & $37 \%$ & $26 \%$ \\
\hline & $\mathrm{VWO}^{4}$ & $55 \%$ & $29 \%$ & $18 \%$ \\
\hline & $10-19$ years old & $54 \%$ & $31 \%$ & $23 \%$ \\
\hline
\end{tabular}

Source (Stivoro, 1996): ' VBO: junior secondary vocational education, ${ }^{2} \mathrm{MAVO}$ : junior general education, ${ }^{3}$ HAVO: senior general education, ${ }^{4} \mathrm{VWO}$ : pre-university education.

\section{Health effects of smoking}

Just after World War II, at which euphoric time nine out of every ten Dutch men were smokers (female figures were significantly lower, namely about one in four) (Stivoro, 2001), was also the time when the first negative health consequences of smoking were reported (Doll \& Hill, 1950; Levin, Goldstein, \& Gerhardt, 1950). Since then, smoking among Dutch men has dropped significantly to $37 \%$, while female smoking increased to $40 \%$ in 1975 and then dropped to $29 \%$ in 2000 (Stivoro, 2001). This smoking pattern is comparable to trends in the United States and in other Western European countries. 
Despite the decreased smoking prevalence among the male population half a century later, smoking is still considered the chief preventable cause of premature disease and death. About half of all American smokers will eventually be killed by their habit (Doll, Peto, Wheatly, Gray, \& Sutherland, 1994). In the Netherlands, smoking is linked to almost $50 \%$ of mortality caused by lung cancer, CORD (chronic obstructive respiratory disorder), coronary heart disease, and CVA (cerebrovascular accident) (Stivoro, 2001). Because of the increase in smoking among women, their cancer-related mortality is expected to increase over the next decades, while this mortality among men is expected to decrease (KWF, 2001).

The above adverse health consequences do not apply only to adult smokers, but also to youngsters. There is evidence that the health problems associated with smoking are a function of the duration (years) and intensity (amount) of use. The younger one begins to smoke, the more likely one is to be a regular smoker as an adult. Early onset of cigarette smoking means that more life-years are available for tobacco use, thus increasing the potential duration of use and the risk of a range of more serious health consequences. Earlier onset is also associated with heavier use; those who begin to use tobacco as younger adolescents are among the heaviest users in later adolescence and adulthood. Heavier users are more likely to experience tobacco-related health problems and are the least likely to quit smoking, due to their established nicotine addiction (Pierce \& Gilpin, 1996; US Department of Health and Human Services, 1994).

Nicotine addiction in adolescence appears to be based on the same basic biological processes that underlie nicotine addiction in adults (Colby, Tiffany, Shiffman, \& Niaura, 2000; Shadel, Shiffman, Niaura, Nichter, \& Abrams, 2000; US Department of Health and Human Services, 1988). As in adults, two medical disorders pertain to adolescence nicotine addiction: nicotine dependence and withdrawal (American Psychiatric Association, 1987). Nicotine dependence and withdrawal symptoms are implicated in the maintenance of tobacco use and difficulties in quitting. More than half of the smoking adolescents report attempting to quit each year, but only some of them finally succeed. The others explain their failure by referring to the prevalence of withdrawal syndrome, involving cravings, a state of anxiety, nervousness, tenseness, restlessness, irritation, anger, hunger/weight gain, depression or problems concentrating (Colby et al., 2000).

Besides long-term health consequences, active smoking by young people is associated with significant health problems during childhood and adolescence (US Department of Health and Human Services, 1994). Cigarette smoking during adolescence seems to reduce the rate of lung growth and the level of maximum lung function that can be achieved, and it also increases the risk of an unfavorable lipid profile that may be a precursor of coronary heart diseases. Young smokers are likely to be less physically fit than young nonsmokers, with fitness levels inversely related to the duration and intensity of smoking. Adolescent smokers' reports show that they are significantly more likely than their nonsmoking peers to experience shortness of breath, coughing spells, phlegm production, wheezing, and overall diminished physical health.

Tobacco use is also associated with a range of problem behaviors during adolescence, like alcohol use and illicit drug use (Jessor \& Jessor, 1977; Kandel \& Faust, 1975). Cigarettes are commonly the first drug used by young people in a sequence that can include tobacco, alcohol, marijuana, and hard drugs (Scheier, Botvin, 
\& Griffin, 2001; Torabi, Bailey, \& Majd Jabbari, 1993; US Department of Health and Human Services, 1994).

In sum, the serious consequences of adolescent smoking, in terms of both health and behavior, mean that the value of prevention of adolescent smoking is beyond dispute.

\section{Smoking prevention strategies in the light of recent theoretical insights}

When the health consequences of smoking became obvious in the 1960s, smoking prevention was recognized as a primary strategy to control smoking in the general population (Public Health Service, 1964). Smoking prevention by then was regulated by legislation and excise duties and was mainly implemented by means of school-based programs and mass media campaigns. Ever since, the content of smoking prevention programs, whether delivered by school or mass media or community-oriented, has developed under the influence of the growing etiological knowledge on smoking behavior and societal changes. In the $1960 \mathrm{~s}$, it was assumed that young people who engaged in smoking behavior simply did not have enough information, a deficit that could be addressed by presenting them with sufficient information. Improved knowledge levels, or cognitive factors, were supposed to lead immediately to behavior change (Thompson, 1978). Comprehensive reviews published at the time showed that smoking prevention programs based on the information-deficit approach did not sufficiently account for the complex relationship between knowledge acquisition and subsequent behavior and that these programs were not effective in terms of the prevention of smoking (Bruvold, 1993; Thompson, 1978).

The 1970s saw the rise of an approach based on the affective education model. The assumption underlying this approach was that adolescents became smokers because their self-perceptions were somehow compatible with smoking (US Department of Health and Human Services, 1994). Important topics in the smoking prevention programs based on this affective education model were increasing adolescents' perceptions of self-worth and establishing or clarifying a health-value system that would support youngsters' decision not to smoke. Again, it was concluded in several reviews that the programs based on the affective education model were as ineffective as those based on the information deficit model (US Department of Health and Human Services, 1994).

At the end of the 1970s, Evans and colleagues showed that smoking among adolescents was related to a range of factors categorized as sociodemographic, environmental, behavioral, and psychological (Evans, 1980, 1983; Evans et al., 1978). It became clear that earlier smoking prevention programs had underestimated the impact of social influences on smoking behavior onset. The new generation of programs that emerged at the time, also called Social Influence programs, differed from the earlier programs in several ways (US Department of Health and Human Services, 1994). Firstly, programs came to be based on social, psychological, and behavioral theories. One commonly applied theory was Bandura's Social Learning Theory (1977), which assumed that children might through observation acquire expectations and learn behaviors with regard to smoking. Children could learn vicariously, for example that 
smoking relieves tension or anxiety. Another prominent theory was McGuire's Social Inoculation Theory (1964), which assumed that providing youngsters with necessary information and skills would make them more resistant against pressures to smoke. Furthermore, intervention design became far more data-driven, that is to say, findings from theory-based and evidence-based etiology research on adolescent smoking were integrated into program development. In the course of time, the interventions included not only ingredients like knowledge, beliefs, and motivation, but also social influences, norms, self-efficacy and skills training. Variations on the Social Influence approach were the inclusion of peer leaders (instead of the traditional teacher-led approach), who were trained to help junior high school students develop the skills to resist social pressures to smoke (De Vries, Dijkstra, \& Kok, 1988; McAlister, Perry, Killen, Slinkard, \& Maccoby, 1980), and an approach called Life Skills Training, developed by Botvin (1986), which included topics like cognitive-behavioral skills for building selfesteem, resisting advertising pressure, managing anxiety, communicating effectively, developing personal relationships, asserting one's rights, and developing specific skills to resist social influences to smoke, drink, or use drugs.

Current smoking prevention programs are characterized by the use of comprehensive theories instead of numerous micro-theories. Examples of such comprehensive theories are the theory of triadic influence (Flay \& Petraitis, 1994; Petraitis, Flay, \& Miller, 1995) and the Attitude-Social-influence-self-Efficacy (ASE) Model (De Vries \& Backbier, 1994; De Vries, Backbier, Kok, \& Dijkstra, 1995; De Vries, Dijkstra, \& Kuhlman, 1988; Dijkstra, Mesters, De Vries, van Breukelen, \& Parcel, 1999). This model, the ASE Model, provided the theoretical framework for the research project reported on in this thesis.

\section{The ASE Model and the explanation of smoking onset}

\section{The ASE Model}

In the Netherlands, the ASE model (see figure 1.1) and its predecessors have been frequently used to assess the determinants of smoking and to develop and evaluate smoking prevention programs for secondary school students (De Vries et al., 1994; De Vries et al., 1995; De Vries, Dijkstra, \& Kuhlman, 1988; M. Dijkstra et al., 1999). The $\mathrm{ASE}_{\text {model }}{ }^{2}$ can be regarded as an integrated model for change, applying insights from the Theory of Reasoned Action (TRA)(Fishbein \& Ajzen, 1975) and its successor the Theory of Planned Behavior (TPB) (Ajzen, 1991), relevant aspects of Bandura's Social Learning Theory (1977) and Prochaska's Transtheoretical Model (Prochaska, Norcross, \& DiClemente, 1994). Just like the TPB, the ASE model assumes that the most important determinant of behavior is a person's behavioral intention. The behavioral intention is assumed to be most directly determined by three types of proximal cognitive factors: attitudes, social influences, and self-efficacy expectations.

\footnotetext{
${ }^{2}$ This thesis describes the Model as it was applied in 1997; meanwhile the ASE model has been further developed. For more recent details, see De Vries et al (De Vries et al., accepted for publication).
} 


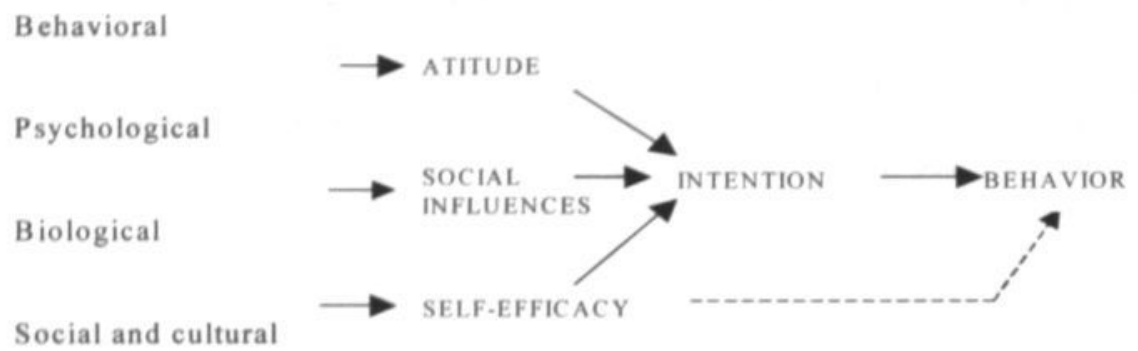

Distal facters

Proximal factors

Figure 1.1 The Attitude-Social-influence-self-Efficacy Model (ASE) (De Vries, Dijkstra, \& Kuhlman, 1988; De Vries \& Mudde, 1998)

Despite the similarities between the ASE model and the TPB, the ASE model has evolved as a separate model with several distinctive features (De Vries, Mudde, Dijkstra, \& Willemsen, 1998). Firstly, the ASE model does not assume that attitudes and social norms should be measured by a multiplicative function, since it is believed that multiplicative factors should be entered separately into regression equations (Evans, 1991). Secondly, the ASE model assesses two types of attitudes: (1) cognitive determinants operationalized by both positive and negative outcome expectations with respect to a particular behavior, and (2) emotional consequences operationalized by the evaluative response of an individual towards the behavior, as described by Ajzen and Fishbein (1980). Thirdly, the ASE model distinguishes three types of social influences: social norms, direct pressure or support and the perceived behavior of others (De Vries et al., 1995). Fourthly, self-efficacy expectations, a construct derived from Bandura's Social Learning Theory (1977), is measured instead of perceived control, by measuring the level of difficulty in performing the desired behavior, and/or by measuring the confidence a person has in their success in performing this behavior in various circumstances. Fifthly, the ASE model has adopted the notion of Prochaska's Transtheoretical Model (Prochaska et al., 1994) that behavioral change should be regarded as a process. Therefore, besides measurement of intention and behavior, the ASE model has also integrated the principles underlying the motivational stages suggested by the Transtheoretical Model (De Vries \& Backbier, 1994). Sixthly, the model assumes that four types of distal factors, namely behavioral (e.g., acquisition of skills and previous experiences with the same and related behaviors), psychological (e.g., self-esteem, anxiety, depressed affect), biological (gender, age, hereditary variables), and social and cultural factors (e.g. social climate, socio-economic status, parental style) influence the behavioral intention through the proximal factors (De Vries \& Mudde, 1998).

\section{Explaining smoking onset}

According to Green and Kreuter's PRECEDE-PROCEED model (1999), prevention efforts should focus on those determinants that are important and can be changed. The present chapter summarizes the most prominent findings about reasons for adolescent 
smoking that have emerged from three successive internationally oriented reviews (Conrad, Flay, \& Hill, 1992; Tyas \& Pederson, 1998; US Department of Health and Human Services, 1994) together with findings that have emerged from Dutch studies among secondary school students (Chatrou, 1992; De Vries et al., 1994; De Vries, Dijkstra, \& Kuhlman, 1988; De Vries \& Kok, 1986; M. Dijkstra et al., 1999). These findings are categorized on the basis of the concepts of the ASE model (De Vries \& Mudde, 1998), first in terms of the proximal factors attitudes, social influences, selfefficacy expectations and behavioral intention, and secondly in terms of distal factors like behavioral, psychological, biological, and social and cultural factors.

Proximal factors. The literature suggests that the intention to smoke is closely related to smoking onset and to the transition from trying to further experimentation with smoking. In terms of attitude, smoking tends to be related to less negative attitudes concerning health consequences, more positive attitudes towards smoking and smokers, and in particular the belief that tobacco use is functional. Perceptions by adolescents that tobacco use is normative, smoking by parents and siblings (albeit both with a variety of outcomes), smoking by peers, and parental approval of smoking also appear to be related to smoking. Finally, smoking initiation has been found to be associated with the lack of self-efficacy in the ability to refuse offers to use tobacco.

Distal factors. Behavioral risk factors like low levels of academic achievement and school involvement, lack of skills required to resist peer influences, and not having a healthy lifestyle (in terms of the use of alcohol, tobacco, and other drugs) are related to smoking. Previous smoking experiences are regarded as a behavioral factor that is closely associated with smoking continuation. Other related factors are psychological factors like feelings of stress and associated feelings of distress or depression, and experiences of low self-esteem. Biological factors related to initiation are increasing age and the developmental challenges of adolescence (especially during the transition years from elementary to secondary school). Finally, adolescent smoking has been found to be related to social and cultural factors, like low socioeconomic family status, low educational level of the parents, living in a single-parent home, ethnicity (presumably the higher level of acculturation), higher personal income among adolescents (more money to spend), lack of parental support with respect to nonsmoking, and accessibility and availability of tobacco products (sometimes influenced by the tobacco industry).

Results of smoking determinant studies in the Netherlands, which so far have only been conducted among secondary school students (Chatrou, 1992; De Vries et al., 1994; De Vries et al., 1995; De Vries, Dijkstra, \& Kuhlman, 1988; De Vries \& Kok, 1986; M. Dijkstra et al., 1999), have mainly supported the findings of the three international reviews (Conrad et al., 1992; US Department of Health and Human Services, 1994; Tyas \& Pederson, 1998). New findings were that school type, e.g. lower educational level (Chatrou, 1992; De Vries et al., 1994) and greater perception of perceived pressures (M. Dijkstra et al., 1999) were also related to smoking. 


\section{The impact of smoking prevention among adolescents}

Recently (January 2003), permission was given for a Dutch study, to be conducted at the University of Maastricht, which will evaluate the effects of a vaccine that might protect against nicotine dependence. It is suggested that if, for instance, adolescents are vaccinated, they will not develop nicotine addiction. If this approach succeeds and is accepted, tobacco addiction might become preventable. However, until positive results are forthcoming and ethical dilemmas are solved, we will have to focus on existing and evaluated smoking prevention strategies.

This thesis emphasizes two approaches of smoking prevention among youngsters, involving in-school and out-of-school prevention efforts, respectively. Reviews of research evidence on recent approaches to preventing the uptake of smoking in young people have also distinguished in-school from out-of-school approaches (Lantz et al., 2000; Stead, Hastings, \& Tudor-Smith, 1996; NHS, 1999). In-school smoking prevention consists of school-based interventions, while out-of-school smoking prevention consists of mass media campaigns, community programs and strategies to prevent access.

\section{School-based interventions}

Two of the most prominent assets of school-based smoking prevention programs are that they can reach wide audiences and that they allow two-sided communication with feedback, which is important for the fine-tuning of the message. Besides, in most developed countries health education is part of the school curriculum, so dealing with health issues is guaranteed (Murray et al., 1992; Wenter, Blackwell, Davis, \& Farrelly, 2002). However, a potential drawback of school-based programs is that their implementation depends on limited time and -sometimes- insufficiently trained personnel (Murray et al., 1992). In addition, the broad range of different health topics might impede a thorough implementation of all the programs.

Several more or less effective school-based smoking prevention programs have been developed worldwide and have been included in a number of reviews (Bruvold, 1993; Cuipers, 2002; Lantz et al., 2000; Stead et al., 1996; Thomas, 2003; Tobler \& Stratton, 1997). In the 2003 Cochrane review on school-based programs for smoking prevention (Thomas, 2003), Thomas identified 76 randomized controlled trials that were mainly based on the supply of information only, on social influence models or on generic social competence training, or were combined with wider multi-modal initiatives such as community participation. He classified 16 of the trials as most valid. No rigorous effects test was available for the programs that were based only on supplying information. For the 15 best programs based on social influences, 8 studies showed some positive effect of the intervention on smoking prevalence (Biglan, Ary, Smolkowski, Duncan, \& Black, 2000; Biglan et al., 1987; Cameron et al., 1999; De Vries et al., 1994; Elder, Sallis, Woodruff, \& Wildey, 1993; Ellickson \& Bell, 1990; Hansen \& Graham, 1991; Sussman, Dent, Stacy, \& Craig, 1998). Great expectations were raised by the large and rigorous program based on the social influences approach, the Hutchinson Smoking Prevention Project (Peterson, Kealy, Mann, Marek, \& Sarason, 2000), which followed students from third grade until two years after 12th grade. However, it failed to show positive effects. 
The evidence to date for the long-term effectiveness of school-based programs in preventing smoking initiation is limited. If any positive prevention effects were found at all, these effects had mostly dissipated after several years (Best, Thomson, Santi, Smith, \& Brown, 1988; Donaldson, Graham, \& Hansen, 1994; Flay, 1985; Lantz et al., 2000; Thomas, 2003; US Department of Health and Human Services, 1994, 2000). The lack of booster sessions is suggested in the literature to be an important reason for this dissipation of effects, implying that boosters should be included into smoke prevention programs (M. Dijkstra et al., 1999; Elder, Wildey et al., 1993; Lantz et al., 2000; Murray, Pirie, Leupker, \& Pallonen, 1989).

\section{Mass media campaigns}

Mass media campaigns have some appealing features for smoking prevention (Lantz et al., 2000; Sowden \& Arblaster, 2003). They allow vast audiences to be exposed to important health messages. Campaign planners can exercise control over the time of exposure and the selection of the messages that are disseminated. Mass media campaigns can provide high visibility for the health messages that they want to put across, so certain issues will remain in the public's eye. In addition, mass media have an important agenda setting function in society. They have the potential to reach particularly groups that may be difficult to access through more traditional approaches. Furthermore, mass media interventions are a relatively inexpensive way of exposing the population to information regarding their health, in terms of the costs per individual potential exposure. According to the Surgeon General's report (1994) an obvious limitation of the mass media is the one-way communication with minimal feedback loop or opportunities for interaction. High quality mass media materials are expensive and airtime for campaign messages destined for radio and television is also costly. Since 1980, psychosocial techniques (techniques ensuring that mass media messages are paid attention, comprehended, and accepted, as well as techniques that convey skills, stimulate social interaction, and reinforce positive behavior) and principles of social and commercial marketing have been incorporated into mass media programs to prevent smoking among young people (US Department of Health and Human Services, 1994). The use of marketing strategies can be regarded as counter-advertising to promotion activities by the tobacco industry. Lantz and colleagues concluded in their review that campaigns that are based on marketing principles and are theory-driven can influence youngsters' attitudes and behaviors regarding tobacco use. The duration and intensity of the campaign both seemed to be important. They recommended appropriate theoretical approaches and appropriate fine-tuning of messages to the target audience at the right time (Lantz et al., 2000).

In their effort to establish the effects of mass media campaigns for their Cochrane review, Sowden and Alblaster (2003) indicated that six out of a total of 63 studies met all the inclusion criteria. Two of these studies found reductions in smoking behavior, as well as effects on intermediate outcomes such as attitudes, social norms, and intentions. One found that a mass campaign was effective in influencing smoking behavior, compared with no intervention (Hafstad, Stray-Pedersen, \& Langmark, 1997). The other found a mass media campaign combined with a school-based program to be more effective than a school-based program alone (Flynn, Worden, Secker-Walker, Bladger, \& Geller, 1995). Just like Lantz and colleagues, Sowden and Alblaster (2003) therefore concluded that, despite some positive evidence of the effectiveness, the overall evidence 
of mass media approaches preventing smoking initiation is not strong. The great challenge will remain the methodologically correct evaluation of mass media campaigns, because randomization and the inclusion of control groups are difficult to achieve.

\section{Community programs}

The increased understanding of the combined effects of environmental, social and cultural conditions on tobacco use has resulted in an emphasis on comprehensive community-based approaches. Community interventions usually have multiple components and involve the use of community resources to influence individual behavior and community norms or practices related to adolescent tobacco use (Lantz et al., 2000). In trials, community-based approaches are compared with no intervention, with school-based programs or with mass media campaigns. In their systematic Cochrane review of community interventions, Sowden and colleagues (2003) indicated that 17 out of 63 studies met all the inclusion criteria (Sowden, Alblaster, \& Stead, 2003). Of thirteen studies that compared community interventions with no intervention controls, two reported lower smoking prevalence (Perry, Kelder, \& Klepp, 1994; Vartiainen, Paavola, McAlister, \& Puska, 1998). Of three studies comparing community interventions with school-based programs, only one found differences in reported smoking prevalence (Biglan et al., 2000), but these effects had disappeared after comparison of samples of expired air carbon monoxide. One study compared a community-wide intervention including a mass media component with a control group that received only the media component (Kaufman, Jason, Sawlski, \& Halpert, 1994). It found that smoking prevalences decreased in both groups from baseline to follow-up. One study reported a lower rate of increase in prevalence in a community receiving a multi-component intervention compared to a community exposed to a mass media campaign alone (Pentz et al., 1989). The results of this study indicated that although smoking rates had increased in both groups from baseline to follow-up, the rate of increase was significantly lower in the intervention group than in the control group.

According the Surgeon General's Reports $(1994,2000)$, community-based programs can be regarded as an important addition to school-based programs. The assumption in these programs is that school-based smoking prevention programs may produce only short-term effects. The Surgeon General's Report therefore recommended mobilizing parents and elements of the community to produce more lasting behavior change. Despite several methodological problems common to a number of studies about community programs, such as high dropout rates and inappropriate use of analysis, some small evidence for effectiveness was found for certain community programs carried out in the United States (Lantz et al., 2000; Sowden et al., 2003; US Department of Health and Human Services, 1994).

\section{Strategies to prevent access}

Controlling access to cigarettes is a well-established strategy to prevent youngsters from becoming addicted to tobacco. Public Smoking Restrictions can contribute to adolescent beliefs that nonsmoking is normative and that smoking creates health problems. Smoking regulations seems to be effective in reducing smoking by teenagers. Price policies can also have preventive effects. Higher prices encourage cessation among current smokers and discourage initiation among young smokers (US Department of 
Health and Human Services, 1994). Research on the impact of school policies has found that schools with strict smoking prevention policies had significantly lower smoking rates than schools with less strict policies and less emphasis on smoking prevention (De Vries, 2000; US Department of Health and Human Services, 1994). A recent systematic review included 27 studies that have evaluated strategies aimed at preventing retailers from selling tobacco to minors (Stead \& Lancaster, 2003). Of the 11 studies that assessed illegal sales, six were found to be successful. However, assessing the rate of illegal sales does not prove whether interventions aimed at deterring retailer sales to minors affect youngsters' perceived ease of access to tobacco or their tobacco use (Lantz et al., 2000). In the Netherlands, the Tobacco Act (VWS, 2002) addresses the protection of youngsters against smoking. Some recent regulations include the prohibition of small -and cheap- packages, increasing excise duties, and a minimum age for sale (16 years), advertising bans, and no-smoking policies at schools. Assessments of the effectiveness of these regulations are expected to be published in the future.

In sum, although the detrimental consequences of smoking became obvious as early as the $1960 \mathrm{~s}$, it unfortunately seems that more than forty years later there is still no 'magic bullet' for tobacco control. However, some conclusions about previous interventions can be drawn. Yach and Ferguson (1999) and Willemsen and de Zwart (1999) suggest that certain elements in an intervention are necessary for sustainable declines in tobacco consumption. These include policies to increase prices, restricted availability of tobacco to youngsters, bans on all forms of advertising and promotion of tobacco products (recently implemented in the Netherlands), counter-advertising to stress the harmful effects of tobacco, and the availability of cessation methods; all in addition to improved and sustained education and skills-building efforts among adolescents in school and out of school (Lynch \& Bonnie, 1994; US Department of Health and Human Services, 1994). In other words, smoking prevention has to address target groups at the micro level (the individual level, i.e., youngsters), at the meso level (the organizational level, i.e., the family and the school), and the macro level (the policy level, i.e., those involved in developing and implementing policies at the regional and national levels) (De Vries, 1999).

\section{Innovative computer-based approaches}

Recent innovations in youth smoking prevention and control involve computer-based programs. Pallonen and colleagues (1998) implemented a computer-based smoking prevention and cessation intervention in a vocational school sample (mean age 16.5 years) and reported follow-up findings after six months. Unfortunately, their sample size was too small to test the efficacy of the intervention. Aveyard and colleagues (2001) used an expert system computer program in a larger sample of 13- to 14-year-old British schoolchildren, and reported one- and two-year follow-up findings. Aveyard and colleagues (2001) used an expert system computer program in a sample of British schoolchildren, and reported one- and two-year follow-up findings. However, they found no evidence of effectiveness for smoking prevention.

Another innovative approach, closely related to the computer-based programs, are the personalized tailored letters mailed to a person's home. The idea of personalized tailored letters originated in the US (Campbell et al., 1994; Rimer et al., 1994; Skinner, 
Siegfried, Kegler, \& Strecher, 1993; Velicer et al., 1993), and has been further developed and tested with good results for several years in the Netherlands, where they have been used to reduce fat intake and increase fruit and vegetable intake (Brug, De Nooijer, Lechner, \& De Vries, 2002; Glanz, Van Assema, Kok, \& Van Breukelen, 1998; Dijkstra \& De Vries, 1999) as well as for adult smoking prevention (Dijkstra, De Vries, \& Roijackers, 1998; Willemsen, De Vries, Oldenburg, \& Van Breukelen, 1999). In a way, such personalized tailored letters combine the advantages of mass media (reaching a large number of people quickly) with interpersonal one-on-one contacts (interaction, feedback opportunities), while the disadvantages of both methods are partly avoided (Brug, Campbell, \& Van Assema, 1999; De Vries \& Brug, 1999; Dijkstra \& De Vries, 1999; Kreuter, Farrell, Olevitch, \& Brennan, 2000).

The development of tailored letters follows the process visualized in figure 1.2 (Brug et al., 1999). Five essential elements, namely a theoretical framework, a screening questionnaire, personal data entered into a computer data file, educational messages entered into a computer source file, and a computer program including tailoring algorithms, are combined to generate tailored feedback that contains highly personalized health messages. These messages can reach many members of a large and diverse population almost instantaneously (Kreuter et al., 2000).

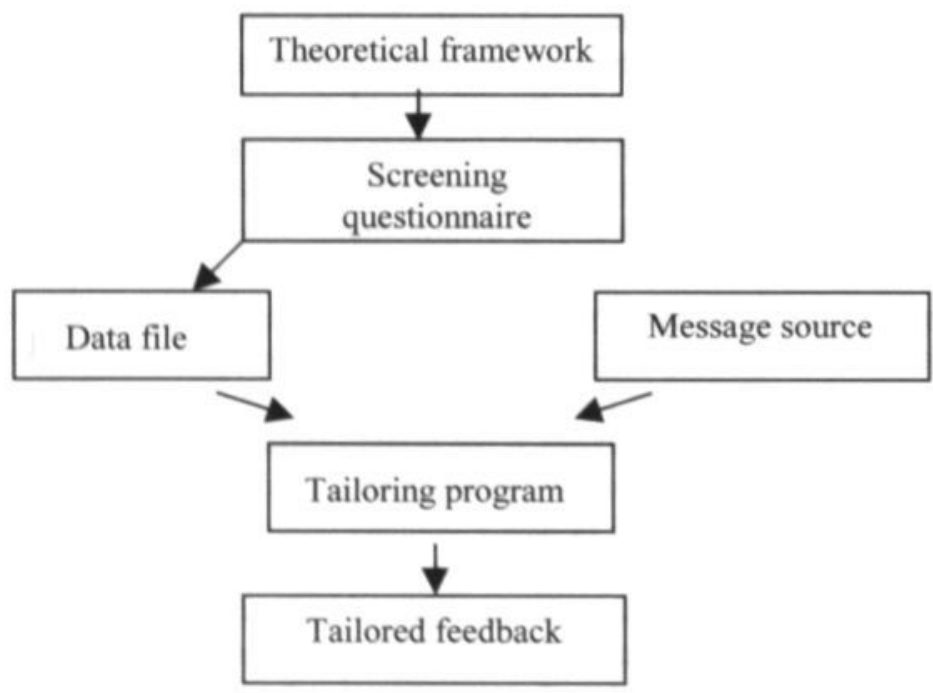

Figure 1.2 The process of computer tailoring (required with permission, Brug et al., 1999)

\section{Context and outline of the smoking prevention project}

The foundation for this thesis was laid in 1994 in a European project named Octopus, which was funded by the European Commission and in which the Universities of 
Birmingham (United Kingdom), Oviedo (Spain) and Maastricht (the Netherlands) participated. The aim of the project was to develop out-of-school smoking prevention programs to enhance prevention of smoking in high-risk adolescents. Furthermore, the project aimed to evaluate (long-term) out-of-school prevention efforts, relative to the impact of existing school-based social influence programs. Two main high-risk target groups were selected, namely highest-grade elementary school students and lowest grade vocational school students. The elementary school students were about to transfer to secondary education, which is considered to be a potential risk for smoking onset. The vocational school students were considered to be at higher risk to start smoking, as students in this school type more often come from low-income families, which are more likely to provide smoking models.

\section{The Dutch out-of-school programs}

By way of preparation for the out-of-school programs, the out-of-school activities of highest-grade elementary school students and first-grade vocational school students were surveyed during the first research period (1994-1995), in order to examine possible settings in which the out-of-school smoking prevention activities might be planned (Bullock et al., 1996). In the second period (1996-1999), each participating country started to develop an out-of-school intervention. Each country was free to develop the most culturally appropriate out-of-school approach. In the Netherlands, it was decided to use tailoring as the out-of-school activity. Although adolescents had never been used as the target group for tailoring, the potential of tailoring to fine-tune information for high-risk adolescents seemed very high.

In the Dutch project, the students who had been randomly assigned to the out-ofschool condition received three personalized letters with smoking information mailed to their home addresses at three-week intervals. Two theories supported the development of the messages, the Social Inoculation Theory (McGuire, 1964), which suggests that providing pupils with the necessary information and skills makes them more resistant against pressures to smoke, and the ASE model (De Vries, Dijkstra, \& Kuhlman, 1988; De Vries \& Mudde, 1998), an extension of the Theory of Reasoned Action (Ajzen \& Fishbein, 1980) and the Social Cognitive Theory (Bandura, 1986), which assumes that the intention to smoke is the best predictor of smoking, and that the intention to smoke results from attitudes, social influences, and self-efficacy expectations in relation to smoking. The content of the messages was refined by empathizing with adolescent lifestyle and, after interviews with students and teachers, by analyzing television programs, magazines etc. designed for youngsters. The source of personalization was the self-administered written questionnaire that students completed during school hours in the presence of a teacher in September 1997. This questionnaire encompassed important determinants of smoking onset (attitudes about short-term and social consequences of smoking), social influences (smoking parents, siblings, peers, perceived pressures to smoke), self-efficacy expectations (in different situations, in increasingly difficult circumstances), smoking behavior, and demographic factors, as well as personal identification information (names and addresses). The content of the messages was tailored to a number of possible answers or combinations of answers from the assessment questionnaire, and was primarily based on the essential elements according to Glynn, namely short-term physical and social consequences of smoking, pressure, other people's smoking behavior and refusal skills (Glynn, 1989). 
Although the themes of the messages were the same for elementary and vocational students, educational and developmental differences between elementary and vocational school students necessitated several adjustments in terms of language and layout. A computer program developed by Maastricht University combined the database file with the message file. The core of the computer program consisted of tailoring algorithms or decision rules- that linked students' answers to personal messages. All successive messages were combined in a letter format. The letters were appended with a picture puzzle and several cartoons to increase attention and attractiveness, and to foster the elaboration and storage of knowledge. In order to increase the elaboration of arguments not to smoke, a competition was included in which children could win one of two CD vouchers by answering the question: 'I don't want that cigarette because..'.

A summary of the content of the letters is depicted in figure 1.3. The first letter contained information regarding students' beliefs about smoking in general, the shortterm consequences of smoking (such as irritated eyes, nausea, bad smell), and social consequences of smoking (such as feeling tough, looking mature). The second letter focused on the influence of the social environment on students' smoking behavior (mostly from smoking parents and peers) and intentions not to smoke in the future. It included a discussion of the smoking prevalence of the Dutch population. Boys and girls received different messages and cartoons.
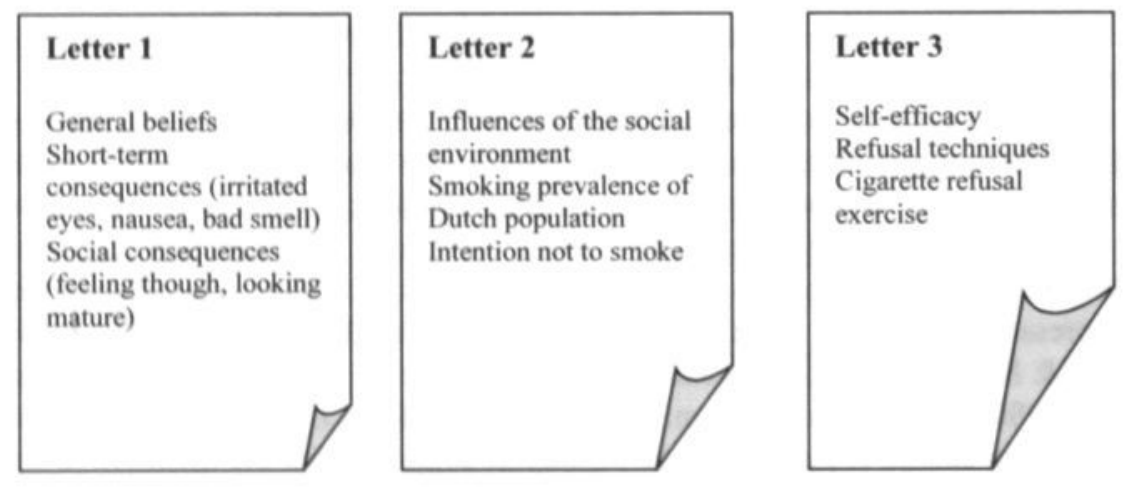

Figure 1.3 Content of the tailored letters

The third letter, based on the score on a self-efficacy scale (low-high), described refusal techniques and included an exercise about cigarette refusal. For instance, if a student had indicated in the pretest questionnaire that $\mathrm{s} / \mathrm{he}$ had doubts about his/her capacity to refuse cigarettes, the message selected by the computer program explained that cigarette-refusal capacity would improve if they did a simulation exercise. Subsequently, it described an exercise in which students were stimulated to practice cigarette refusal step by step. Students already equipped with high self-efficacy received a message in which these capacities were reinforced, followed by the simulation exercise and an explanation that cigarette refusal capacity could be improved through practice. 


\section{The Dutch in-school programs}

Both elementary and vocational school students were exposed to existing school-based smoking programs in 1996. Programs were only included in the study if they complied (or very nearly complied) with the essential elements of school-based smoking prevention programs formulated by Glynn (1989):

- Classroom sessions should be delivered at least five times per year in each of two years in the sixth through eight grades (comparable to grades seven and eight of the elementary school and the first grade of secondary school in the Netherlands).

- The program should emphasize the social factors that influence smoking onset, shortterm consequences and refusal skills.

- The program should be incorporated into the existing school curricula.

- The program should be introduced during the transition from elementary school to junior high school.

- Students should be involved in the presentation and delivery of the program.

- Parental involvement should be encouraged.

- Teachers should be adequately trained.

- The program should be socially and culturally acceptable to each community.

For the elementary schools, it was decided to use the 'Don't play with fire' program developed by the Dutch Foundation on Smoking and Health (Stivoro). This package consisted of a teacher manual and a student workbook. The intervention was administered over seven lessons, each lasting between 45 and 60 minutes. Each lesson comprised a general explanation by the teacher, a classroom discussion, a workbook task, a preparation task, and a final creative activity. Topics addressed included shortand long-term health consequences (e.g., costs and addiction), social images (e.g., feeling mature), advantages of nonsmoking, social pressures (including those from commercials), second-hand smoke and refusal skills.

For the vocational schools we made use of the 'Healthy Schools and Stimulants Program', a program aimed at prevention of tobacco and cannabis smoking, alcohol consumption, and gambling, developed by the Netherlands Institute of Mental Health and Addiction (Trimbos Institute). This comprehensive program consists of teaching, formulating rules for managing stimulants, attention to signals, supporting students with problems and involving parents. The smoking prevention component consisted of three lessons, each lasting about 50 minutes, for which student and teacher manuals were available. Each lesson comprised a general introduction by the teacher, a reading text in the workbook, a classroom discussion, a workbook task, and an additional task that summarized the main points of the lesson. The first lesson explained the ingredients of tobacco and the physical and mental reactions involved in smoking, while the second discussed norms concerning smoking and the third emphasized the pressures to smoke and the skills that are helpful in resisting cigarettes. Before the implementation of these in-school programs, teachers were instructed in their use.

\section{Boosters}

The third part of the study, funded by the Dutch Cancer Foundation, started in 1999. In this phase, the out-of-school school intervention for elementary school students was supplemented with three booster sessions. The aim of these boosters was to review and 
reinforce the tailored information that had been offered during the first year of the intervention. The content of the boosters was based on data from a May 1999 questionnaire, which was again based on the ASE model. The booster intervention, implemented between September 1999 and January 2000, was comparable with the tailored out-of-school intervention (i.e., three letters sent to students' home addresses, providing information about smoking), except that the messages in the booster intervention were based on specific items regarding beliefs, motives, and perceptions about smoking, rather than on the scales (sum scores) used in the tailored out-of-school intervention.

\section{Design}

The elementary schools were randomly assigned in May 1997 within regionally defined blocks to the in-school condition (I), out-of-school condition $(\mathrm{O})$, in- and out-of-school condition $(\mathrm{I}+\mathrm{O})$ or control group condition $(\mathrm{C})$. Before the start of this study, part of the vocational schools was already working with the in-school materials. In May 1997, those vocational schools already participating in the in-school program were randomly assigned within regionally defined blocks to the in-school condition (I) or to the in- and out-of-school condition $(\mathrm{I}+\mathrm{O})$. The remaining vocational schools (those who had not worked with the in-school program) were randomly assigned to the out-of-school condition $(\mathrm{O})$ or to the control condition $(\mathrm{C})$. Regarding the program effects, and in line with the two-way design of the study, the factor condition was dummy-coded, comparing main effects of the in-school and out-of-school interventions plus their interaction.

Furthermore, in August 1999, elementary schools from the out-of-school condition $(\mathrm{O})$ and in- and out-of-school condition $(\mathrm{I}+\mathrm{O})$ were randomly assigned to a booster $(+\mathrm{B})$ or a no-booster condition (-B). In line with the two-way design, treatment effects were tested by comparing dummy indicators for the in-school and booster treatments and their interaction.

\section{Timeline}

Table 1.2 shows the timeline for the smoking prevention implementation and evaluation project among elementary and vocational school students. In September 1997, pretest data were collected among students from 156 elementary schools and 36 vocational schools by means of a written questionnaire. The information gathered in these questionnaires was also used to construct the data file for the development of the tailored letters.

Both elementary and vocational school data (collected from students from the outof-school conditions) were entered into a computer data file, and then linked to the messages from the library file. Subsequently, the students received the tailored letters with personalized messages at their home addresses. The elementary and vocational inschool and out-of-school interventions were implemented between October 1997 and February 1998 in the schools that were randomized to the relevant condition.

Outcome effects of the in-school and out-of-school interventions were evaluated five times within a 36-months period in the elementary school sample and three times within an 18-months period in the vocational school sample, again using questionnaires based on the ASE model. Outcome effects were based on both smoking initiation among pretest never smokers and smoking continuation among pretest ever smokers. A process 
evaluation for the in-school program was conducted among schoolteachers, while the in-school, out-of-school and booster programs were process-evaluated among elementary and vocational school students who were involved in them. The main concerns of the process evaluation were exposure and appreciation.

Table 1.2 Timeline and program activities

\begin{tabular}{lll}
\hline & Elementary school sample & Vocational school sample \\
\hline September 1997 & Pretest questionnaires & Pretest questionnaires \\
October 1997 - February 1998 & In-school program and/ or & In-school program and/or \\
February 1998 & Out-of-school program & Out-of-school program \\
June 1998 & Follow-up I questionnaire & Follow-up I questionnaire \\
September 1998 & Follow-up 2 questionnaire & \\
February 1999 & & Follow-up 2 questionnaire \\
May 1999 & Follow-up 3 questionnaire & Follow-up 3 questionnaire \\
September 1999 - January 2000 & Booster intervention & \\
February 2000 & Follow-up 4 questionnaire & \\
September 2000 & Follow-up 5 questionnaire & \\
\hline
\end{tabular}

\section{Outline of the thesis}

The present thesis consists of two parts. The first part describes the results of two approaches to smoking prevention, namely in-school and tailored out-of-school programs, aimed at elementary and vocational school students. Chapter 2 discusses short-term effects of in-school and out-of-school programs for elementary school students. Chapter 3 discusses follow-up results of the elementary school programs after nine months, in terms of behavioral and mediating outcomes. Chapter 4 presents longterm effects (up to 36 months after pretest) of the in-school and out-of-school programs for elementary school students, while chapter 5 focuses on the effects of the boosters that were appended to the out-of-school intervention for elementary school students. Finally, chapter 6 summarizes the effects (up to 18 months after pretest) of the in-school and tailored out-of-school programs that were implemented in vocational schools.

The second part of the thesis is devoted to an in-depth analysis of the data that were derived from this project to assist future program development. In particular, it focuses on the distinction between three stages in the process of smoking to analyze whether different programs may be needed for these groups. These results are described in chapter 7. Although reviews of gender differences suggest that our understanding of the effect of gender on smoking initiation and continuation is limited, very few studies have concentrated on gender differences in elementary school students. Chapter 8 therefore 
chapter 1

provides results of analyses to check whether predictors of smoking initiation and continuation among elementary school students differ in general, as well as for girls and boys. The thesis ends with a chapter providing a summary and discussion of the conclusions, and indicating implications for smoking prevention and further research. 


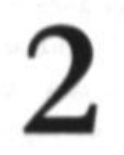

\section{Short-term effects of a randomized computer-based out-of-school smoking prevention trial aimed at elementary schoolchildren}

Published as: Ausems, M., Mesters, I., van Breukelen, G., De Vries, H. (2002). Shortterm effects of a randomized computer-based out-of-school smoking prevention trial aimed at elementary schoolchildren. Preventive Medicine, 34, 581-589 


\begin{abstract}
Background: Smoking prevention programs usually run during school hours. In our study, an out-of-school program was developed consisting of a computer-tailored intervention aimed at the age group before school transition (11-12 years old elementary schoolchildren). The aim of this study is to evaluate the additional effect of out-ofschool smoking prevention.

Methods: 156 participating schools were randomly allocated to one of four research conditions: 1. the in-school condition, an existing 7-lesson program; 2 . the out-of-school condition, three computer-tailored letters sent to the students' homes; 3 . the in-school and out-of-school condition, a combined approach; 4. the control condition. Pretest and six months follow-up data on smoking initiation and continuation, and data on psychosocial variables were collected from 3349 students.

Results: Control and out-of school conditions differed regarding posttest smoking initiation $(18.1 \%$ and $10.4 \%)$ and regarding posttest smoking continuation $(23.5 \%$ and $13.1 \%$ ). Multilevel logistic regression analyses showed positive effects of the out-of school program. Significant effects were not found regarding the in-school program, nor did the combined approach show stronger effects than the single-method approaches.

Conclusions: The findings of this study suggest that smoking prevention trials for elementary school children can be effective when using out-of-school computer-tailored interventions.
\end{abstract}




\section{Introduction}

In 1997, approximately $50 \%$ of the Dutch population aged 10-19 years had tried cigarettes, 22\% were occasional or daily smokers (Stivoro, 1997). Smoking Dutch youths had in many cases tried their first cigarette at the age of 11-12 years (De Zwart, Stam, \& Kuipers, 1997). In the Netherlands, 27 to $36 \%$ of 11-12 years old youths have smoked a cigarette (Stivoro, 1997). Many authors state that smoking prevention programs should be aimed at preventing or delaying tobacco use (Bush \& Iannotti, 1993; Glynn, 1993; Glynn, Anderson, \& Schwarz, 1991; Kelder, Perry, Klepp, \& Lytle, 1994), implying the need for effective prevention programs targeted at youngsters from the age of 11 years, when they are in the last grade of Dutch elementary schools. The focus of these programs should be to prevent youngsters from starting to smoke and to prevent those youngsters already experimenting from continuing with smoking.

In recent decades, several effective school-based smoking prevention programs for secondary school students were developed worldwide with a special emphasis on social influences (Bruvold, 1993), which represent the most important determinant of smoking initiation (Conrad et al., 1992; Evans et al., 1978; Petraitis et al., 1995). Similar schoolbased smoking prevention programs for elementary schools appeared less successful in reducing tobacco use (Murray et al., 1992; Nutbeam et al., 1993). Until now, prevention programs for 11-12 year olds in the Netherlands have never been evaluated.

There are various advantages to the use of school settings for smoking prevention; they can reach wide audiences; health education is part of the curriculum in many countries; there are opportunities for interpersonal communication; and lastly, the school setting is optimal for evaluation studies (Sussman, Dent, Burton, Stacy, \& Flay, 1995). A potential drawback of school-based smoking prevention programs is that their implementation is subject to limited time and untrained personnel (Murray et al., 1992). To overcome the disadvantages of in-school interventions, and because of the laborious reach of youngsters who are disaffected with school and who may reject health messages from those whom they regard as unsympathetic authority figures (Bullock et al., 1996), an out-of-school program was developed consisting of personalized tailored letters mailed to the students' homes. The idea of personal tailored letters originates in the United States (Campbell et al., 1994; Rimer et al., 1994; Skinner et al., 1993; Velicer et al., 1993), and has been further developed and tested for several years in the Netherlands (e.g. Brug et al., 1998; Dijkstra \& De Vries, 1999).

The goal of this study is to describe the effectiveness of: 1. a computer-based tailored out-of-school smoking prevention program; 2. an existing Dutch in-school smoking prevention program; and 3. a combined approach containing the in-school and out-of-school programs. The combined approach was included because research indicates that multiple prevention strategies produce better results for the reduction of tobacco use (Glynn, Greenwald, Mills, \& Manley, 1993; Glynn et al., 1991). This report describes the effects of in-school and out-of school smoking prevention on both smoking initiation among those who have never smoked and smoking continuation among those who ever smoked. 


\section{Methods}

\section{Design and procedure}

During the spring of 1997, 414 schools from southern, eastern and central parts of the Netherlands were approached with the assistance of local health departments. Eight local health departments, of which 54 existed in the Netherlands at that time, were asked to participate. Six of them agreed to assist in recruiting schools. The principals of all elementary schools within the local health department's region received an introductory letter, followed by a telephone call to discuss participation in the smoking prevention project. School principals in the Netherlands in 1997 were entitled to decide whether or not their students would participate in educational programs, provided that the school's representative advisory body, which consists of parents and staff, authorized this participation.

In June 1997, the 156 schools that finally approved participation were randomly assigned within regionally defined blocks to the in-school condition (I), out-of-school condition $(\mathrm{O})$, in- and out-of-school condition $(\mathrm{I}+\mathrm{O})$ or control group condition $(\mathrm{C})$. Teachers within the $\mathrm{I}$ and $\mathrm{I}+\mathrm{O}$ conditions were trained by volunteers for instruction in the in-school program. Volunteers supplied the schools with the in-school materials, the pretest questionnaires and explained the assessment procedure. Schools participating in the $\mathrm{O}$ and $\mathrm{I}+\mathrm{O}$ conditions distributed consent forms to students' parents, as their children had been selected to receive educational materials sent to their home addresses. Twenty-one parents refused to participate. Schools allocated to the $\mathrm{O}$ and $\mathrm{C}$ conditions received the pretest questionnaires by mail in July 1997. A letter with instructions regarding the assessment procedure was included. All teachers were instructed to schedule one hour for completing the pretest questionnaires in September 1997, to collect the questionnaires after students' completion at class level, to put them in a postage-paid envelope and - having sealed them - to return the envelopes to the researchers.

Objective validation did not apply to this young age group because the available methods only detect very recent -at most weekly- smoking, or smoking family members induces elevated readings (Murray, O'Connell, Schmid, \& Perry, 1987; Sussman et al., 1995). Self-reported results are accurate when confidentiality is assured and an identification coding system is used (Akers, Massey, Clarke, \& Lauer, 1983; Botvin \& Botvin, 1992; De Vries et al., 1994; Murray \& Perry, 1987; US Department of Health and Human Services, 1990). This procedure was used in our study. The front pages of both the pretest and the posttest questionnaires provided information about confidence. An identification code was used in the data-file and the researchers replaced students' names before the data entry was done.

Table 2.1 presents a timeline following the sample from approach to follow-up. The in-school program was implemented from October to December. The out-of-school program started in November 1997 and ended early February 1998. The posttest was in mid-February 1998. At the same time, students in the treatment conditions and teachers who implemented the in-school program completed a process evaluation questionnaire. 
Table 2.1 Number of schools from approach to follow-up

\begin{tabular}{lllllll}
\hline & & I & O & 1+O & C & Total \\
\hline May 97 & Approach & & & & & 414 \\
& Approval +Randomization & 39 & 39 & 38 & 40 & 156 \\
Sept 97 & Pretest & 36 & 36 & 37 & 34 & 143 \\
Sept $97-$ Feb 98 & Intervention & + & + & + & & \\
Feb 98 & Posttest & 34 & 36 & 36 & 34 & 140 \\
\hline
\end{tabular}

Note. I, In-school intervention; O, Out-of-school intervention; $1+0$, In-school and Out-ofschool intervention; $\mathrm{C}$, Control condition

\section{The interventions}

The in-school intervention consisted of a school-based social influence program, called 'Don't play with Fire', which was developed by the Dutch Foundation on Smoking and Health. This package included the essential components of successful social influence programs (Sussman et al., 1993). Instances of direct pressure were discussed and training in refusal skills was given. Awareness of the smoking behavior of other influencing people was enhanced and the short-term physical and social consequences of smoking were discussed. The package for this study contained a teacher manual and student workbook. The intervention consisted of seven lessons of between 45 and 60 minutes in length. Each lesson comprised a general explanation by the teacher, a classroom discussion, a workbook task, a preparation part, and a creative activity such as singing a song.

The out-of-school intervention consisted of three tailored letters with smoking prevention messages, which were mailed to students' homes at three-week intervals, sealed in envelopes addressed to the students. This procedure was used to ensure optimal confidentiality. The letters included the - aforementioned - essential components of successful social influence programs. The contents of the letters, however, were fine-tuned to individual characteristics. Through the means of the pretest questionnaire on attitudes, social norms, self-efficacy, smoking intention, and behavior, a database file was created containing personal information. Pilot testing and revision of concepts resulted in the creation of a message file. The content of the messages was based on the Social Inoculation Theory (McGuire, 1964), which suggests that providing pupils with necessary information and skills makes them more resistant to pressure to smoke, on the Theory of Reasoned Action (Ajzen \& Fishbein, 1980), which assumes that behavior results from attitudes and social norms, and on Bandura's Social Cognitive Theory (1986), which describes the operationalization of modeling and selfefficacy. A computer program, developed by the Maastricht University, combined the database file with the message file. The core of the computer program consisted of decision rules that provided the translation of students' answers into personal messages. 
All successive messages were combined into a letter format. The letters were appended with a picture puzzle and several cartoons to increase attention and attractiveness, and to foster the elaboration and storage of knowledge (Redman, 1997). In order to increase the elaboration of arguments not to smoke, a competition was included in which children could win one of two CD vouchers by answering the question: 'I don't want that cigarette because..'.

The first letter (eight versions) contained information regarding students' beliefs about smoking in general, the short-term consequences of smoking (such as irritated eyes, nausea, bad smell), and social consequences of smoking (such as feeling tough, looking mature). The second letter ( 32 versions) focused on the influence of the social environment on students' smoking behavior and intentions not to smoke in the future. It included a discussion of the smoking prevalence of the Dutch population. Boys and girls received different messages and cartoons. The third letter (two versions) was based on the score on a self-efficacy scale (low-high), described refusal techniques and included an exercise about cigarette-refusal. For instance, if a student indicated in the pretest questionnaire that $\mathrm{s} / \mathrm{he}$ had doubts about his/her capacity to refuse cigarettes, the message selected by the computer program explained that the cigarette-refusal capacity would improve through carrying out a simulation exercise. Subsequently, an exercise was described in which students were stimulated to practice cigarette-refusal step by step. A child already equipped with high self-efficacy received a message in which the capacities were reinforced, followed by the simulation exercise and an explanation that cigarette-refusal capacity would be improved through practice.

\section{Measurement}

\section{Outcome measurement for students}

An updated version of the ASE (Attitude-Social influence-self-Efficacy) questionnaire was used to assess both the predictors of smoking: attitudinal beliefs, social influences, self-efficacy expectations and intentions; and the outcome measure: smoking behavior (De Vries et al., 1994; De Vries, Dijkstra, \& Kuhlman, 1988; M. Dijkstra et al., 1999). Demographic variables like age, gender, religion, family composition, pocket money and parents' work were included as predictors as well, although they are assumed to influence smoking via attitudes, social influences and self-efficacy expectations.

Factor analyses confirmed four attitude subscales:

- Disadvantages of smoking, 11 items (Cronbach's $\alpha=80$ ) ranging from 'negative' (1) to 'very positive towards non-smoking' (5), referring to nausea, coughing, irritated eyes, breathing problems, unwise, expense, bad for your health, disturbing others, causes passive smoking, regret, and bad smell;

- Advantages of smoking, 5 items $(\alpha=.63)$ ranging from 'positive' (1) to 'very negative towards non-smoking' (5), referring to growing up, relieving boredom, relieving tension, tasting good, feeling tough;

- Social acceptance, 3 items $(\alpha=.75)$ ranging from 'very negative' $(-3)$ to 'very positive towards non-smoking' (3), referring to receiving attention from friends, acceptance by friends and making contacts;

- Long term physical consequences, 2 items $(r=.57)$ ranging from 'very negative' $(-3)$ to 'very positive towards non-smoking' (3), referring to risks of cancer and heart diseases. 
Social influence was measured by four indices:

- Modeling 'nuclear network', 4 items ranging from 'smoking' (-2), 'absent' (-1), and 'not smoking' ( 0$)$, referring to perceived smoking behavior of student's father, mother, brother/ sister and best friend;

- Modeling 'diffuse network', 4 items ranging from 'almost all are smokers' $(-4)$ to, 'almost none are smokers' $(0)$, measuring the number of smoking friends, peers, teachers and family members;

- Social norms, 6 items ranging from 'very negative' (-3) to 'very positive towards nonsmoking' (3), measuring the perceived beliefs of student's father, mother, brother, sister, best friend and friends;

- Social pressure, 10 items ranging from 'very often' $(-5)$ to 'never' $(0)$, measuring the perceived pressure to smoke from student's father, mother, brother, sister, best friend, friends, peers, teacher, family, and advertisements.

Self-efficacy, 6 items ( $\alpha=91)$ ranging from 'very uncertain' $(-3)$ to 'very certain' (3), each item referring to the student's expectations regarding refraining from smoking in different situations with increasing magnitude (when others smoke, when friends smoke, or when a cigarette is offered by someone, by parents or by friends, or when you are called a coward).

Intention to smoke was measured by one item ranging from 'definitely do' $(-3)$ to 'definitely do not intent to smoke' (3).

Smoking behavior was based on self-reports, categorizing students as: 1. Neversmokers: students who never smoked one (puff of a) cigarette; 2 . Non-current smokers: students who have smoked in the past, but not during the past month; and 3. Current smokers: students who have smoked during the past month.

For treatment effects on (the outcome) smoking initiation, we assessed the percentage of pretest never-smoking pupils (category 1) that indicated to have initiated smoking at posttest (categories 2-3). For treatment effects on (the outcome) smoking continuation, we assessed the percentage of pretest ever smokers (categories 2-3) that indicated at posttest to have smoked during the past month (category 3 ).

\section{Process measurement for students}

The process evaluation assessed exposure and appreciation. Exposure to the in-school condition was measured by 35 questions on a two-point scale: 'yes' (1) or 'no' (0), assessing for each of the seven lessons whether students received an explanation, preparation, class discussion, workbook task or creative activity at the end of the lesson. Appreciation of each lesson was evaluated from 'very bad' (0) to 'excellent' (10). Exposure to the out-of-school condition was recorded by asking if students had received each of the three letters: 'yes' (1) or 'no' (0); and by asking the extent to which they had read each letter: 'completely' (4) to 'not at all' (1). Students furthermore indicated how many times they read the letters. Appreciation of the letters was scored on a 4-point scale: 'liked reading it very much' (4) to 'not' (1) and students judged the visual appearance of the letters: 'very nice' (4) to 'not nice' (1). In order to find out how students perceived the essence of tailoring, that is the personal approach, the degree of personal approach was assessed: 'completely personally directed' (4) to 'not personally directed' (1). Lastly, students could indicate which of their parents, siblings or friends they had allowed to read the letters. 


\section{Process measurement for teachers}

The teachers' questionnaire assessed the performance of the above-mentioned five elements for the seven lessons on a two-point scale: 'yes' (1) or 'no' (0). In addition, teachers indicated their appreciation of each lesson from 'very bad' $(0)$ to 'excellent' (10).

\section{Analyses}

Students were nested within schools, and schools were randomly assigned to treatment conditions. Ignoring this nesting may lead to type I errors and too narrow confidence intervals for treatment effects (Flay et al., 1995). Therefore, almost all analyses were carried out using multilevel regression modeling, i.e. the program MIXREG (linear regression) for continuous outcomes (Hedeker \& Gibbons, 1996b), and MIXOR (logistic regression) for dichotomous outcomes (Hedeker \& Gibbons, 1996a).

To check whether the randomization was successful, the treatment conditions were compared on age, gender, pretest ever smoking and pretest psychosocial variables. Dropout was checked with attrition at posttest as outcome, and pretest demographic, pretest ever smoking and psychosocial variables and treatment conditions as predictors.

Regarding the program effects, and in line with the two-way design of the study, the factor condition was dummy-coded, comparing main effects of the in-school and out-ofschool interventions, plus their interaction. To test the in-school intervention effects, the factor in-school was computed: both in-school conditions (1) versus both not in-school conditions (0). To test the out-of-school intervention effects, the factor out-of-school was computed: both out-of-school conditions (1) versus both not out-of-school conditions ( 0 ). To test the additional effects of the in-school intervention on the out-ofschool intervention, the interaction term 'in-school $\mathrm{x}$ out-of-school' was included in the analyses.

Running large regression models with MIXOR might cause problems; therefore logistic regression was first conducted using SPSS 9.0 (SPSS Inc, 1999) to determine the final model containing significant covariates and interaction terms for the prediction of posttest ever and current smoking. The following strategy was used: posttest ever and current smoking were predicted from treatment factors (in-school, out-of-school and their interaction). Furthermore, pretest psychosocial measures and demographic variables were entered as covariates, as previous research showed that these were predictors of smoking (De Vries et al., 1994). Non-significant predictors and interactions were deleted stepwise $(\alpha=0.05)$, with the restriction that predictors were never removed from the model if they were involved in some interaction term in the model. The two treatment factors (in-school, out-of-school) were never removed, as their effects are the focus of this study. The final models were entered in the multilevel analyses to test the intervention effects.

The results of the process measurements were first calculated for each student or teacher, averaging across letters and lessons respectively, and subsequently for each school, averaging across students and teachers respectively. 


\section{Results}

\section{Sample characteristics}

The pretest questionnaires were returned by 143 schools $(91.7 \%)$. The most frequent reason for non-participation was teachers' perceptions of inexperience of their students concerning smoking. Table 2.2 shows the pretest characteristics of the students in the four conditions. At pretest, no differences were found between the conditions with respect to demographic and psychosocial variables.

Table 2.2 Pretest demographic and psychosocial characteristics of students by treatment condition, with ranges of the response scales

\begin{tabular}{|c|c|c|c|c|c|}
\hline & $\begin{array}{l}\mathrm{I} \\
\mathrm{N}=1002\end{array}$ & $\begin{array}{l}O \\
\mathrm{~N}=871\end{array}$ & $\begin{array}{l}\mathrm{I}+\mathrm{O} \\
\mathrm{N}=1068\end{array}$ & $\begin{array}{l}\mathrm{C} \\
\mathrm{N}=793\end{array}$ & $\begin{array}{l}\text { Total } \\
\mathrm{N}=3734\end{array}$ \\
\hline Male (\%) & 49 & 48 & 50 & 51 & 49 \\
\hline \multirow[t]{2}{*}{ Ever smokers (\%) } & 34.0 & 35.0 & 36.3 & 38.4 & 35.8 \\
\hline & mean & mean & mean & mean & mean \\
\hline Age & 11.6 & 11.7 & 11.6 & 11.6 & 11.6 \\
\hline Attitude & & & & & \\
\hline - Disadvantages: 11 (neg) - 55 (pos) & 36.3 & 36.2 & 36.4 & 36.0 & 36.2 \\
\hline - Advantages: 5 (pos) -25 (neg) & 10.6 & 10.5 & 10.3 & 10.9 & 10.6 \\
\hline - Social acceptance: -9 (neg) -9 (pos) & 0.2 & 0.3 & 0.4 & 0.3 & 0.3 \\
\hline - Long term consequences: -6 (neg) $-6(p o s)$ & 2.5 & 2.6 & 2.5 & 2.7 & 2.6 \\
\hline \multicolumn{6}{|l|}{ Social influences } \\
\hline - Modeling 'nuclear': -8 (neg) - 0 (pos) & -0.9 & -1.0 & -0.9 & -1.0 & -1.0 \\
\hline - Modeling 'diffuse': -16 (neg) - 0 (pos) & -3.1 & -3.1 & -2.9 & -2.9 & -3.0 \\
\hline - Social norms: - 18 (neg) - 18 (pos) & 10.0 & 10.3 & 10.1 & 10.3 & 10.1 \\
\hline - Pressure: -50 (neg) -0 (pos) & -2.7 & -2.4 & -2.1 & -2.6 & -2.4 \\
\hline Self-efficacy: -18 (neg) - 18 (pos ) & 9.4 & 9.5 & 9.6 & 8.8 & 9.4 \\
\hline Intention: -3 (neg) -3 (pos) & 2.0 & 2.0 & 2.0 & 1.9 & 2.0 \\
\hline
\end{tabular}

Notes, I, In-school intervention; O, Out-of-school intervention; $\mathrm{I}+\mathrm{O}$, In-school and Out-of-school intervention; C, Control condition. 'Neg' means negative towards non-smoking, 'pos' means positive towards non-smoking 


\section{Response}

The posttest questionnaires were returned by 140 schools (I: $\mathrm{N}=843$ students; $\mathrm{O}$ : $\mathrm{N}=807 ; \mathrm{I}+\mathrm{O}: \mathrm{N}=984 ; \mathrm{C}: \mathrm{N}=715$ ). Attrition, at student level, from pretest to posttest was $10.3 \%$. Apart from three schools that did not return the questionnaires, absenteeism and difficulties with matching pretest and posttest data were the main causes of attrition. Logistic regression with attrition as dependent variable, suggested that younger children were more likely to drop out compared to older students $(\mathrm{OR}=0.82 ; 95 \% \mathrm{CI}=0.68-0.98)$. Students in the out-of-school conditions $(\mathrm{O}, \mathrm{I}+\mathrm{O})$ were less likely (although not significantly) to drop out compared with students in the not out-of-school conditions $(\mathrm{I}, \mathrm{C})(\mathrm{OR}=0.80 ; 95 \% \mathrm{CI}=0.64-1.01)$.

\section{Program effects on smoking}

Changes in smoking prevalence at posttest are shown in table 2.3. Regarding the pretest 'never-smoked' sample, smoking initiation was lowest in the out-of-school condition $(10.4 \%)$ and highest in the control condition (18.1\%). In the 'ever-smoked' sample, the lowest rates of smoking continuation were found in the out-of-school condition $(13.1 \%)$ and the highest rates were in the control group (23.5\%).

Table 2.3 Smoking initiation, $\%$ with $95 \%$ confidence intervals among the pretest never smokers and smoking continuation, $\%$ with $95 \%$ confidence intervals, among the pretest ever smokers, by treatment condition with schools as unit of analysis

\begin{tabular}{lllll}
\hline & $\begin{array}{l}\mathbf{I} \\
(\mathbf{N}=\mathbf{3 4})\end{array}$ & $\begin{array}{l}\mathbf{O} \\
(\mathbf{N}=\mathbf{3 6})\end{array}$ & $\begin{array}{l}\mathbf{I + O} \\
(\mathbf{N}=\mathbf{3 6})\end{array}$ & $\begin{array}{l}\mathbf{C} \\
(\mathbf{N}=\mathbf{3 4})\end{array}$ \\
\hline Smoking initiation among pretest never smokers & 14.9 & 10.4 & 15.2 & 18.1 \\
Smoking continuing among pretest ever smokers & 21.6 & 13.1 & 14.2 & 23.5 \\
& $(11.2-18.7)$ & $(6.8-14.0)$ & $(10.2-20.3)$ & $(12.5-23.7)$ \\
& $(15.4-27.8)$ & $(9.2-19.3)$ & $(7.4-18.9)$ & $(17.0-30.1)$ \\
\hline
\end{tabular}

Notes, $\mathrm{I}=$ In-school intervention; $\mathrm{O}=$ Out-of-school intervention; $\mathrm{I}+\mathrm{O}=\mathrm{In}$ - and Out-of-school; Intervention; $\mathrm{C}=\mathrm{Control}$ condition

SPSS logistic regression analyses assessed modeling 'nuclear network', pressure, attitude 'disadvantages', intention, and age to be significant predictors of posttest smoking initiation. No significant interaction between the in-school and out-of-school factors was found. Table 2.4 presents the results of multilevel analyses of the final regression model regarding posttest smoking initiation. The out-of-school program tended to prevent pretest never smokers from initiating smoking at posttest $(\mathrm{p}=0.08)$. Furthermore, students with a positive intention towards smoking, students who felt under stronger pressure to smoke and older students had a significantly increased risk of being an initial smoker at posttest $(\mathrm{p}<.05)$. Students who perceived fewer disadvantages and who had more smokers in their immediate environment tended to be at higher risk of being an initial smoker at posttest $(\mathrm{p}<.1)$. 
Table 2.4 Significant predictors of posttest smoking initiation (1=yes, 0 -no) using the final regression model

\begin{tabular}{|c|c|c|}
\hline Pretest never smokers $\left(\mathrm{N}_{\text {madem }}=2130, \mathrm{~N}_{\text {stoot }}=140\right)$ & Odds Ratio & $95 \% \mathrm{Cl}$ \\
\hline In-school program $(1=$ yes, $0=$ no) & 1.09 & $0.77-1.56$ \\
\hline Out-of-school program (1=yes, 0 =no) & $0.73^{\prime}$ & $0.50-1.03$ \\
\hline Age (years) & $1.31 * *$ & $1.04-1.64$ \\
\hline Pretest attitude disadvantages: 11 (neg) - 55 (pos) & $0.99^{\dagger}$ & $0.97-1.01$ \\
\hline Pretest modeling 'nuclear': -8 (neg) -0 (pos) & $0.93^{\prime}$ & $0.86-1.01$ \\
\hline Pretest pressure: - 50 (neg) - 0 (pos) & $0.96 * *$ & 0.93-0.99 \\
\hline Pretest intention: -3 (neg) - 3 (pos) & $0.79 \bullet \bullet$ & $0.71-0.88$ \\
\hline
\end{tabular}

Notes, ${ }^{\cdots *} p<001 ;{ }^{*} p<, 01 ;{ }^{*} p<.05 ; ' p<, 10$; 'Neg' means negative towards non-smoking, 'pos' means positive towards non-smoking

Table 2.5 Significant predictors of posttest smoking continuation $(1=y e s, 0=n o)$ using the final regression model

\begin{tabular}{|c|c|c|}
\hline Pretest ever smokers $\left(\mathrm{N}_{\text {students }}=1190, \mathrm{~N}_{\text {schoob }}=137\right)$ & Odds Ratio & $95 \% \mathrm{CI}$ \\
\hline In-school program ( $1=$ yes, $0=$ no $)$ & 0.86 & $0.57-1.30$ \\
\hline Out-of-school program $(1=$ yes, $0=$ no $)$ & $0.65^{*}$ & $0.42-0.99$ \\
\hline Age (years) & 1.01 & $0.77-1.32$ \\
\hline Pretest attitude advantages: 5 (pos) - 25 (neg) & $1.06^{*}$ & $1.01-1.12$ \\
\hline Pretest attitude disadvantages: 11 (neg) - 55 (pos) & 0.99 & $0.97-1.01$ \\
\hline Pretest modeling 'nuclear': -8 (neg) - 0 (pos) & 0.96 & $0.87-1.04$ \\
\hline Pretest pressure: -50 (neg) -0 (pos) & 1.01 & $0.99-1.03$ \\
\hline Pretest intention: $-\mathbf{3}$ (neg) - 3 (pos) & 0.95 & $0.86-1.06$ \\
\hline
\end{tabular}

Notes, ${ }^{* * *} \mathrm{p}<.001 ;{ }^{* *} \mathrm{p}<.01 ;{ }^{*} \mathrm{p}<.05 ;{ }^{\dagger} \mathrm{p}<.10$; 'Neg' means negative towards non-smoking, 'pos' means positive towards non-smoking 
SPSS logistic regression analyses assessed modeling 'nuclear network', pressure, attitude 'disadvantages', attitude 'advantages', intention, and age to be significant predictors of posttest smoking continuation. Table 2.5 shows the results of the multilevel analyses using the final regression model of posttest smoking continuation. No interaction between the treatment factors turned up. The out-of-school treatment was effective in preventing pretest ever smokers from continuing smoking $(\mathrm{p}<.05)$. The inschool treatment effect was not significant. Also, students who perceived more advantages of smoking were more likely to continue smoking at posttest $(\mathrm{p}<.05)$.

The school intraclass correlation coefficient reflects the proportion of unexplained outcome variance that was accounted for by the schools. With regards to posttest smoking initiation, the intraclass correlation was 0.07 , for posttest smoking continuation this was 0.14 , as obtained with the regression models in tables 2.4 and 2.5 respectively.

Because attrition at posttest could be predicted by age and possibly also by treatment, selective dropout might influence the results. To check for this effect, analyses were repeated in two ways (Heyting, Tolboom, \& Essers, 1992). Firstly, the missing data of dropouts was replaced by their pretest observation, the so-called 'last observation carried forward' analyses. Secondly, dropouts were treated as smokers, 'worst case' analyses. Both analyses were performed for all students $(\mathrm{N}=3734)$ and no relevant differences compared with the previous analyses were found.

\section{Process evaluation}

Of the intervention schools, $91 \%(\mathrm{~N}=64)$ returned the teacher process questionnaires. In five schools two teachers realized the implementation of the school program, hence 69 questionnaires were returned. The response rates of the students' process questionnaire were identical to those from the outcome measurement questionnaire, as data collection was combined.

With respect to the in-school exposure, $87 \%$ of the teachers carried out the explanation activities of all seven lessons; the preparation activities were implemented by $72 \%$ of the teachers; $80 \%$ of the teachers used the class discussions; $87 \%$ used the workbook tasks; and the creative end-of-session activity was carried out by $55 \%$ of the teachers. Students responded almost similarly. Teachers rated the seven lessons with a grade of $7.5(95 \% \mathrm{CI}, 7.3-7.6)$ on a scale from bad (0) to excellent (10); students gave them a $7(95 \% \mathrm{Cl}, 6.8-7.2)$.

With respect to the out-of-school exposure, $85 \%$ of the students received the letters, and the students read them, on average, 1.3 times; $70 \%$ read them (almost) completely, $51 \%$ liked reading the letters; and $48 \%$ liked the appearance of the letters. Furthermore, $59 \%$ of the students felt more or less personally addressed by the letters; $58 \%$ of the mothers, $41 \%$ of the fathers, $12 \%$ of students' siblings, and $6 \%$ of their friends were allowed to read the letters. 


\section{Discussion}

The goal of this study was to describe the effectiveness regarding smoking prevention for Dutch elementary schoolchildren (11-12 years old) of a computer tailored out-ofschool program, an in-school program and a combined approach containing both inschool and out-of-school programs. The out-of-school program was effective in preventing ever smokers continuing to smoke at posttest. Furthermore, pretest never smokers in the out-of school program were better able to resist smoking initiation, although this effect was only borderline significant. No significant effects were found for the in-school program regarding smoking initiation and continuation. The combined approach did not result in additional effects. Smoking initiation in the combined approach was comparable with the in-school condition; more specifically, the out-ofschool program seems only to have a preventive effect if no in-school program is run simultaneously.

Comparable tailored out-of-school interventions targeting elementary school children do not exist, as far as is known. However, interventions targeted at adult smokers, who received tailored letters with smoking cessation information, and tailored interventions aimed at healthy fat, fruit and vegetable intake also showed successful results (Brug et al., 1998; Dijkstra, De Vries, \& Roijackers, 1999).

Comparably disappointing results of in-school smoking prevention interventions as found in our study - showed up in a British study (Nutbeam et al., 1993), aimed at schoolchildren aged 11-12 years, although this study was not fully comparable. Schoolchildren in the Netherlands aged 11-12 years have not yet made the school transition, in contrast to British children of that age, who have already passed the stressful school transition, which is assumed to be a predictor of smoking (Sussman et al., 1995).

Because the in-school and out-of-school interventions had a comparable theoretical basis (resistance skills, social norms and pressure, short and long term consequences of smoking), the tailoring aspect in the out-of-school program might have been an important predictor of success. The assessment of determinants of the target group and the educational fine-tuning of these determinants during the modification phase might be regarded to be of great importance. Azjen and Fishbein concluded that if proper individually based instructions are included in educational sessions, a greater level of success can be expected (Ajzen, 1985; Ajzen \& Fishbein, 1980). The out-of-school intervention made use of computerized tailoring as a personalized fine-tuning instrument, and confirms their recommendation.

The out-of-school aspect can also be a reason for the positive effects. The letters were mailed to each student's home and a method of direct personal approach was used, which may result in higher personal involvement with the message and a stronger attitude-behavior relationship. In-school programs lack individual fine-tuning, so lower personal involvement may result in a weaker attitude-behavior relationship (Petty \& Cacioppo, 1986). More than half of the students (59\%) in the out-of-school group felt personally addressed by the letters. The involvement rate would undoubtedly have improved if the information in the letters had been tuned to students' smoking behavior. However, this option was not used in this study in order to prevent arguments in student's family. Although the letters were addressed to the students themselves, more 
than half of the mothers and more than one third of the fathers were allowed to read the letters. This spontaneous parental involvement might stimulate discussions at home about (not) smoking. At the age of 11-12 years, parental influence is still dominant, compared to older children where peers turn out to be more influential. This effective impact of parental influence was demonstrated in a family-linked program (Charlton, 1986). Our study shows that through the tailored letters, parental influence on smoking prevention can be activated.

A relationship was found between age, treatment and posttest attrition. Attrition could mainly be attributed to three schools in the in-school and in-and-out-of-school conditions that did not send back the questionnaires, absenteeism, and difficulties with matching pretest and posttest data. Analyses including all dropouts, either as posttest smokers or with the same pretest smoking-scores, did not yield results very different from those obtained by excluding drop-outs from the analyses.

A limitation of the study is that the timing of posttest measurement, two months after the end of the in-school intervention and almost immediately after the end of the out-of-school intervention, may have influenced the results of this study. The letters were fresh in students' memory and could therefore have been more effective than the in-school intervention. However, another argument could be that substantial time is needed to be able to show significant effects, thus making the results of the computer tailored letters notable.

No validation of self-reported smoking behavior was used in this study, because objective measurements for 11-12 years old are unreliable. These measurements only detect very recent smoking. However, most smokers in our selected age group are experimenting with smoking. Furthermore, self-reports have been demonstrated to be accurate when confidentiality is assured and an identification coding system is used (Akers et al., 1983; Botvin \& Botvin, 1992; Murray \& Perry, 1987; US Department of Health and Human Services, 1990). In this study these precautions were taken.

Process evaluation results of both in-school and out-of-school programs indicated that there is room for implementation improvements. Concerning the out-of-school intervention, the attractiveness with regards to content and appearance could be further refined.

The results discussed in this study are based on short-term assessments. Elementary schoolchildren aged 11-12 years find themselves confronting some stressful life events, such as school transition and puberty. Smoking prevalence at 11-12 year is still low, however literature indicates that a strong increase in smoking initiation is expected in the years that follow (De Zwart et al., 1997). Therefore, long-term assessment should determine whether the tailored out-of-school program remains a promising instrument for the prevention of smoking initiation and continuation, and whether preventive capacities of the in-school program will become evident after all. 


\section{In-school and out-of-school smoking prevention aimed at Dutch elementary school children: Behavioral and mediating follow-up results of a randomized controlled trial}

Manuscript submitted for publication as: Ausems, M., Mesters, I., van Breukelen, G., De Vries, H. 'In-school and out-of-school smoking prevention aimed at Dutch elementary school children: Behavioral and mediating follow-up results of a randomized controlled trial' 


\begin{abstract}
In general, smoking prevention programs for youngsters are implemented in school settings. In order to remedy some drawbacks of in-school programs, such as lack of time and skills to deliver the programs, an out-of-school smoking prevention program was developed. This study compares the out-of-school program (three computer-tailored letters with smoking information sent to the students' homes) with an existing in-school program (a seven lesson smoking prevention program). Schools were randomly allocated to: 1. In-school program; 2 . Out-of-school program; 3 . In- plus out-of-school program; 4. Control condition. In September 1997, 3734 students from 143 elementary schools returned the pretest questionnaire, which, besides baseline information, provided information for the content of the tailored letters. Both in-school and out-ofschool programs started in September 1997. Pretest and nine months follow-up data on smoking initiation and continuation, and data on psychosocial variables were collected from 3201 students (mean age at pretest was 11.6 years). While significant effects were found at 6-months follow-up, these effects were non-significant after nine months. At 9months follow-up, both treatments did have a positive effect on the perception of the disadvantages of smoking, self-efficacy expectations about refusing cigarettes among never smokers increased as a result of the out-of-school intervention. Booster sessions are recommended, since earlier research has demonstrated their effectiveness. More research is indicated on approaches to increase self-efficacy expectations about cigarette refusal among ever smokers.
\end{abstract}




\section{Introduction}

Over the past ten years, smoking figures among Dutch young people have shown stable patterns. Generally, about $50 \%$ of youngsters aged $10-19$ try cigarettes, $22 \%$ of them smoke at least occasionally. Most daily smokers started experimenting with cigarettes at the age of twelve or even earlier (De Zwart et al., 1997). In 1997, 26 to $32 \%$ of the 11 12 year-olds indicated lifetime smoking, while 4 to $9 \%$ of the $11-12$ year-olds indicated having smoked during the past month (Stivoro, 1998). Because smoking is the most preventable risk factor for lung cancer and cardiovascular diseases (US Department of Health and Human Services, 1994), approaching upper grade elementary school students with effective educational programs is relevant to prevent them experimenting or continuing with smoking.

According to Bartholomew and colleagues (1998), effective educational programs are those that are theory-driven and that are based on problem analyses including the target group perspective. In the Netherlands, the ASE model (Attitude -Social Influence- Self-Efficacy; figure 3.1 ) has been used to assess the determinants of smoking and to evaluate smoking prevention programs for secondary school children (De Vries et al., 1995; M. Dijkstra et al., 1999). The ASE Model can be regarded as an extended version of the Theory of Planned Behavior (TPB) (Ajzen, 1991), the extension being the concepts of social support/pressure and modeling as social predictors of intention. Furthermore, the ASE Model has evolved as a separate model with several distinctive features, predominantly of a methodological nature (De Vries et al., 1998).

Since smoking prevention programs directed at elementary school children had not been evaluated in the Netherlands, a randomized controlled trial aimed at smoking prevention among upper grade elementary school students aged 11-12 years old started in 1997. The interventions consisted of an unevaluated in-school program and an out-ofschool program (involving tailored letters sent to students' home addresses). Until this study, smoking prevention programs for youngsters had mostly been implemented in school settings. The present study included an out-of-school program in order to remedy some drawbacks of in-school programs, for instance that schoolteachers already have overloaded teaching programs and do not always possess the necessary skills to teach health lessons (Murray et al., 1992). Short-term evaluation -six months after a pretestdid not reveal any effects of the in-school program but was promising for the out-ofschool program (Ausems, Mesters, van Breukelen, \& De Vries, 2002). In the pretest never-smoking sample, the out-of-school program had led to less, although not significant, smoking initiation ( $10.4 \%$ versus $18.1 \%$ in the control condition), while the pretest ever-smoking sample showed significant lower levels of smoking continuation ( $13.1 \%$ versus $23.5 \%$ in the control condition).

The present study had three goals. The first was to analyze at follow-up (nine months after pretest) in elementary schoolchildren intervention program effects on preventing smoking initiation among pretest never smokers, and secondly, to analyze program effects on preventing smoking continuation among pretest ever smokers. Thirdly, this study aimed at analyzing program effects on intermediate outcomes, namely attitudes, self-efficacy expectations and intention. To this end, schools taking part in the in-school program were compared with schools not taking part. Likewise, schools taking part or not taking part in the out-of-school intervention were compared. 
The effectiveness of a combined approach, including both the in-school and out-ofschool conditions, was also tested.

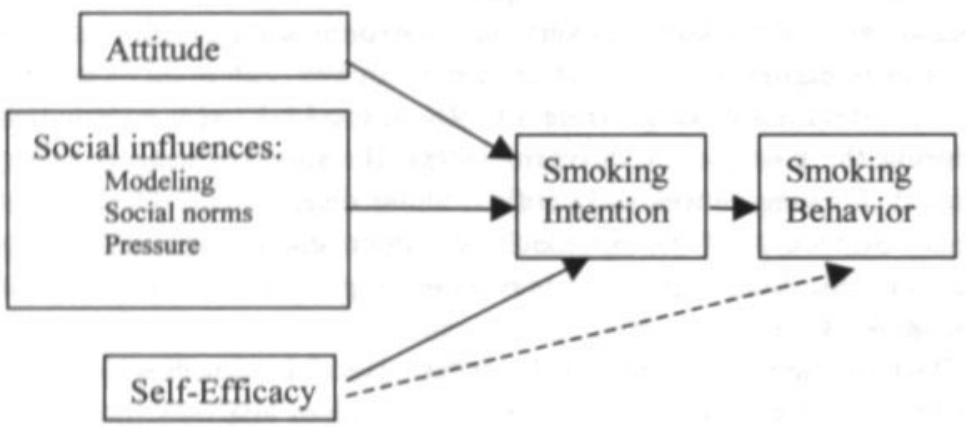

Fig 3.1 The ASE-model (De Vries et al., 1998)

\section{Method}

\section{Participants}

With the assistance of six local health departments, 414 primary school principals from southern, eastern and central parts of the Netherlands were invited during the spring of 1997 to participate in a smoking prevention research project. The principals received an introductory letter, followed by a telephone call to discuss participation, including the possibility of being a control school. Those refusing to participate often motivated this by referring to busy schedules due to participation in other health education courses.

\section{Design and procedure}

Table 3.1 outlines the design of the present study. In June 1997, the 156 participating schools were randomly assigned, in blocks defined by region, to the in-school condition (I), the out-of-school condition $(\mathrm{O})$, the in-school plus out-of-school condition $(\mathrm{I}+\mathrm{O})$ or the control group $(\mathrm{C})$. Teachers of schools assigned to the $\mathrm{I}$ and $\mathrm{I}+\mathrm{O}$ conditions were instructed by trained volunteers for the I program. The volunteers supplied the schools with the in-school materials, pretest questionnaires and assessment procedure. Schools participating in the $\mathrm{O}$ and $\mathrm{I}+\mathrm{O}$ conditions distributed consent forms to students' parents, because their children had been selected to receive educational materials at their home addresses. Twenty-one parents refused to participate.

Schools allocated to the $\mathrm{O}$ and $\mathrm{C}$ conditions received the pretest questionnaires by mail in July 1997. A letter with instructions about the assessment procedure was included. All teachers were instructed to schedule one hour for completion of the pretest questionnaires in September 1997, to collect the questionnaires after their students had completed them in the classroom, to put them in a postage-paid envelope and -having sealed it- to return the envelopes to the researchers. The I and $\mathrm{O}$ programs were both 
implemented between the pretest in September of 1997 and the first posttest in the middle of February of 1998. The results of the first posttest have been reported elsewhere (Ausems et al., 2002). The present study reports the data of the follow-up assessment, conducted nine months after the pretest, in June 1998.

Table 3.1 Number of schools from initial approach to follow-up.

\begin{tabular}{lllllll}
\hline & & I & O & 1+O & C & Total \\
\hline May 1997 & Approached & & & & & 414 \\
& Approval +Randomization & 39 & 39 & 38 & 40 & 156 \\
Sept 1997 & Pretest & 36 & 36 & 37 & 34 & 143 \\
Sept 1997- Febr 1998 & Intervention & + & + & + & & \\
Febr 1998 & Posttest 1 & 34 & 36 & 36 & 34 & 140 \\
June 1998 & Posttest 2 & 31 & 35 & 36 & 33 & 135 \\
\hline
\end{tabular}

Note, I, In-school intervention; O, Out-of-school intervention; $\mathrm{I}+\mathrm{O}$, In-school plus Out-of-school interventions; $\mathrm{C}$, Control condition

\section{The interventions}

The $\mathrm{I}$ and $\mathrm{O}$ interventions used in this study were both based on essential components for successful social influence programs (Sussman et al., 1993). Topics included were the short-term physical and social consequences of smoking, pressure, other people's smoking behavior, and refusal skills.

The in-school intervention, called 'Don 't play with fire', was developed by the Dutch Foundation on Smoking and Health. The package used in the present study contained a teacher manual and a student workbook. The complete intervention consisted of seven lessons, each lasting between 45 and 60 minutes. Each lesson comprised a general explanation by the teacher, a classroom discussion, a workbook task, a preparation part, and a creative activity.

The out-of-school intervention consisted of three computer-generated, individually tailored letters with smoking prevention messages mailed to students' homes at threeweek intervals. The three- to five-page letters were based on scores obtained at the pretest questionnaire on attitudes, social norms, self-efficacy, smoking intention and behavior, although the latter was not explicitly raised to prevent arguments in the students' family. Pilot testing and revision of concepts resulted in the creation of a message file. The content of the messages was based on the Social Inoculation Theory (McGuire, 1964), which suggests that providing pupils with the necessary information and skills makes them more resistant to pressures to smoke, and on the ASE model (De Vries, Dijkstra, \& Kuhlman, 1988). A computer program, developed by Maastricht University, linked the pretest scores with the appropriate message in the message file, 
and combined the messages in a letter format. In addition, the letters included a picture puzzle, a contest and several cartoons to arouse the students' attention and increase the attractiveness of the package, and to foster elaboration and storage of the information (Redman, 1997).

The first letter (eight versions) provided information on students' beliefs about smoking in general, and the short-term (nausea, bad smell) and social (feeling tough, looking mature) consequences of smoking. The second letter (32 versions) focused on the influence of the social environment on students' smoking behavior and their intention not to smoke in the future. The third letter described refusal techniques ( 2 versions).

\section{Questionnaire}

The surveys were an updated version of the ASE questionnaire that had been used in earlier Dutch smoking prevention research (De Vries et al., 1994; M. Dijkstra et al., 1999). The ASE questionnaire assessed: 1) the outcome measures (smoking initiation and continuation); 2) the psychosocial determinants of smoking (attitudinal beliefs, social influences, self-efficacy expectations and intentions); and 3) demographic backgrounds (age, gender, religion, family composition, pocket money and parents' profession and country of origin). Demographic variables were included as predictors in the regression analyses, although they are assumed to influence smoking via attitudes, social influences and self-efficacy expectations (De Vries et al., 1998).

Smoking behavior was, consistent with previous literature (World Health Organization, 1998; Flay, 1993) based on self-reports, categorizing students as: (1) never smokers: students who have never smoked even one cigarette (or puff of a cigarette); (2) non-current smokers: students who have smoked in the past, but not during the past month; and (3) current smokers: students who have smoked during the past month.

By way of treatment effects on smoking initiation, we assessed the percentage of never-smoking students (category 1) at pretest who indicated at follow-up that they had initiated smoking (categories 2-3). By way of treatment effects on smoking continuation, we assessed the percentage of ever smokers (category 2-3) at pretest who indicated at follow-up to have smoked during the past month (category 3 ).

Objective validation was not feasible for this young age group, firstly because of the financial and organizational problems it would cause and secondly because available methods detect only very recent smoking (within one week), while smoking family members may induce elevated readings (Murray \& Perry, 1987; Sussman et al., 1995). Self-reported results have been found to be more accurate provided confidentiality is assured and an identification coding system is used (Akers et al., 1983; Botvin \& Botvin, 1992; De Vries et al., 1994; Murray et al., 1987; US Department of Health and Human Services, 1990). This procedure was used in our study. The front pages of the questionnaires provided information about confidence. An identification code was used in the data file and the researchers replaced students' names before data entry.

Four attitude subscales were confirmed by factor analyses:

- Disadvantages of smoking: 11 items (Cronbach's $\alpha=.80$ ) ranging from 'negative' (1) to 'very positive towards non-smoking' (5), referring to nausea, coughing, irritated 
eyes, breathing problems, being unwise, expenses, health hazard, disturbing others, causing passive smoking, regret, and bad smell;

- Advantages of smoking: 5 items ( $\alpha=.63)$ ranging from 'positive' (1) to 'very negative towards non-smoking' (5), referring to growing up, relieving boredom, relieving tension, pleasant taste, feeling tough;

- Social acceptance: 3 items ( $\alpha=.75)$ ranging from 'very negative' $(-3)$ to 'very positive towards non-smoking' (3), referring to receiving attention from friends, acceptance by friends and making contacts;

- Long term physical consequences: 2 items ( $r=.57)$ ranging from 'very negative' $(-3)$ to 'very positive towards non-smoking' (3), referring to risks of cancer and heart diseases.

Social influence was measured by four indices, obtained by summing the items concerned:

- Modeling 'nuclear network': 4 items ranging from 'smoking' (-2), 'absent' (-1), to 'not smoking' ( 0 ), measuring the perceived smoking behavior of a student's father, mother, brother/ sister and best friend;

- Modeling 'diffuse network': 4 items ranging from 'almost all are smokers' (-4) to, 'hardly any are smokers' (0), measuring the number of smoking friends, peers, teachers and relatives;

- Social norms: 6 items ranging from 'very positive' $(-3)$ to 'very negative towards smoking' (3), measuring the perceived beliefs of a student's father, mother, brother, sister, best friend and friends in general;

- Social pressure: 10 items ranging from 'very often' $(-5)$ to 'never' $(0)$, measuring the perceived pressure from a student's father, mother, brother, sister, best friend, friends in general, peers, teacher, relatives, and advertisements.

Self-efficacy expectations: 6 items $(\alpha=.91)$ ranging from 'very uncertain' $(-3)$ to 'very certain' (3), each item referring to a student's expectation about refraining from smoking in different situations of increasing magnitude (when others / friends smoke, or when a cigarette is offered by someone, by parents or by friends, or when you are called a coward).

Intention to smoke was measured by one item, ranging from 'definitely do' (-3) to 'definitely do not intend to smoke' (3).

\section{Analyses}

In line with the two-way design of the study, the conditions were compared for their program effects using regression analyses with dummy variables for the in-school and out-of-school interventions, and their interaction. The in-school intervention effects were tested by calculating the in-school factor (In): both in-school conditions ( In=1) versus both no in-school conditions $(\mathrm{In}=0)$. The out-of-school intervention effects were tested by calculating the out-of-school factor (Out): both out-of-school conditions (Out=1) versus both no out-of-school conditions (Out $=0$ ). To test the additional effects of the in-school intervention on the out-of-school intervention, the interaction term 'in*out' was included in the analyses.

Since the nesting of students within schools had to be taken into account in the data analyses, most analyses were carried out using multilevel regression modeling, with the help of MIXOR (logistic regression), a program for dichotomous variables (Hedeker \& Gibbons, 1996a) and MIXREG (linear regression), a program for continuous variables 
(Hedeker \& Gibbons, 1996b). Because large regression models with MIXOR may cause problems, logistic regression was first done with SPSS (SPSS Inc, 1999) to determine the final model. The following strategy was used: smoking initiation and continuation at follow-up (nine months after pretest) was predicted from treatment factors (in-school, out-of-school and their interaction). Furthermore, pretest psychological measures and demographic variables were entered as covariates, as previous research had shown these to be predictors of smoking (De Vries et al., 1994). Non-significant covariates and in*out interactions were deleted in a stepwise procedure $(\alpha=0.05)$. The final model was entered into the multilevel analyses to test the intervention for behavioral effects.

Treatment effects were also tested, using a Bonferroni correction ( $\alpha=0.05 /$ number of outcomes) to prevent type I errors due to multiple testing, on the follow-up recordings of the following intermediate outcomes: perceived disadvantages, advantages, social acceptance and long term physical consequences of smoking, selfefficacy expectations and intention. The social predictors like modeling, pressure and social norms were excluded from the tests for intermediate follow-up outcomes, since studying changes in these determinants was not the aim of the present interventions.

Finally, to check the randomization, the treatment conditions were compared for age, gender, pretest ever smoking and pretest psychosocial variables. Dropout rate was checked by means of logistic regression with follow-up attrition as outcome and pretest demographic, pretest ever smoking and psychosocial variables, and treatment conditions as predictors.

\section{Results}

\section{Randomization, attrition, and sample characteristics}

Randomization analyses revealed no differences between the conditions with respect to demographic and psychosocial variables. Seven schools did not return the questionnaires, mainly because of time constraints due to the students' being in their final year of elementary school. Questionnaires from one school were apparently lost in the mail. Five schools that dropped out had been assigned to the in-school condition. This does not imply, however, that the in-school condition was responsible for these attrition rates, since the in-school condition and the combined condition were equally implemented and attrition in the combined condition was less. We therefore assumed that the higher attrition rate in the in-school condition was a chance event, and we performed the attrition analyses without the eight dropout schools. In the remaining 135 schools (3472 students), $6.8 \%$ of the children dropped out (in-school condition: $7.3 \%$; out-of-school condition: $6.4 \%$; combined condition: $5.3 \%$; and control condition: $8.8 \%$ ). Logistic regression analysis with attrition as the dependent variable suggested that younger children were more likely to drop out than older students ( $O R=0.78$; $95 \% \mathrm{CI}=0.63-0.96$ ). Furthermore, children who participated in the in-school program were less likely to drop out than children not participating in the in-school program $(\mathrm{OR}=0.64 ; 95 \% \mathrm{CI}=0.42-0.96)$. 
Smoking and demographic scores from 35 respondents were missing, therefore these respondents were excluded from the analyses. The average pretest age of the respondents was 11.6 years, $49.5 \%$ were male and $35.8 \%$ reported lifetime smoking.

\section{Program effects on smoking behavior}

Table 3.2 shows the changes in smoking initiation and continuation at follow-up, nine months after pretest. The lowest rates of smoking initiation among pretest never smokers were found in the I and $\mathrm{O}$ conditions ( 16.9 and $16.7 \%$ respectively), while the highest smoking initiation rates were found in the $\mathrm{I}+\mathrm{O}$ and $\mathrm{C}$ conditions (19.7 and $20.5 \%$ respectively). As regards smoking continuation among pretest ever smokers, fewer children in the $\mathrm{I}+\mathrm{O}$ condition continued smoking $(16.9 \%)$ than in the $\mathrm{I}, \mathrm{O}$, and $\mathrm{C}$ conditions $(23.3,21.9$, and $21.8 \%$ respectively). However, none of these differences in smoking between conditions was statistically significant according to the regression analyses below.

Table 3.2 Smoking initiation and continuation by treatment condition, with schools as the unit of analysis

\begin{tabular}{|c|c|c|c|c|}
\hline $\begin{array}{l}\text { Smoking initiation among pretest never } \\
\text { smokers }\end{array}$ & I $(\mathrm{N}=31)$ & $O(N=35)$ & $1+O(N=36)$ & $\mathrm{C}(\mathrm{N}=33)$ \\
\hline Average $\%$ & 16.9 & 16.7 & 19.7 & 20.5 \\
\hline $95 \%$ confidence interval & (11.6-22.3) & (11.8-21.5) & $(15.4-24.0)$ & $(16.1-24.9)$ \\
\hline $\begin{array}{l}\text { Smoking continuation among pretest ever } \\
\text { smokers }\end{array}$ & I $(\mathrm{N}=30)$ & $\mathrm{O}(\mathrm{N}=34)$ & $\mathrm{I}+\mathrm{O}(\mathrm{N}=36)$ & $C(\mathrm{~N}=33)$ \\
\hline Average $\%$ & 23.3 & 21.9 & 16.9 & 21.8 \\
\hline $95 \%$ confidence interval & $(14.9-31.6)$ & $(13.5-30.2)$ & $(10.5-23.3)$ & $(14.9-28.7)$ \\
\hline
\end{tabular}

Notes, I, In-school intervention; O, Out-of-school intervention; I+O, In-school plus Out-of-school interventions; $\mathrm{C}$, Control condition

Firstly, we analyzed the results of the programs on preventing smoking initiation among pretest never smokers. The results for the final model are presented in table 3.3. No interaction between the in-school and out-of-school factors was found. The analysis regarding the effects of the programs on prevention of smoking initiation failed to find an effect for the in-school and the out-of-school programs at follow-up, nine months after the pretest. Predictors of smoking initiation were age (older students having a higher risk of smoking initiation), gender (boys having a higher risk), modeling 'nuclear' (students with smokers in their close environment having a higher risk), modeling 'diffuse' (students with smokers in their extended environment having a higher risk), and intention (students with a negative intention towards non-smoking having a higher risk). 
Table 3.3 Program effects at follow-up, nine months after pretest, using the final regression model among pretest never smokers, $\mathrm{N}_{\text {students }}=2052, \mathrm{~N}_{\text {schools }}=135$ (smoking initiation; $0=$ never smoking; 1=ever smoking) and among pretest ever smokers $\mathrm{N}_{\text {students }}=1149, \mathrm{~N}_{\text {schools }}=133$ (smoking continuation; 0 -not smoking; $1=$ smoking)

\begin{tabular}{|c|c|c|c|c|}
\hline & \multicolumn{2}{|c|}{$\begin{array}{l}\text { Pretest never smokers } \\
\text { Smoking initiation }\end{array}$} & \multicolumn{2}{|c|}{$\begin{array}{l}\text { Pretest ever smokers } \\
\text { Smoking continuation }\end{array}$} \\
\hline & $\begin{array}{l}\text { Odds } \\
\text { Ratio }\end{array}$ & $95 \%$ CI & $\begin{array}{l}\text { Odds } \\
\text { Ratio }\end{array}$ & $95 \% \mathrm{CI}$ \\
\hline In-school program (1=yes, 0-no) & 1.04 & $0.79-1.36$ & 0.84 & $0.52-1.36$ \\
\hline Out-of-school program ( 1 -yes, 0-no) & 0.99 & $0.75-1.30$ & 0.89 & $0.57-1.38$ \\
\hline Age (years) & $1.43 \bullet$ & $1.14-1.80$ & $1.38^{*}$ & $1.00-1.89$ \\
\hline Gender (ref, male) & $0.76^{*}$ & $0.59-0.97$ & & \\
\hline Attitude 'disadvantages': 11 (neg) - 55 (pos) & & & $0.96 * *$ & $0.94-0.99$ \\
\hline Modeling 'nuclear': -8 (neg) - 0 (pos) & $0.88 \bullet \bullet$ & $0.82-0.95$ & $0.83 \bullet \bullet$ & $0.76-0.90$ \\
\hline Modeling 'diffuse': - 16 (neg)- 0 (pos) & $0.94^{\circ}$ & $0.90-0.99$ & 0.97 & $0.92-1.03$ \\
\hline Pressure:-50 (neg) - 0 (pos) & 0.98 & $0.95-1.01$ & & \\
\hline Self-efficacy: -18 (neg) -18 (pos) & & & $0.98^{*}$ & $0.96-1.00$ \\
\hline Intention: -3 (neg) - 3 (pos) & $0.83^{* * \bullet}$ & $0.74-0.92$ & $0.87^{*}$ & $0.77-0.99$ \\
\hline
\end{tabular}

Notes, $\mathrm{p} \leq .05 ; \cdots p \leq .01 ; \cdots+\mathrm{p} \leq .001 ;$; “Neg' means negative towards non-smoking, 'pos' means positive towards non-smoking

Secondly, we analyzed the programs effects on smoking continuation among pretest ever smokers. The results for the final model are presented in table 3.3. Again, no significant interaction was found between the treatment factors. The analysis regarding the effects of both programs to prevent smoking continuation also failed to find an effect at follow-up. Predictors of smoking continuation at follow-up were age (older students having a higher risk of smoking continuation), perceived disadvantages (students perceiving fewer disadvantages having a higher risk), modeling 'nuclear' (students with smokers in their close environment having a higher risk), modeling 'diffuse' (students with smokers in their extended environment having a higher risk), self-efficacy expectations (students with lower self-efficacy expectations having a higher risk), and intention (students with a negative intention towards non-smoking having a higher risk).

The school intraclass correlation coefficient reflects the proportion of unexplained outcome variance that was accounted for by the schools. The intraclass correlation using 
the regression models of table 3.3 was 0.03 for smoking initiation at follow-up, while that on smoking continuation at follow-up was 0.17 . Because age and treatment were able to predict attrition nine months after pretest, selective dropout may have influenced the results. Two checks were performed, both including all students except those in the eight dropout schools $(\mathrm{N}=3472)$. Dropout schools were excluded because we did not assume a relation between attrition and the experimental conditions. First, missing data of dropouts were replaced by their last observation, the so-called 'last observation carried forward' analyses, and second, an 'extreme case' analysis was run in which dropouts were treated as smokers. Both analyses did not result in any relevant differences with the analyses excluding the dropouts.

Table 3.4 Unweighted mean of school means for intermediate outcomes, per treatment condition

\begin{tabular}{|c|c|c|c|c|c|}
\hline & & \multicolumn{2}{|c|}{$\begin{array}{l}\text { Pretest never smoking sample } \\
(\mathrm{N}=135)\end{array}$} & \multicolumn{2}{|c|}{$\begin{array}{l}\text { Pretest ever smoking sample } \\
(\mathrm{N}=133)\end{array}$} \\
\hline & & Pretest & Follow-up & Pretest & Follow-up \\
\hline \multirow[t]{4}{*}{ Disadvantages } & I & 38.0 & 39.0 & 34.6 & 35.4 \\
\hline & o & 37.0 & 38.7 & 33.9 & 34.4 \\
\hline & $1+0$ & 37.3 & 39.4 & 34.3 & 36.4 \\
\hline & C & 37.8 & 36.3 & 34.3 & 33.1 \\
\hline \multirow[t]{4}{*}{ Self-efficacy } & I & 11.1 & 11.8 & 7.7 & 9.6 \\
\hline & o & 10.5 & 12.5 & 7.4 & 9.4 \\
\hline & $\mathbf{I}+\mathbf{O}$ & 10.7 & 12.3 & 7.3 & 9.8 \\
\hline & C & 9.7 & 11.7 & 7.2 & 8.9 \\
\hline \multirow[t]{4}{*}{ Intention } & $\mathbf{I}$ & 2.5 & 2.6 & 1.2 & 1.5 \\
\hline & o & 2.4 & 2.5 & 1.2 & 1.6 \\
\hline & $\mathbf{I}+\mathbf{O}$ & 2.5 & 2.5 & 1.2 & 1.7 \\
\hline & C & 2.4 & 2.3 & 1.2 & 1.3 \\
\hline
\end{tabular}

Note, I, In-school intervention; O, Out-of-school intervention; $\mathrm{I}+\mathrm{O}$, In-school plus Out-of-school interventions; $\mathrm{C}$, Control condition 


\section{Program effects on intermediate outcomes}

Table 3.4 presents the changes between pretest and follow-up in the intermediate outcome scores of pretest never and ever smokers, per condition with school as unit of analysis and school mean as outcome.

The attitude 'disadvantages', as well as self-efficacy expectations and intention, were examined as intermediate outcomes, because these variables had previously been found to be important predictors of either smoking initiation or continuation. Social influences were excluded from the analyses because these outcomes are not assumed to change as a result of the interventions.

Most of the pretest never smoking sample showed an increase between pretest and follow-up in the level of perceived disadvantages of smoking, the level of perceived self-efficacy expectations about non-smoking and the intention not to start smoking. exceptions were students in the $\mathrm{I}+\mathrm{O}$ condition, whose intentions had not changed, and students in the control condition, who perceived fewer disadvantages of smoking and possessed a more negative intention not to start smoking at follow-up than at pretest. In the pretest ever smoking sample, all scores increased between the pretest and follow-up assessments, except the perceived disadvantages of smoking scores in the control group, which decreased.

Table 3.5 Betas ( $B$ ) of contrasts with standard errors (SE) and intraclass correlation (i.c.c.) between treatment conditions for intermediate outcome scores at follow-up

\begin{tabular}{|c|c|c|c|c|}
\hline & \multicolumn{2}{|c|}{$\begin{array}{l}\text { In-school versus } \\
\text { no in-school }\end{array}$} & \multicolumn{2}{|c|}{$\begin{array}{l}\text { Out-of-school versus } \\
\text { no out-of-school }\end{array}$} \\
\hline & B & SE & B & SE \\
\hline \multicolumn{5}{|c|}{ Pretest never-smokers $\left(N_{\text {student }}=2052 ; N_{\text {schoots }}=135\right)$} \\
\hline Disadvantages of smoking (i.c.c. $=0.09$ ) & $1.52 * *$ & $(0.51)$ & $1.66 * *$ & $(0.52)$ \\
\hline Self-efficacy (i.c.c. $=0.02$ ) & -0.10 & $(0.32)$ & $1.03 * * *$ & $(0.32)$ \\
\hline Intention ( i.c.c. $=0.03$ ) & 0.09 & $(0.05)$ & 0.07 & $(0.05)$ \\
\hline \multicolumn{5}{|c|}{ Pretest ever smokers $\left(N_{\text {students }}=1149 ; N_{\text {stooos }}=133\right)$} \\
\hline Disadvantages of smoking (i.c.c $=0.05$ ) & $1.50^{* *}$ & $(0.52)$ & $1.28^{*}$ & $(0.52)$ \\
\hline Self-efficacy (i.c.c. $=0.04$ ) & 0.20 & $(0.50)$ & 0.34 & $(0.50)$ \\
\hline Intention (i.c.c. $=0.06$ ) & 0.12 & (0.11) & 0.19 & $(0.11)$ \\
\hline
\end{tabular}

Notes, All analyses are corrected for age, gender and the pretest score of the intermediate variable. $* p<0.017 ; \cdots p<0.01 ; \cdots * p<0.001$ 
Table 3.5 shows the results of the comparisons between the treatment conditions. Multiple testing necessitated the use of the Bonferroni correction (i.e. an alpha of 0.05/ $3=0.017$ ), because three outcomes were analyzed. Within the subgroup of pretest never smokers, significant treatment effects on perceived disadvantages of smoking were found for both the in-school and the out-of-school programs. The out-of-school program led to significant increases in students' self-efficacy expectations $(\mathrm{p}<0.001)$. Within the subgroup of pretest ever smokers, significant treatment effects on perceived disadvantages of smoking were found for both the in-school and the out-of-school program.

\section{Discussion}

The two types of theory-driven interventions for 11-12 year old elementary school students, the in-school and the out-of-school program, did not prove to be effective in preventing smoking behavior at follow-up, i.e., nine months after the pretest assessment. No extra effects were found either for the combined approach, consisting of the inschool plus out-of-school interventions. The promising early results of the out-of-school program in the pretest never smoking sample, as assessed six months after the pretest ( $10.4 \%$ smoking initiation in the $\mathrm{O}$ condition compared with $18.1 \%$ in the $\mathrm{C}$ condition) and in the pretest ever smoking sample ( $13.1 \%$ smoking continuation in the $\mathrm{O}$ condition compared with $23.5 \%$ in the C condition) had disappeared at follow-up. This is not an isolated finding. Similar conclusions have been drawn in several reviews about smoking prevention (Rooney \& Murray, 1996; Stead et al., 1996), although most samples described in these reviews refer to older adolescence populations, which impedes adequate comparison.

Both treatments, In and Out, had a positive effect on ever and never smokers' perception of the disadvantages of smoking. Apparently, children's perception of disadvantages increases regardless of the way the educational information is offered to them. Self-efficacy expectations about refusing cigarettes among never smokers increased as a result of the out-of-school intervention. The third letter that children in the out-of-school condition received contained messages that were tailored to their selfefficacy expectations about non-smoking. Thus, it seems that this approach possesses the capacity to increase self-efficacy expectations about cigarette refusal among children without smoking experience. Neither the in-school nor the out-of-school program influenced self-efficacy expectations of ever smokers. It might be that ever smokers experienced a failure to refuse cigarettes that might have resulted in lower selfefficacy expectations, which is in agreement with Bandura's explanation that selfefficacy experiences are highly dependent on performance attainment (Bandura, 1986). Obviously, increasing self-efficacy expectations about refusing cigarettes among children with and without smoking experience requires different approaches.

The population described in this article, with an average age below 12 years, is about to enter secondary education and is yet not greatly involved in steady smoking behavior. Smoking prevalence in the Netherlands increases considerably after the transition to secondary school, i.e., above the age of 12 (Stivoro, 1998). In view of the attitude-behavior relation (Andrews \& Duncan, 1998) and the positive effects of self- 


\section{chapter 3}

efficacy on behavior (Bandura, 1986), the attitude and efficacy shifts found in the present study might become effective against detrimental behavioral changes after transition to secondary school when tobacco might come more into students' prominence. Consequently, the effects of the interventions might be delayed. In terms of the social inoculation theory developed by McGuire (1964), the inoculation was fairly successful, considering the cognitive changes in perceptions of disadvantages resulting from the in-school and out-of-school programs and considering the changes in selfefficacy expectations resulting from the out-of-school program.

A relation was found between age, treatment and attrition at follow-up. Attrition could be attributed to the eight schools that did not send back the questionnaires, to absenteeism and to difficulties in matching baseline and follow-up data. Two checks were performed to analyse whether the effects were influenced by selective dropout, namely 'last observation carried forward' and 'extreme case' analyses. These analyses were also performed without the schools that completely dropped out, and found no intervention effects.

In sum, no behavioral effects of the out-of-school and in-school programs were found nine months after pretest. The experimental conditions did, however, result in some cognitive changes, which may, according to social cognitive theories (Bandura, 1986; De Vries et al., 1998), lead to later behavioural effects. Hence, longer-term follow-up is needed to verify this hypothesis. Moreover, it is conceivable that the outof-school program, which produced successful short-term results, needs reinforcement. Hence, booster sessions are recommended, since research has demonstrated their effectiveness (M. Dijkstra et al., 1999). Finally, more research should be done on approaches to increase self-efficacy expectations about cigarette refusal among ever smokers. 


\section{4}

\section{In-school and tailored out-of-school smoking prevention: Long-term effects of a Dutch randomized controlled trial using different strategies for handling missing data}

Manuscript submitted for publication as: Ausems, M., Mesters, I., van Breukelen, G., De Vries, H. 'In-school and tailored out-of-school smoking prevention: Long-term effects of a Dutch randomized-controlled trial using different strategies for handling missing data' 
chapter 4

\begin{abstract}
The aim of this article is to describe the long-term effects of a Dutch smoking prevention intervention, consisting of in-school and tailored out-of-school elements, which was implemented in 1997 among last grade elementary school students. 156 participating schools were randomly allocated to one of four research conditions: 1 . inschool; 2. out-of-school; 3. combined approach; 4. control condition. Pretest data and 20,30 , and 36 months follow-up data related to smoking initiation and continuation were collected. Because of substantial dropout during follow-up, an additional goal is to compare the outcomes of different strategies for handling missing data: complete case, extreme case, and carried forward analyses. The three different strategies used in our study to handle dropout resulted in highly similar conclusions for the complete case and carried forward analyses revealing unfortunately no significant program effects. The extreme case strategy resulted in very high, if not too high, estimations of smoking initiation and continuation percentages.
\end{abstract}




\section{Introduction}

It is well known that smoking causes health problems ranging from annoying symptoms, like morning cough, to serious diseases, like cancer, heart disease, pulmonary disease and cerebrovascular disease (US Department of Health and Human Services, 1994) and mortality, with about $85 \%$ of lung cancer mortality and $33 \%$ of mortality from other cancers attributable to smoking (Doll et al., 1994). In addition, smoking tobacco causes physical and psychological addiction, which complicates the voluntary choice to smoke. Morbidity, mortality, and addiction not only apply to adults but also to youngsters, in view of the association between an early onset of tobacco use and future (adult) smoking behavior. The younger people begin to smoke, the more likely they are to be regular smokers as adults. Early onset of cigarette smoking implies a longer potential duration of use and therefore a greater risk of various serious health consequences. Early onset is also associated with heavier use: those who start smoking as younger adolescents are among the heaviest users in adolescence and adulthood. Heavier smokers are more likely to experience tobacco-related health problems and are less likely to quit smoking, due to the established nicotine addiction (Pierce \& Gilpin, 1996; US Department of Health and Human Services, 1994). Hence, the importance of prevention of both smoking initiation and continuation aimed at young people is beyond doubt.

Over the last three decades, smoking prevention efforts aimed at youngsters have often been embedded in the school setting. This seems a logical approach, since schools reach wide audiences, health education is part of the school curriculum in many countries, interpersonal communication is possible, and the school setting provides good opportunities for evaluation studies (Sussman et al., 1995). A potential drawback of school-based smoking prevention programs is that their implementation depends on limited time and untrained personnel (Murray et al., 1992), while schools may also have a certain negative connotation for some youngsters, which may reduce the suitability of schools as an access point for reaching youngsters (Bullock et al., 1996). Innovative out-of-school programs have been recommended to overcome these disadvantages of inschool interventions.

In this context, a Dutch smoking prevention intervention aimed at last-grade elementary schoolchildren was implemented, in order to evaluate the impact of a newly developed computerized out-of-school program, consisting of personalized tailored letters mailed to the students' homes. Its impact was assessed relative to the impact of an existing school-based social influence program. The idea of personal tailored letters originated in the United States (Campbell et al., 1994; Rimer et al., 1994; Skinner et al., 1993; Velicer et al., 1993), and has been further developed and tested for several years in the Netherlands (Brug et al., 1998; De Nooijer et al., 2002; Dijkstra \& De Vries, 1999; Dijkstra, De Vries, \& Roijackers, 1998; Dijkstra, De Vries, Roijackers, \& Van Breukelen, 1998; Dijkstra, De Vries, \& Roijackers, 1998; Willemsen \& De Vries, 1995). Significant short-term effects (six months after pretest) in terms of lower smoking continuation rates were found for the out-of school program (Ausems et al., 2002), but these effects had disappeared nine months after pretest (Ausems, Mesters, van Breukelen, \& De Vries, submitted-a).

In this study the long-term effects $(20,30$, and 36 months after pretest) of the inschool and the tailored out-of-school interventions on smoking initiation and 
continuation will be discussed. Since the trial was confronted with considerable levels of dropout the original random treatment allocation might have been violated (Hollis \& Campbell, 1999). Hence, an additional goal of this study is to compare outcomes of different strategies for handling missing data: complete case, extreme case and carried forward analyses.

\section{Methods}

\section{Design and procedure}

The complete timeline is presented in Table 4.1. The present study initially involved 3734 elementary school children living in Southern, Eastern and Central parts of the Netherlands. In May 1997, schools were randomly assigned to an in-school, out-ofschool, in+out-of-school or no intervention condition. The $T_{2}$ questionnaire (June 1998) asked students whether they were willing to participate in a follow-up study, which was added to the initial study in order to assess long-term effects. If the student agreed, she or he could write down their home addresses, after which the student received another three posttest questionnaires in May $1999\left(\mathrm{~T}_{3}\right)$, February $2000\left(\mathrm{~T}_{4}\right)$ and September 2000 $\left(T_{5}\right)$. Unlike the $T_{0}, T_{1}$ and $T_{2}$ questionnaires, that had been sent to the elementary schools and were completed in the classroom, the $T_{3}, T_{4}$ and $T_{5}$ questionnaires and instructions were sent to students' home addresses, because the students transferred to a wide range of secondary schools. Students were asked to complete the questionnaires at home and return them to the research team in a prepaid envelope. A reminder was sent two weeks after each mailing. To enhance the response rate, 15 cinema vouchers were put up for raffle at each assessment.

\section{The interventions}

Between the pretest $\left(\mathrm{T}_{0}\right)$ and the first posttest $\left(\mathrm{T}_{1}\right)$, two interventions were implemented; an in-school and a tailored out-of-school program. Both programs were based on essential components of successful social influence programs (Glynn, 1989; Sussman et al., 1993). Topics included the short-term physical and social consequences of smoking, pressure, other people's smoking behavior, and refusal skills.

The in-school intervention, called 'Don 't play with fire', was developed by the Dutch Foundation on Smoking and Health. The intervention package used in the present study included a teacher manual and a student workbook. The complete intervention consisted of seven lessons, each lasting between 45 and 60 minutes. Each lesson comprised a general explanation by the teacher, a classroom discussion, a workbook task, a preparation part, and a creative activity.

The out-of-school intervention consisted of three computer-generated, individually tailored letters with smoking prevention messages mailed to students' homes at threeweek intervals. The three- to five-page letters included messages that were based on sum scores obtained by the pretest questionnaire on attitudes, social norms, selfefficacy, smoking intention and behavior. 


\section{long-term effects}

Table 4.1 Number of schools (students) from initial approach to Posttest 5

\begin{tabular}{|c|c|c|c|c|c|c|}
\hline & & I & $\mathbf{o}$ & $1+0$ & C & Total \\
\hline \multirow[t]{3}{*}{ May 1997} & Approach & & & & & 414 \\
\hline & Approval+ & 39 & 39 & 38 & 40 & 156 \\
\hline & Randomization & & & & & \\
\hline \multirow[t]{2}{*}{ Sept 1997} & Pretest $T_{0}$ & 36 & 36 & 37 & 34 & 143 \\
\hline & & (1002) & (871) & (1068) & (793) & (3734) \\
\hline Sept 1997 - Febr 1998 & Interventions & + & + & + & & \\
\hline \multirow[t]{2}{*}{ Febr 1998} & Posttest $1\left(\mathrm{~T}_{1}\right)$ & 34 & 36 & 36 & 34 & 140 \\
\hline & & (843) & (807) & (984) & (715) & (3349) \\
\hline \multirow[t]{2}{*}{ June 1998} & Posttest $2\left(\mathrm{~T}_{2}\right)$ & 31 & 35 & 36 & 33 & 135 \\
\hline & & (785) & (787) & (967) & (697) & (3236) \\
\hline \multirow[t]{2}{*}{ June 1998} & Approval & 30 & 35 & 36 & 33 & 134 \\
\hline & & (319) & (612) & (638) & (296) & $(1865)$ \\
\hline \multirow[t]{2}{*}{ May 1999} & Posttest $3\left(\mathrm{~T}_{3}\right)$ & 30 & 35 & 35 & 31 & 131 \\
\hline & & (273) & (487) & (488) & (227) & (1475) \\
\hline Sept 1999-Jan 2000 & Booster & & + & + & & \\
\hline \multirow[t]{2}{*}{ Feb 2000} & Posttest $4\left(\mathrm{~T}_{4}\right)$ & 29 & 35 & 35 & 30 & 129 \\
\hline & & (221) & (376) & (375) & (166) & (1138) \\
\hline \multirow[t]{2}{*}{ Sept 2000} & Posttest $5\left(\mathrm{~T}_{5}\right)$ & 29 & 35 & 35 & 29 & 128 \\
\hline & & (197) & (332) & (342) & (153) & (1024) \\
\hline
\end{tabular}

Notes, 8 entire schools dropped out between $\mathrm{T}_{0}$ and $\mathrm{T}_{2}$. I, In-school; $\mathrm{O}$, Out-of-school; $\mathrm{I}+\mathrm{O}$, In-school plus Out-of-school; C, Control condition; The effects of the booster implemented in half of the $\mathrm{O}$ and $\mathrm{I}+\mathrm{O}$ conditions were tested in separate analyses, which are described in chapter 5 
Pilot testing and revision of concepts had resulted in the creation of a message file, with message content based on the Social Inoculation Theory (McGuire, 1964), which suggests that providing students with the necessary information and skills makes them more resistant to pressures to smoke, and on the Attitude-Social influence-self Efficacy (ASE) model (De Vries, Dijkstra, \& Kuhlman, 1988; De Vries \& Mudde, 1998). A computer program, developed by Maastricht University, linked the pretest scores with the appropriate message in the message file, and combined the messages in a letter format. In addition, the letters included a picture puzzle, a contest and several cartoons to draw the students' attention and increase the attractiveness of the package, and to foster processing and storage of the information (Redman, 1997).

The first letter ( 8 potential different versions) provided information on students' beliefs about smoking in general, and the short-term (nausea, bad smell) and social (feeling tough, looking mature) consequences of smoking. The second letter (32 potential different versions) focused on the influence of the social environment on students' smoking behavior and their intention not to smoke in the future. The third letter ( 2 potential different versions) described self-efficacy expectations together with refusal techniques.

\section{Measurements}

\section{Outcome evaluation}

The questionnaires used at $\mathrm{T}_{0}-\mathrm{T}_{5}$ were based on the ASE questionnaire (De Vries et al., 1994; De Vries, Dijkstra, \& Kuhlman, 1988; M. Dijkstra et al., 1999). They included questions about attitude ( 21 items), social influences ( 24 items), self-efficacy expectations ( 6 items), intention ( 1 item), and demographic variables like age, gender, religion, family composition, pocket money and parents' job and origin. The operationalization of the attitude, social influences, self-efficacy and intention has been described elsewhere (Ausems et al., 2002).

Smoking behavior was based on self-reports, categorizing students as: (1) never smokers: students who have never smoked even one cigarette (or a puff of a cigarette); (2) non-current smokers: students who have smoked in the past, but not during the past month; and (3) current smokers: students who have smoked during the past month (World Health Organization, 1998; Flay, 1993).

As for treatment effects on smoking initiation, we assessed the percentage of neversmoking students (category 1) at pretest who indicated at follow-up that they had initiated smoking (categories 2-3). As for treatment effects on smoking continuation, we assessed the percentage of ever smokers (category 2-3) at pretest who indicated at follow-up to have smoked during the past month (category 3 ).

\section{Process evaluation}

The measurement of the outcomes at $T_{1}$ was combined with a process evaluation that assessed exposure and appreciation with students who had participated in the in-school and/ or out-of-school programs and with teachers who had participated in the in-school 
program. The content and the results of the process questionnaires have been described elsewhere (Ausems et al., 2002).

\section{Analyses}

At the start of our study, students were nested within schools, and schools were randomly assigned to treatment conditions. Ignoring this nesting might lead to type I errors and too narrow confidence intervals for treatment effects (Flay et al., 1995). Therefore, most analyses were carried out with multilevel regression modeling, using the MIXREG program (linear regression) for continuous outcomes (Hedeker \& Gibbons, 1996b), and MIXOR (logistic regression) for dichotomous outcomes (Hedeker \& Gibbons, 1996a).

To check whether the randomization had been successful, the treatment conditions were compared for age, gender, pretest ever smoking and pretest psychosocial variables.

Between $T_{0}$ and $T_{2}$, eight schools, including five from the in-school condition, totally dropped out. The students from the in-school condition were not assumed to be responsible for this dropout rate, since the implementation of the in-school and combined programs was the same and attrition in the combined condition approximated the out-only and control conditions. Therefore, we performed the attrition analyses in a sample of 3472 students without the eight schools that dropped out between $T_{0}$ and $T_{2}$, using the attrition rates at posttests 3-4-5 as outcome and pretest demographic, pretest smoking, pretest psychosocial variables, and treatment conditions as predictors. Students from schools that completely dropped out after $\mathrm{T}_{2}$ (at which time they had been transformed into secondary school students) remained in the research sample that was used for the attrition analyses, because it was assumed that dropout of complete schools was a coincidence, due to substantial dropout of individual secondary school students combined with a small number of students per school. The agreement with further participation in June 1998 might have induced selection bias. Therefore, readiness to continue participation after school transition was checked using readiness at $\mathrm{T}_{2}$ as outcome, and pretest demographic, pretest ever smoking, pretest psychosocial variables, and treatment conditions as predictors.

All effect analyses were done separately for the third, fourth and fifth posttests, and separately for pretest never and ever smokers. In line with the two-way study design, treatment effects were evaluated by including the following covariates in the regression models, a dummy indicator for each intervention (in-school, out-of-school, booster; yes $=1, n_{0}=0$ ) and the interaction of the in-school and out-of-school interventions. ${ }^{3}$ If a significant interaction was found, the effect of one treatment was tested within the levels of the other treatment. Nonsignificant interactions were removed from the regression model in order to test main effects of the treatments. Since our sample was confronted with substantial dropout we used three different strategies to compute the treatment results (Hollis \& Campbell, 1999). First by including only those students whose smoking status was known at follow up (complete case analyses) to estimate

\footnotetext{
${ }^{3}$ Table 4.1 reports on a booster intervention implemented in half of the out-of-school conditions between September 1999 and January 2000 . In the present analyses a dummy indicator for the booster intervention has been included as a predictor in the regression model (no interaction effects, since they did not approach significance) to analyze the effects of the in-school and out-of-school interventions. The booster effects were tested by separate analyses, which are described in chapter 5 .
} 
interventions' efficacy, i.e. whether an intervention works in people who remained in the study. Complete case analyses assume that dropouts do not differ from complete cases who have the same treatment, pretest smoking status, and covariate values, with respect to their smoking status at follow-up. Because one never knows whether this assumption might have been violated, we additionally performed intention to treat analyses by including all students who had been randomized to treatment in May 1997. We replaced the missing outcome value of dropouts in two ways: (a) with the value 1 ('yes') for smoking, assuming that all dropouts had initiated or continued smoking at follow-up (extreme case analyses); and (b) with their last observed smoking status, assuming that all dropouts had maintained this smoking status at follow-up (carried forward analyses). Although all three methods of dealing with dropout (i.e. complete case, extreme case or carried forward analyses) make a different assumption, their combined use enables us to find out which results on treatment effects are robust against different assumptions about dropout.

Because running large regression models with MIXOR might cause problems, model reduction was first performed using SPSS 9.0 (SPSS Inc, 1999) to determine the final models containing significant covariates and interaction terms for the prediction of $T_{3}, T_{4}$ and $T_{5}$ attrition, and smoking initiation and continuation. The following strategy was used: attrition, smoking initiation and continuation at $T_{3}, T_{4}$ and $T_{5}$ were both predicted from treatment factors (in-school, out-of-school, and their interaction). Subsequently, demographic and pretest psychosocial (ASE) measures were entered as covariates, as previous research had shown that these were predictors of smoking (De Vries et al., 1994). Non-significant covariates and interactions were deleted stepwise, with the restriction that predictors were never removed from the models if they were involved in some interaction term in the model. The treatment factors (in-school, out-ofschool) were never removed, as their effects were the focus of the study. The final models were entered into the multilevel analyses to test attrition and the intervention effects.

\section{Results}

\section{Sample characteristics and attrition}

Table 4.1 presents the flow of participants (schools and -in brackets- students). At $\mathrm{T}_{0}$, the mean age of the students was 11.6 years, $51 \%$ were female and no differences were found between the four conditions with respect to demographic and psychosocial variables.

In June $1998\left(\mathrm{~T}_{2}\right)$, the students were asked permission to be included in the followup study, to which 1865 of the students agreed. Logistic regression analysis (without the eight schools that had dropped out; $\mathrm{N}=3472$ ) showed that students from the out-ofschool conditions were most likely to agree, followed by students from the intout condition, while students from the in-school and control conditions were least likely to agree participation. Girls were more likely to agree than boys. A total of 1475 students ( $42.5 \%$ of the $\mathrm{N}=3472$ sample and $79.1 \%$ of those who agreed to further participate in June 1998) completed and returned the $T_{3}$ questionnaire in May 1999. The follow-up 
assessment in February $2000\left(\mathrm{~T}_{4}\right)$ was completed and returned by 1138 students $(32.8 \%$ of the $\mathrm{N}=3472$ sample and $61.1 \%$ of those who agreed to participate in June 1998). The follow-up assessment in September $2000\left(\mathrm{~T}_{5}\right)$ was completed and returned by 1024 students $(29.5 \%$ of the $\mathrm{N}=3472$ sample and $54.9 \%$ of those who agreed to participate in 1998). Dropout at $T_{3}, T_{4}$ and $T_{5}$ was highest in the in-school and control conditions, followed by the $\mathrm{I}+\mathrm{O}$ condition, while dropout was lowest in the out-of-school condition. Furthermore, boys were more likely to dropout at $T_{3}, T_{4}$ and $T_{5}$ and pretest ever smokers were more likely to dropout at $\mathrm{T}_{4}$ and $\mathrm{T}_{5}$.

Table 4.2 Smoking initiation among pretest never smokers in experimental and control groups: Effects of various methods of handling missing data, percentages (\%) with $95 \%$ confidence intervals (CI)

\begin{tabular}{|c|c|c|c|c|c|}
\hline & $\begin{array}{l}\text { Sample } \\
\text { size }\end{array}$ & $\begin{array}{l}\text { Complete case } \\
\text { analysis }\end{array}$ & $\begin{array}{l}\text { Sample } \\
\text { size }\end{array}$ & $\begin{array}{l}\text { Extreme case } \\
\text { analysis }\end{array}$ & $\begin{array}{l}\text { Carry forward } \\
\text { analysis }\end{array}$ \\
\hline & N1 & $\%(95 \% \mathrm{Cl})$ & $\mathrm{N} 2$ & $\%(95 \% \mathrm{CI})$ & $\%(95 \% \mathrm{CD})$ \\
\hline \multicolumn{6}{|l|}{ POSTTEST 3} \\
\hline In-school & 185 & $21(15-27)$ & 559 & $74(70-77)$ & $24(20-27)$ \\
\hline Out-of-school & 332 & $23(18-27)$ & 536 & $51(47-55)$ & $24(20-27)$ \\
\hline In+out of school & 331 & $24(20-29)$ & 645 & $61(57-65)$ & $25(21-28)$ \\
\hline Control & 146 & $21(15-28)$ & 463 & 75 (71-79) & $29(25-33)$ \\
\hline \multicolumn{6}{|l|}{ POSTTEST 4} \\
\hline In-school & 153 & $32(25-40)$ & 559 & $81(78-85)$ & $27(23-31)$ \\
\hline Out-of-school & 265 & $31(25-36)$ & 536 & $65(61-69)$ & $28(24-32)$ \\
\hline Intout of school & 267 & $31(24-39)$ & 645 & $71(68-75)$ & $28(24-31)$ \\
\hline Control & 113 & $25(17-33)$ & 463 & $81(78-85)$ & $31(26-35)$ \\
\hline \multicolumn{6}{|l|}{ POSTTEST 5} \\
\hline In-school & 138 & $38(29-46)$ & 559 & $85(82-88)$ & $29(25-33)$ \\
\hline Out-of-school & 240 & $36(30-42)$ & 536 & $71(67-75)$ & $31(27-35)$ \\
\hline Intout of school & 248 & $39(33-45)$ & 645 & $76(73-80)$ & $31(27-35)$ \\
\hline Control & 103 & $28(19-37)$ & 463 & $84(80-87)$ & $32(27-36)$ \\
\hline
\end{tabular}

Notes, N1: Sample in which the complete case analyses were performed. N2: Sample in which extreme case and carried forward analyses were performed

\section{Program results}

Smoking initiation and continuation were analyzed separately and because of the substantial dropout rate, complete-case and intention-to-treat analyses were performed (see Analyses, Methods). Changes in smoking initiation at $\mathrm{T}_{3}, \mathrm{~T}_{4}$, and $\mathrm{T}_{5}$ are shown in table 4.2 , presenting the prevalences computed as a result of the complete case, extreme 
case, and carried forward analyses. In the extreme case analyses missing data were treated as smokers, whilst in the complete case analyses no missing data were included and in the carried forward analyses only the last observation was imputed.

As can be noted from table 4.2, this resulted in substantial differences in the percentages estimated to initiate smoking at all posttests. The prevalence rates were lowest in the complete case and carried forward samples and highest in the extreme case samples. Considering the complete case samples, the prevalence rates of initiation were lowest in the control condition, in contrast with the extreme case and carried forward samples, where the initiation rates in the control condition were (among the) highest.

Changes in smoking continuation at $\mathrm{T}_{3}, \mathrm{~T}_{4}$, and $\mathrm{T}_{5}$ are shown in table 4.3. Similar to the findings found for analyzing smoking initiation, the percentages of youngsters continuing to smoke for the three posttests were again very high when using extreme case analyses, and much lower for the other two strategies. Considering the complete case samples, the prevalence rates of continuation were lowest in the in-school and control condition, in the carried forward sample the continuation rates were lowest in the control condition, in the extreme case sample the continuation rates were lowest in the out-of-school condition

Table 4.4 presents the long-term effects of the out-of-school and in-school interventions with the odds ratios for the program effects on smoking initiation at $T_{3}, T_{4}$, and $T_{5}$. The odds ratios were adjusted with significant covariates that were also listed in table 4.4. The complete-case analysis at $\mathrm{T}_{5}$ suggests that pretest never smokers in the out-ofschool condition were more likely to have initiated smoking than never smokers who were not involved in the out-of-school intervention. Extreme-case analyses at $T_{3}$ and $T_{4}$ showed significant out-of-school effects on smoking initiation (pretest never smokers who had received the letters were less likely to have initiated smoking than pretest never smokers who did not receive them). Carried forward analyses did not show significant treatment effects.

Considering the covariates that were included in the regression models, we will only focus on significant covariates $(\mathrm{p}<.01)$, to prevent type I errors due to multiple testing. Regarding smoking initiation, smoking people in students' immediate environment (modeling 'nuclear'), low self-efficacy expectations and a negative intention towards non-smoking predicted smoking initiation. 


\section{long-term effects}

Table 4.3 Smoking continuation among pretest ever smokers in experimental and control groups: Effects of various methods of handling missing data, percentages (\%) and $95 \%$ confidence intervals $(\mathrm{CI})$

\begin{tabular}{|c|c|c|c|c|c|}
\hline & $\begin{array}{l}\text { Sample } \\
\text { size }\end{array}$ & $\begin{array}{l}\text { Complete case } \\
\text { analysis }\end{array}$ & $\begin{array}{l}\text { Sample } \\
\text { size }\end{array}$ & $\begin{array}{l}\text { Extreme } \\
\text { case analysis }\end{array}$ & $\begin{array}{l}\text { Carry forward } \\
\text { analysis }\end{array}$ \\
\hline & N1 & $\%(95 \% \mathrm{CI})$ & N2 & $\%(95 \% \mathrm{Cl})$ & $\%(95 \% \mathrm{Cl})$ \\
\hline \multicolumn{6}{|l|}{ POSTTEST 3} \\
\hline In-school & 88 & $13(5-20)$ & 287. & $73(68-78)$ & $24(19-29)$ \\
\hline Out-of-school & 155 & $15(9-21)$ & 305 & $56(51-62)$ & $21(16-26)$ \\
\hline Intout of school & 157 & $17(11-22)$ & 376 & $65(60-69)$ & $20(16-24)$ \\
\hline Control & 81 & $12(5-20)$ & 301 & $76(72-81)$ & $19(14-23)$ \\
\hline \multicolumn{6}{|l|}{ POSTTEST 4} \\
\hline In-school & 68 & $19(10-29)$ & 287 & $81(76-85)$ & $25(20-30)$ \\
\hline Out-of-school & 111 & $25(17-33)$ & 305 & $72(67-77)$ & $25(20-30)$ \\
\hline Intout of school & 108 & $21(13-29)$ & 376 & $77(73-81)$ & $22(18-26)$ \\
\hline Control & 53 & $19(8-30)$ & 301 & $86(82-90)$ & $20(16-25)$ \\
\hline \multicolumn{6}{|l|}{ POSTTEST 5} \\
\hline In-school & 59 & $25(14-37)$ & 287 & $85(80-89)$ & $26(21-32)$ \\
\hline Out-of-school & 92 & $35(25-45)$ & 305 & $80(76-85)$ & $29(24-34)$ \\
\hline In+out of school & 94 & $26(17-35)$ & 376 & $81(77-85)$ & $24(20-29)$ \\
\hline Control & 50 & $28(15-41)$ & 301 & $88(84-92)$ & $22(17-27)$ \\
\hline
\end{tabular}

Notes, N1: Sample in which the complete case analyses were performed. N2: Sample in which extreme case and carried forward analyses were performed 


\section{chapter 4}

Table 4.4 Smoking initiation ( $1=y e s, 0=$ no) among pretest never smokers: Long-term program effects using complete case, extreme case and carry forward analyses, Odds ratios and $95 \%$ confidence intervals

\begin{tabular}{|c|c|c|c|c|c|c|}
\hline \multirow[t]{2}{*}{ POSTTEST 3} & \multicolumn{2}{|c|}{ Complete case } & \multicolumn{2}{|c|}{ Extreme case } & \multicolumn{2}{|c|}{ Carry forward } \\
\hline & OR & $95 \% \mathrm{CI}$ & OR & $95 \% \mathrm{CI}$ & OR & $95 \% \mathrm{CI}$ \\
\hline Out-of-school: I-yes, 0-no & 0.88 & $(0.59-1.31)$ & $0.41^{* * *}$ & $(0.28-0.56)$ & 1.10 & $(0.82-1.49)$ \\
\hline In-school: 1-yes, 0-no & 0.92 & $(0.64-1.32)$ & 0.74 & $(0.55-1.01)$ & 1.01 & $(0.75-1.36)$ \\
\hline Age, years & $1.43^{\circ}$ & $(1.03-2.00)$ & & & & \\
\hline Modeling 'nuclear':-8 (neg) - 0 (pos) & $0.86^{* \bullet}$ & $(0.77-0.97)$ & & & & \\
\hline Intention: -3 (neg)-3 (pos) & $0.80^{\bullet \bullet}$ & $(0.69-0.93)$ & & & & \\
\hline \multicolumn{7}{|l|}{ POSTTEST 4} \\
\hline Out-of-school: $1=y e s, 0=$ no & 1.29 & $(0.88-1.88)$ & $0.79^{\bullet}$ & $(0.63-1.00)$ & 0.94 & $(0.77-1.16)$ \\
\hline In-school: I-yes, 0-no & 1.18 & $(0.85-1.62)$ & 1.12 & $(0.91-1.37)$ & 0.96 & $(0.80-1.16)$ \\
\hline Modeling 'nuclear': -8 (neg)- 0 (pos) & $0.78 \bullet \bullet \bullet$ & $(0.72-0.85)$ & & & & \\
\hline Self-efficacy: -18 (neg)-18 (pos) & $0.97^{*}$ & $(0.96-1.00)$ & & & & \\
\hline Intention:-3 (neg) -3 (pos) & $0.76 \bullet \bullet \bullet$ & $(0.65-0.89)$ & & & & \\
\hline \multicolumn{7}{|l|}{ POSTTEST 5} \\
\hline Out-of-school: $1=$ yes, 0 -no & $1.49^{*}$ & $(1.02-2.19)$ & 0.84 & $(0.66-1.08)$ & 1.04 & $(0.85-1.27)$ \\
\hline In-school: I=yes, 0-no & 1.21 & $(0.88-1.67)$ & 1.16 & $(0.93-1.44)$ & 0.96 & $(0.80-1.16)$ \\
\hline $\begin{array}{l}\text { Attitude 'long-term consequences': } \\
-6 \text { (neg) }-6 \text { (pos) }\end{array}$ & $0.93^{*}$ & $(0.87-0.99)$ & & & & \\
\hline Pressure: -50 (neg)- 0 (pos) & $0.96^{*}$ & $(0.92-0.99)$ & & & & \\
\hline Modeling 'nuclear':-8 (neg)- 0 (pos) & $0.86 * * *$ & $(0.79-0.94)$ & & & & \\
\hline Self-efficacy $(-18>+18)$ & $0.97^{\bullet *}$ & $(0.95-0.99)$ & & & & \\
\hline
\end{tabular}

Notes, *p<0.05, $\cdots p<0.01, \cdots * p<0.001$; 'Neg' means negative towards non-smoking, 'pos' means positive towards non-smoking 


\section{long-term effects}

Table 4.5 Smoking continuation ( $1=$ yes, $0=$ no) among pretest ever smokers: Long-term effects of complete case, extreme case and carry forward analyses, Odds ratios (OR), $95 \%$ confidence intervals (CI)

\begin{tabular}{|c|c|c|c|c|c|c|}
\hline \multirow[t]{2}{*}{ POSTTEST 3} & \multicolumn{2}{|c|}{ Complete case } & \multicolumn{2}{|c|}{ Extreme case } & \multicolumn{2}{|c|}{ Carry forward } \\
\hline & OR & $95 \% \mathrm{Cl}$ & OR & $95 \% \mathrm{CI}$ & OR & $95 \% \mathrm{Cl}$ \\
\hline Out-of-school: 1=yes, 0=no & 0.83 & $(0.45-1.54)$ & $0.45 * \bullet \bullet$ & $(0.31-0.65)$ & 1.10 & $(0.75-1.62)$ \\
\hline In-school: 1=yes, 0=no & 0.95 & $(0.50-1.78)$ & 0.91 & $(0.61-1.34)$ & 0.91 & $(0.61-1.36)$ \\
\hline Age, years & $2.21^{*}$ & $(1.11-4.41)$ & & & & \\
\hline $\begin{array}{l}\text { Attitude 'short-term consequences' } \\
11 \text { (neg) }-55 \text { (pos) }\end{array}$ & $0.93 * *$ & $(0.88-0.98)$ & & & & \\
\hline Modeling 'nuclear': -8 (neg) -0 (pos) & $0.73 \bullet * \bullet$ & $(0.63-0.84)$ & & & & \\
\hline Self-efficacy: - 18 (neg) - 18 (pos) & $0.96^{*}$ & $(0.92-0.99)$ & & & & \\
\hline \multicolumn{7}{|l|}{ POSTTEST 4} \\
\hline Out-of-school: $1=y e s, 0=$ no & 1.30 & $(0.63-2.71)$ & 1.05 & $(0.75-1.47)$ & 1.06 & $(0.78-1.44)$ \\
\hline In-school: $1=y e s, 0=$ no & 0.86 & $(0.48-1.53)$ & 0.91 & $(0.68-1.22)$ & 1.08 & $(0.81-1.43)$ \\
\hline Gender: $1=$ female, $0=$ male & $0.39 * *$ & $(0.21-0.73)$ & & & & \\
\hline Age, years & $2.09 * *$ & $(1.23-3.52)$ & & & & \\
\hline $\begin{array}{l}\text { Attitude 'short-term consequences': } \\
11 \text { (neg) - } 55 \text { (pos) }\end{array}$ & $0.96^{*}$ & $(0.92-1.00)$ & & & & \\
\hline Pressure: -5 (neg) -0 (pos) & $0.93^{* *}$ & $(0.89-0.97)$ & & & & \\
\hline Modeling 'nuclear': -8 (neg) -0 (pos) & $0.83^{*}$ & $(0.72-0.96)$ & & & & \\
\hline Self-efficacy: -18 (neg) -18 (pos) & $0.96^{*}$ & $(0.93-1.00)$ & & & & \\
\hline \multicolumn{7}{|l|}{ POSTTEST 5} \\
\hline Out-of-school: $1=y e s, 0=$ no & 1.79 & $(0.90-3.53)$ & 1.29 & $(0.89-1.86)$ & 1.20 & $(0.85-1.53)$ \\
\hline In-school: $1=y e s, 0=$ no & 0.72 & $(0.42-1.25)$ & 0.82 & $(0.60-1.13)$ & 1.03 & $(0.78-1.34)$ \\
\hline Gender: $1=$ female, $0=$ male & $0.53^{*}$ & $(0.30-0.92)$ & & & & \\
\hline $\begin{array}{l}\text { Origin: } 1=1 / 2 \text { non-Dutch, } 0=2 \text { Dutch } \\
\text { parents }\end{array}$ & $2.49 * *$ & $(1.25-4.97)$ & & & & \\
\hline $\begin{array}{l}\text { Attitude 'short-term consequences': } \\
11 \text { (neg) - } 55 \text { (pos) }\end{array}$ & $0.94 * *$ & $(0.91-0.98)$ & & & & \\
\hline Pressure: -50 (neg) -0 (pos) & $0.93^{* *}$ & $(0.88-0.97)$ & & & & \\
\hline
\end{tabular}

Notes, ${ }^{*} \mathrm{p}<0.05,{ }^{* *} \mathrm{p}<0.01,{ }^{* * *} \mathrm{p}<0.001$; 'Neg' means negative towards non-smoking, 'pos' means positive towards non-smoking 
Table 4.5 presents the long-term effects of the out-of-school and in-school interventions with the odds ratios for the program effects on smoking continuation at $T_{3}, T_{4}$, and $T_{5}$. Complete case and carried forward analyses did not show significant treatment effects, extreme case analysis resulted in positive effects at $T_{3}$ for the out-of school program.

The odds ratios were adjusted with significant covariates that were also listed in table 4.5. Significant covariates $(p<.01)$ were gender, age, origin, perception of short-term consequences of smoking, modeling 'nuclear', and perceived pressure. Thus, male students, older students, students with one or two non-Dutch parents, students who perceived fewer short-term consequences, students who perceived more smoking people in their 'nuclear' environment, and students who perceived more pressure towards smoking were more likely to continue smoking.

Since multilevel analyses demonstrated negligible intraclass correlation (i.c.c. $=0.000$ ) regarding smoking initiation and continuation at $\mathrm{T}_{4}$ and $\mathrm{T}_{5}$, logistic regression analyses for the $T_{4}$ and $T_{5}$ effect evaluations were carried out using SPSS 9.0 instead of MIXOR. Since no significant interactions were found between the in-school and out-of-school factors, all effect analyses were restricted to the main effects.

\section{Discussion}

This chapter describes the long-term effects of an in-school intervention and a tailored out-of-school intervention. Besides complete case analyses, also intention to treat analyses (extreme case and carried forward analyses) were performed in order to control for the substantial dropout that occurred during follow-up.

Two main conclusions can be drawn from this chapter. The first is that when using extreme case analyses, where all missing values on smoking status are recoded by a smoking value, results in extremely high initiation and continuation figures. These figures are probably much too high, taken into account the figures that were identified by the complete case and the carried forward analyses, the latter imputing the missing smoking status to the last observed smoking status. Complete case and carried forward methods resulted in reasonable similar figures, a finding that can probably be attributed to the fact that the changes in smoking behavior between the three posttests $(20,30$, and 36 months after pretest) were not extremely great. The second conclusion is that the complete case and the carried forward analyses did not reveal preventive long-term effects of either the in- or out-of-school programs. At the last posttest $\left(T_{5}\right)$ the complete case analysis even suggested a counter productive effect of the out-of-school intervention. The extreme case analysis did reveal, however, preventive effects of the in- and out-of-school programs at $T_{3}$ and $T_{4}$ (only the out-of-school program) on smoking initiation, and for the out-of-school program on smoking continuation for the third posttest. Since the extreme case analyses are probably too strict in terms of interpreting missings as smokers we propose to base our conclusions in this study using the other two strategies.

The period between the pretest in September 1997 and the last posttest $\left(\mathrm{T}_{5}\right)$ lasted three years. Other smoking prevention studies also reported positive short-term effects, 
but like in our study, these effects tend to dissipate over time (Ellickson et al., 1993; Flay et al., 1989; Lantz et al., 2000; US Department of Health and Human Services, 1994). The lack of booster sessions is suggested in the literature to be an important reason for these dissipating effects, implicating the inclusion of boosters into smoking prevention programs (Elder, Wildey et al., 1993; Lantz et al., 2000; Murray et al., 1989).

This study has limitations. Firstly, during the study period, a large part of the participants was lost due to withdrawal. At the time of the second posttest, when 8 complete schools already were lost, attrition was modest (13.3\%). Most attrition was found after the renewal of the participation request $(36.7 \%)$ at the end of the elementary school period. Flay and colleagues (1995) reported comparable dropout rates during the transition into secondary school. Pretest smokers and boys were more likely to dropout 30 and 36 months after pretest. These findings were fairly consistent with previous studies (Sowden \& Arblaster, 2003). Dropout might have biased program effects, and although we used different strategies for handling missing data, future research should concentrate on minimizing of attrition.

Secondly, although at the start of our study, students were nested within schools, and schools were randomly assigned to treatment conditions, multilevel regression analyses were required, with schools as level- 2 units and students as level-1 units, since school influences are supposed to contribute to the unexplained variation. However, posttest $\mathrm{T}_{4}$ and $\mathrm{T}_{5}$ effect analyses did not reveal any intraclass correlation. This might be the result of the transition to secondary school that had occurred more than a year before, and elementary school's influence, although still present at $T_{3}$, may have faded at $T_{4}$ and $T_{5}$. In view of this lack of intraclass correlation, the $T_{4}$ and $T_{5}$ analyses were performed with students, instead of schools, as the unit of analysis.

Thirdly, no validation of self-reported smoking behavior was used in this study, because objective measurements for young adolescents are unreliable and detect only very recent smoking, whereas most smokers in the age group selected for the present study are only experimenting with smoking. Nevertheless, self-reports have been demonstrated to be more accurate when confidentiality is assured and an identification coding system is used (Akers et al., 1983; Botvin \& Botvin, 1992; Murray \& Perry, 1987; US Department of Health and Human Services, 1990), precautions that were indeed taken in the present study.

In this study it was again (Ausems, Mesters, van Breukelen, \& De Vries, 2003; Engels, Knibbe, De Vries, Drop, \& van Breukelen, 1999; Mayhew, Flay, \& Mott, 2000) confirmed that smoking initiation, and to a certain extent also smoking continuation, were associated with the number of smokers in students' 'nuclear' environment, such as smoking parents, brothers, sisters and best friends. It needs to be defined that prevention of smoking aimed at adolescents should be embedded in family directed, comprehensive programs.

In sum, the three different strategies used in our study to handle with drop-out resulted in highly similar conclusions for the complete case and carried forward analyses revealing unfortunately no significant program effects. Moreover, the extreme case strategy resulted in very high, if not too high, estimations of smoking initiation and continuation percentages. 



\section{Do boosters contribute to tailored out-of- school smoking prevention?}

Manuscript submitted for publication as: Ausems, M., Mesters, I., van Breukelen, G., De Vries, H. 'Do boosters contribute to tailored out-of-school smoking prevention?' 
chapter 5

\begin{abstract}
This chapter describes the evaluation of boosters that were added to a tailored out-ofschool smoking prevention intervention using different strategies for handling missing data. Springtime 1997, 156 Dutch elementary schools were randomly assigned to an existing in-school (I), tailored out-of-school (O), combined in- and out-of-school (I+O) or no intervention condition (C). Short-term results of the out-of-school program turned up, but these effects had disappeared in the long-term. Summer 1999, 70 schools, that initially received the out-of-school program $(\mathrm{O}, \mathrm{I}+\mathrm{O})$, were randomly assigned to the tailored booster intervention or to a control group. In sum, tailored out-of-school programs seem promising considering smoking prevention, but only if supplemented with booster sessions. Program effects might be fruitfully improved by extending the educational period with tailored booster sessions. Furthermore, the extreme case strategy for handling missing data does not seem to be appropriate in adolescent smoking prevention research.
\end{abstract}




\section{Introduction}

The importance of prevention of both smoking initiation and continuation aimed at young people is beyond doubt considering the serious health consequences and more severe levels of nicotine addiction that are related to young-aged smoking initiation (Pierce \& Gilpin, 1996; Taioli \& Wynder, 1991; US Department of Health and Human Services, 1994; Warren et al., 2000).

Over the last three decades, smoking prevention efforts aimed at youngsters have often been embedded in the school setting. This seems reasonable, since schools reach wide audiences, health education is part of the school curriculum in many countries, interpersonal communication is possible, and the school setting provides good opportunities for evaluation studies (Sussman et al., 1995).

A potential drawback of school-based smoking prevention programs is that their implementation depends on limited time and untrained personnel (Murray et al., 1992), while schools may also have a particular negative connotation for some youngsters, which may reduce the suitability of schools as an access point for reaching youngsters (Bullock et al., 1996). Innovative out-of-school programs have been recommended to overcome these disadvantages of in-school interventions (Peterson et al., 2000; US Department of Health and Human Services, 2000). In this context, a Dutch smoking prevention intervention aimed at elementary schoolchildren was implemented, in order to evaluate the impact of a newly developed computerized out-of-school program, consisting of individualized tailored letters mailed to the students' homes. The idea of personal tailored letters originated in the United States (Campbell et al., 1994; Rimer et al., 1994; Skinner et al., 1993; Velicer et al., 1993) and has been further developed and tested for several years in the Netherlands (Brug et al., 1998; De Nooijer et al., 2002; Dijkstra \& De Vries, 1999; Dijkstra, De Vries, \& Roijackers, 1998; Dijkstra, De Vries, Roijackers et al., 1998; Dijkstra, De-Vries et al., 1998; Willemsen \& De Vries, 1995). The impact of the computerized out-of-school smoking prevention intervention was assessed relative to the impact of an existing school-based social influence program. Significant short-term effects in terms of lower smoking continuation rates were found for the out-of school program (Ausems et al., 2002), but these effects had disappeared after a longer period (Ausems, Mesters, van Breukelen, \& De Vries, submitted-b).

According to Chaffee and Roser (1986), repetition of non-smoking messages might increase students involvement in smoking prevention, resulting in a positive change in both knowledge and attitudes about non-smoking, which are both considered to be stable and good predictors of future smoking behavior. Because earlier studies in which the effects of booster interventions are described (Botvin, Baker, Dusenbury, Botvin, \& Diaz, 1995; Botvin, Baker, Filazzola, \& Botvin, 1990; M. Dijkstra et al., 1999; Flay, 1985; Rooney \& Murray, 1996; White \& Pitts, 1998) seemed to confirm Chaffee and Roser's argumentation, our out-of-school intervention was extended with three booster sessions.

The first main goal of this chapter is to analyze the effects of booster sessions, and to describe their process evaluation. It was hypothesized that the tailored booster intervention would result in less smoking initiation among never smoking students, and less smoking continuation among those students who already have smoking experiences. 
Our trial was confronted with serious dropout. Hence, the second goal of the study described in this chapter is to compare three analyses strategies that deal missing data differently (complete case, extreme case, and carried forward analyses), since the results of an earlier study (Ausems et al., submitted-b) suggested that extreme case analysis (that imputes missing data on smoking status by the last observation) might yield unreliable results.

\section{Methods}

\section{Design and procedure}

Table 5.1 shows the timeline of the present study. Schools were randomly assigned to an in-school (I), out-of-school (O), a combined in- and out-of-school $(\mathrm{I}+\mathrm{O})$ or no intervention (C) condition, before 3734 elementary school children completed the $T_{0}$ questionnaire in September 1997. The $T_{2}$ questionnaire (June 1998) asked respondents whether they consented to participate in a follow-up study, which was aimed at assessing the effects of a booster intervention among students who initially started in the $\mathrm{O}$ or the $\mathrm{I}+\mathrm{O}$ programs. If students agreed, they could write down their home addresses, at which they received a $T_{3}$ questionnaire in May 1999.

Unlike the $T_{0}, T_{1}$ and $T_{2}$ questionnaires, that had been sent to the elementary schools and were completed in the classroom, the $T_{3}$ questionnaires and instructions were sent to students' home addresses, because the students transferred to a wide range of secondary schools, thus making schools unusable as access point. Students were asked to complete the questionnaires at home and return them to the research team in a prepaid envelope. A reminder was sent two weeks after the mailing. To enhance the response rate, 15 cinema vouchers were put up for raffle. In August 1999, the schools from the $\mathrm{O}$ and $\mathrm{I}+\mathrm{O}$ conditions were randomly assigned to a booster $(+\mathrm{B})$ or a nobooster (-B) condition.

The booster intervention was implemented between September 1999 and January 2000. The fourth $\left(\mathrm{T}_{4}\right)$ and fifth $\left(\mathrm{T}_{5}\right)$ follow-up assessments, with a mailing procedure analogous to that used at $T_{3}$, took place in February 2000 and September 2000, respectively. Like the students who received the $\mathrm{O}$ intervention completed a process evaluation questionnaire at $T_{1}$, the students who received the booster intervention also completed a process evaluation questionnaire, together with the follow-up assessment at $T_{4}$. 
boosters

Table 5.1 Number of schools (students) from initial approach to Posttest 5

\begin{tabular}{|c|c|c|c|c|c|c|c|c|}
\hline & & I & $\mathbf{o}$ & & $1+0$ & & C & Total \\
\hline \multirow[t]{3}{*}{ May 1997} & Approach & & & & & & & 414 \\
\hline & Approval+ & 39 & 39 & & 38 & & 40 & 156 \\
\hline & Randomization & & & & & & & \\
\hline \multirow[t]{2}{*}{ Sept 1997} & Pretest $\left(T_{0}\right)$ & 36 & 36 & & 37 & & 34 & 143 \\
\hline & & $(1002)$ & ) $(87$ & & (1068) & & (793) & (3734) \\
\hline Sept 1997 - Febr 1998 & Interventions & + & + & & + & & & \\
\hline \multirow[t]{2}{*}{ Febr 1998} & Posttest $1\left(\mathrm{~T}_{1}\right)$ & 34 & 36 & & 36 & & 34 & 140 \\
\hline & & (843) & $\left(80^{-}\right.$ & & (984) & & (715) & (3349) \\
\hline \multirow[t]{2}{*}{ June 1998} & Posttest $2\left(\mathrm{~T}_{2}\right)$ & 31 & 35 & & 36 & & 33 & 135 \\
\hline & & (785) & $(78$ & & (967) & & (697) & (3236) \\
\hline \multirow[t]{2}{*}{ June 1998} & Approval & 30 & 35 & & 36 & & 33 & 134 \\
\hline & & (319) & (61: & & (638) & & (296) & (1865) \\
\hline \multirow[t]{3}{*}{ May 1999} & Posttest $3\left(\mathrm{~T}_{3}\right)$ & 30 & 35 & & 35 & & 31 & 131 \\
\hline & & (273) & $(48$ & & (488) & & (227) & (1475) \\
\hline & & & $k$ & & $k v$ & & & \\
\hline \multirow[t]{2}{*}{ August 1999} & Booster & & 18 & 17 & 17 & 18 & & 70 \\
\hline & randomization & & (266) & (221) & (229) & (259) & & (975) \\
\hline Sept 1999 - Jan 2000 & Booster & & B & & B & & & \\
\hline \multirow[t]{2}{*}{ Feb 2000} & Posttest $4\left(\mathrm{~T}_{4}\right)$ & & 18 & 17 & 17 & 18 & & 70 \\
\hline & & & (203) & (173) & (166) & (209) & & (751) \\
\hline \multirow[t]{2}{*}{ Sept 2000} & Posttest $5\left(\mathrm{~T}_{5}\right)$ & & 18 & 17 & 17 & 18 & & 70 \\
\hline & & & (176) & (156) & (158) & (184) & & $(674)$ \\
\hline
\end{tabular}

Note, I, In-school; O, Out-of-school; I+O, In-school plus Out-of-school; C, Control condition; B, Booster

\section{Interventions}

During the first part of the study, up to and including posttest $2\left(\mathrm{~T}_{2}\right)$, two interventions were implemented; an in-school and a tailored out-of-school program. Both programs were based on essential components of successful social influence programs (Sussman et al., 1993). Topics included the short-term physical and social consequences of smoking, pressure, other people's smoking behavior, and refusal skills.

The in-school intervention, called 'Don 't play with fire', was developed by the Dutch Foundation on Smoking and Health. The package used in the present study 
contained a teacher manual and a student workbook. The complete intervention consisted of seven lessons, each lasting between 45 and 60 minutes. Each lesson comprised a general explanation by the teacher, a classroom discussion, a workbook task, a preparation part, and a creative activity.

The out-of-school intervention consisted of three computer-generated, individually tailored letters with smoking prevention messages mailed to students' homes at threeweek intervals. The three- to five-page letters included messages that were based on sum scores obtained at the pretest questionnaire $\left(\mathrm{T}_{0}\right)$ on attitudes, social norms, selfefficacy, smoking intention and behavior. Pilot testing and revision of concepts had resulted in the creation of a message file. A computer program, developed by Maastricht University, linked the pretest scores with the appropriate message in the message file, and combined the messages in a letter format. In addition, the letters included a picture puzzle, a contest and several cartoons to draw the students' attention and increase the attractiveness of the package, and to foster processing and storage of the information. The first letter ( 8 potential different versions) provided information on students' beliefs about smoking in general, and the short-term (nausea, bad smell) and social (feeling tough, looking mature) consequences of smoking. The second letter (32 versions) focused on the influence of the social environment on students' smoking behavior and their intention not to smoke in the future. The third letter ( 2 versions) described selfefficacy expectations together with refusal techniques.

The tailored booster intervention was designed to review and reinforce the tailored information offered during the first year of the intervention and was based on data accumulated by means of the May 1999 questionnaire $\left(\mathrm{T}_{3}\right)$. The booster intervention was comparable with the tailored out-of-school intervention (i.e. three letters sent to students' home addresses, providing individualized information about smoking), except that the messages in the booster intervention were based on specific items regarding beliefs, motives, and perceptions about smoking and not on scales (sum scores), as was the case in the tailored out-of-school intervention. This resulted in a large number of potential different versions of the booster letters. The first booster letter $(2,834,352$ versions) included information regarding student's beliefs about several consequences of smoking like tightness of the chest, nausea, coughing, cancer, heart diseases, sociability, concealing one's unease, and relaxing. The second booster letter (108 versions) included information about perceived pressure and smoking behavior by other people in the Netherlands as a whole, in the student's peer environment, and in the student's family. The third booster letter (768 versions) included information about the student's intention to start smoking and the student's perceptions about his/her ability to refuse cigarettes offered by friends or upon being called a coward. This third letter also included a test measuring the level of difficulty experienced with cigarette refusal, and suggestions for handling environmental smoking. The booster letters were appended with a poem on the occasion of the millennium celebration, and several cartoons.

\section{Measurements}

\section{Outcome measurement}

The questionnaires used at $\mathrm{T}_{0}-\mathrm{T}_{5}$ were based on the Attitude-Social influence-self Efficacy (ASE) questionnaire (De Vries et al., 1994; De Vries, Dijkstra, \& Kuhlman, 1988; M. Dijkstra et al., 1999). They included questions about attitude (21 items; 5- and 
7- point scales), social influences (24 items; 3-, 5-, 6-, and 7-point scales), self-efficacy expectations ( 6 items; 7-point scales), intention ( 1 item; 7-point scale), and demographic variables like age, gender, religion, family composition, pocket money and parents' job and origin. The operationalization of the four attitude, four social influences, one self-efficacy and one intention scales has been described elsewhere (Ausems et al., 2002). Smoking behavior was based on self-reports, categorizing students as: (1) never smokers: students who have never smoked even one cigarette (or a puff of a cigarette); (2) non-current smokers: students who have smoked in the past, but not during the past month; and (3) current smokers: students who have smoked during the past month (World Health Organization, 1998; Flay et al., 1995).

As for treatment effects on smoking initiation, we assessed the percentage of neversmoking students (category 1) at pretest who indicated at follow-up that they had initiated smoking (categories 2-3). As for treatment effects on smoking continuation, we assessed the percentage of ever smokers (category 2-3) at pretest who indicated at follow-up to have smoked during the past month (category 3 ).

\section{Process measurements}

The process evaluations assessed exposure to and appreciation of the out-of-school and booster interventions. Each intervention, exposure was recorded by asking if students had received each of the three letters and by asking for the degree to which they had read each letter ('completely' (4) to 'not at all' (1)). Students also indicated how many times they had read the letters. Students used 4-point scales to score their appreciation ('enjoyed reading it very much' (4) to 'not' (1)) and the visual appearance of the letters ('very attractive' (4) to 'unattractive' (1)). In order to find out how students perceived the essence of tailoring, namely the personalized approach, the degree of personal approach was assessed by a scale from 'completely personally directed' (4) to 'not personally directed at all' (1). Lastly, students could indicate if they had allowed their parents, siblings or friends to read the letters.

\section{Analyses}

Students were nested within schools, and schools were randomly assigned to treatment conditions. Ignoring this nesting might lead to type I errors and too narrow confidence intervals for treatment effects (Flay et al., 1995). Therefore, most analyses were carried out with multilevel regression modeling, using the MIXREG program for continuous outcomes (Hedeker \& Gibbons, 1996b) and MIXOR for dichotomous outcomes (Hedeker \& Gibbons, 1996a).

Running large regression models with MIXOR might provide no solutions, therefore model reduction was first performed using SPSS 9.0 (SPSS Inc, 1999) to determine the final models containing significant covariates and interaction terms for the prediction of $\mathrm{T}_{4}$ and $\mathrm{T}_{5}$ attrition, and smoking initiation and continuation. The following strategy was used: attrition, and smoking initiation and continuation at $\mathrm{T}_{4}$ and $\mathrm{T}_{5}$ were each predicted from treatment factors (in-school, booster, and their interaction) ${ }^{4}$. Subsequently, pretest

\footnotetext{
${ }^{4}$ Only the booster effects are reported in this chapter, since the in-school effects have already been analyzed and described in chapter 4, using all schools and students that were randomized at the start of the study in spring 1997. In fact, since the analyses described in this chapter included only students who approved continuation after the in-school intervention and a substantial amount of dropout had taken place, the inschool effects can not be validly evaluated together with the booster effects.
} 
demographic and psychosocial covariates were entered, as previous research had shown that these were predictors of smoking (De Vries et al., 1994). Non-significant covariates and interactions were deleted stepwise, apart from the treatment factors (in-school, booster) that were never deleted. The final models were entered into the multilevel analyses to check attrition and to test the intervention effects.

Dropout rates at $T_{4}$ and $T_{5}$ were checked, including those students from the $\mathrm{O}$ and $\mathrm{I}+\mathrm{O}$ groups who were randomized to the booster and no-booster conditions $(\mathrm{N}=975)$, using the dropout at posttests $4-5$ as outcomes and pretest smoking and pretest demographic and psychosocial variables as predictors.

The effect analyses were done separately for the fourth and fifth posttests, and separately for pretest never and ever smokers. In line with the two-way study design, treatment effects were evaluated by including in the regression models, as predictors of smoking, a dummy indicator for each treatment (in-school, booster; yes $=1$, no $=0$ ) and the interaction booster*in-school. If a significant interaction was found, the effect of one treatment was tested within the level of the other treatment that interacted with it. Nonsignificant interactions were removed from the regression model in order to test main effects of the treatments.

The booster intervention was evaluated in various ways. Firstly, by complete-case analyses to estimate intervention's efficacy, i.e. whether an intervention works in people who maintained in the study, including only those students whose smoking status was known at follow up (Hollis \& Campbell, 1999). Complete case analyses assume that dropouts do not differ from complete cases who have the same treatment, pretest smoking status, and pretest covariate values, with respect to their smoking status at follow-up. Because this assumption could be rejected, we furthermore performed intention to treat analyses, by including all students who were randomized to the booster or no booster condition in August 1999. We replaced the missing outcome value of dropouts in two ways: First with the value ' 1 ' for smoking, assuming that all dropouts had initiated or continued smoking at follow-up (extreme case analysis). Secondly, with their last observed smoking status, assuming that all dropouts had maintained this smoking status at follow-up (carried forward analysis). Although these methods of dealing with dropout make a questionable assumption, their combined presentation enables us to find out which results on treatment effects are robust against different assumptions about dropout.

Finally, the results of the process measurements were first calculated for each student, averaging across letters, and subsequently for each school, averaging across students.

\section{Results}

\section{Sample characteristics and attrition}

Table 5.1 presents the flow of participants of the booster study (schools and -in brackets- students). At $T_{0}$, the mean age of the students was 11.6 years, and $51 \%$ were female. In June 1998, the students were asked permission to be included in the booster intervention. Girls were relatively more likely to agree participation. Pretest ever and 
never smokers did not differ in their readiness to continue participation. At $T_{3}$, the mean age of the students was 13.1 years and $60 \%$ was female. Attrition analyses showed that dropout was predicted by gender (boys were more likely to drop out at $T_{4}$ and $T_{5}$ ), religion (religious students were less likely to drop out at $T_{4}$ and $T_{5}$ ), modeling 'nuclear' (students with more smoking people in their nearest environment were more likely to drop out at $T_{4}$ and $T_{5}$ ), smoking (pretest ever smoking students were more likely to drop out at $T_{4}$ and $T_{5}$ ), and treatment (students who received the booster intervention were more likely to dropout at $\mathrm{T}_{4}$ than students who did not receive the boosters, although significance $(\mathrm{p}=0.09)$ was not convincing).

Table 5.2 Smoking initiation among pretest never smokers. Effects of various methods of handling missing data, percentages (\%) with $95 \%$ confidence intervals (CI)

\begin{tabular}{|c|c|c|c|c|c|}
\hline & $\begin{array}{l}\text { Sample } \\
\text { size }\end{array}$ & $\begin{array}{l}\text { Complete case } \\
\text { analysis }\end{array}$ & $\begin{array}{l}\text { Sample } \\
\text { size }\end{array}$ & $\begin{array}{l}\text { Extreme case } \\
\text { analysis }\end{array}$ & $\begin{array}{l}\text { Carry forward } \\
\text { analysis }\end{array}$ \\
\hline & N1 & $\%(95 \%$ CI $)$ & $\mathbf{N} 2$ & $\%(95 \%$ CI $)$ & $\%(95 \%$ CI $)$ \\
\hline \multicolumn{6}{|c|}{ POSTTEST $4\left(\mathrm{~T}_{4}\right)$} \\
\hline $\mathrm{O}^{-8}$ & 129 & $38(29-46)$ & 156 & $49(41-57)$ & $34(26-41)$ \\
\hline $\mathrm{O}^{-8}$ & 136 & $24(16-31)$ & 176 & $41(34-48)$ & $25(19-31)$ \\
\hline $1+0^{-8}$ & 151 & $31(24-39)$ & 181 & $43(35-50)$ & $29(23-36)$ \\
\hline $\mathrm{I}+\mathrm{O}^{+\mathrm{B}}$ & 116 & $30(22-39)$ & 150 & $46(38-54)$ & $32(24-40)$ \\
\hline \multicolumn{6}{|c|}{ POSTTEST $5\left(T_{5}\right)$} \\
\hline $\mathrm{O}^{-\mathrm{B}}$ & 118 & $42(33-51)$ & 156 & $56(48-64)$ & $40(32-48)$ \\
\hline $\mathrm{O}^{+\mathrm{B}}$ & 122 & $30(22-39)$ & 176 & $52(44-59)$ & $31(24-38)$ \\
\hline $1+O^{-B}$ & 137 & $41(33-49)$ & 181 & $55(48-63)$ & $39(32-46)$ \\
\hline $\mathrm{I}+\mathrm{O}^{+\mathrm{B}}$ & 111 & $36(27-45)$ & 150 & $53(45-61)$ & $34(26-42)$ \\
\hline
\end{tabular}

Notes, O, Out-of-school condition; $\mathrm{I}+\mathrm{O}$, In+Out-of-school condition; ${ }^{+\mathrm{B}}$, plus Booster; ${ }^{-\mathrm{B}}$, without Booster. N1: Sample in which the complete case analyses were performed. N2: Sample in which extreme case and carried forward analyses were performed

\section{Program results}

Smoking initiation and continuation were analyzed separately. In order to handle dropout, besides complete-case also intention-to-treat analyses were performed (see Analyses, Methods). Changes in smoking initiation at $\mathrm{T}_{4}$ and $\mathrm{T}_{5}$ are shown in table 5.2, presenting the prevalences computed as a result of the complete case, extreme case, and carried forward analyses. In the extreme case analyses missing data were treated as smokers, whilst in the complete case analyses no missing data were included and in the carried forward analyses only the last observation was imputed.

As can be noted from table 5.2, this resulted in different percentages estimated to initiate smoking at the posttests. The prevalence rates were lowest in the complete case and carried forward samples and highest in the extreme case samples. Regarding 
program effects, the three analytic approaches yielded almost similar results: lowest initiation in the out-of-school with booster condition $\left(\mathrm{O}^{+\mathrm{B}}\right)$ and highest initiation in the out-of-school without booster condition $\left(\mathrm{O}^{-\mathrm{B}}\right)$.

Table 5.3 Smoking continuation among pretest ever smokers. Effects of various methods of handling missing data, percentages (\%) with $95 \%$ confidence intervals (CI)

\begin{tabular}{|c|c|c|c|c|c|}
\hline & $\begin{array}{l}\text { Sample } \\
\text { size }\end{array}$ & $\begin{array}{l}\text { Complete } \\
\text { case analysis }\end{array}$ & $\begin{array}{l}\text { Sample } \\
\text { size }\end{array}$ & $\begin{array}{l}\text { Extreme case } \\
\text { analysis }\end{array}$ & $\begin{array}{l}\text { Carry forward } \\
\text { analysis }\end{array}$ \\
\hline & N1 & $\%(95 \% \mathrm{CI})$ & N2 & $\%(95 \% \mathrm{CI})$ & $\%(95 \% \mathrm{CI})$ \\
\hline \multicolumn{6}{|c|}{ POSTTEST $4\left(\mathrm{~T}_{4}\right)$} \\
\hline $\mathrm{O}^{-1}$ & 44 & $32(17-46)$ & 65 & $54(41-66)$ & $26(15-37)$ \\
\hline $\mathrm{O}^{\prime \prime \prime}$ & 67 & $21(11-31)$ & 90 & $41(31-51)$ & $22(13-31)$ \\
\hline $1+0^{-1}$ & 58 & $17(7-27)$ & 78 & $38(27-50)$ & $17(8-25)$ \\
\hline $\mathrm{I}+\mathrm{O}^{+8}$ & 50 & $26(13-39)$ & 79 & $53(42-64)$ & $25(16-35)$ \\
\hline \multicolumn{6}{|c|}{ POSTTEST $5\left(T_{5}\right)$} \\
\hline $\mathrm{O}^{-8}$ & 38 & $47(31-64)$ & 65 & $69(58-81)$ & $35(23-47)$ \\
\hline $\mathrm{O}^{\prime \prime \prime}$ & 54 & $26(14-38)$ & 90 & $56(45-66)$ & $28(13-31)$ \\
\hline $1+\mathrm{O}^{-18}$ & 47 & $23(11-36)$ & 78 & $54(43-65)$ & $23(14-33)$ \\
\hline $1+\mathrm{O}^{+8}$ & 47 & $28(14-41)$ & 79 & $57(46-68)$ & $30(20-41)$ \\
\hline
\end{tabular}

Notes, $\mathrm{O}$, Out-of-school condition; $\mathrm{I}+\mathrm{O}, \mathrm{In}+\mathrm{Out}-\mathrm{of}-\mathrm{school}$ condition; ${ }^{+\mathrm{B}}$, plus Booster; ${ }^{-\mathrm{B}}$, without Booster. N1: Sample in which the complete case analyses were performed. N2: Sample in which extreme case and carried forward analyses were performed

Changes in smoking continuation at $\mathrm{T}_{4}$ and $\mathrm{T}_{5}$ are shown in table 5.3. As can be noted, similar to the findings found for analyzing smoking initiation, the percentages of youngsters continuing to smoke were again high when using extreme case analyses, and much lower for the other two strategies. Regarding program effects, the three analytic approaches resulted in continuation rates that were lowest in the combined in- and out of school without booster condition $\left(\mathrm{I}^{+} \mathrm{O}^{-\mathrm{B}}\right)$ and highest in the out-of-school without booster conditions $\left(\mathrm{O}^{-\mathrm{B}}\right)$.

Since multilevel analyses demonstrated negligible intraclass correlation (i.c.c. $=0.000$ ) regarding smoking initiation and continuation at $T_{4}$ and $T_{5}$, the effect analyses were carried out using SPSS 9.0. Since no interactions were found between the in-school and booster factors, the logistic regression analyses were restricted to the main effects. Only booster effects are reported in this chapter, the in-school effects are already discussed in chapter 4 (see also footnote 4). 


\section{boosters}

Table 5.4 Smoking initiation ( $1=$ yes, $0=$ no) among pretest never smokers: Booster effects using complete case analyses and (extreme case and carry forward), Odds ratios (OR) adjusted for pretest values of covariates, and $95 \%$ confidence intervals $(95 \% \mathrm{CI})$

\begin{tabular}{|c|c|c|c|c|c|c|}
\hline & \multicolumn{2}{|c|}{$\begin{array}{l}\text { Complete case } \\
\text { analysis }\end{array}$} & \multicolumn{2}{|c|}{$\begin{array}{l}\text { Extreme case } \\
\text { analysis }\end{array}$} & \multicolumn{2}{|c|}{$\begin{array}{l}\text { Carry forward } \\
\text { analysis }\end{array}$} \\
\hline & OR & $95 \% \mathrm{Cl}$ & OR & $95 \% \mathrm{Cl}$ & OR & $95 \% \mathrm{Cl}$ \\
\hline \multicolumn{7}{|l|}{ POSTTEST $4\left(\mathrm{~T}_{4}\right)$} \\
\hline Booster: $1=y e s, 0=$ no & 0.74 & $(0.61-1.07)$ & 1.05 & $(0.78-1,42)$ & 0.92 & $(0.62-1.36)$ \\
\hline Modeling 'nuclear': -8 (neg)- 0 (pos) & $0.77 * * \bullet$ & $(0.69-0.85)$ & & & & \\
\hline Self-efficacy: -18 (neg) - 18 (pos) & $0.97 * \bullet$ & $(0.94-0.99)$ & & & & \\
\hline Intention: -3 (neg) -3 (pos) & $0.70^{* * *}$ & $(0.58-0.85)$ & & & & \\
\hline \multicolumn{7}{|l|}{ POSTTEST $5\left(\mathrm{~T}_{5}\right)$} \\
\hline Booster: $1=$ yes, $0=$ no & $0.67^{\bullet}$ & $(0.48-0.94)$ & 0.92 & $(0.68-1.26)$ & $0.71^{\bullet}$ & (0.53-0.96) \\
\hline Modeling 'nuclear': -8 (neg)- 0 (pos) & $0.89^{\bullet}$ & $(0.80-0.99)$ & & & & \\
\hline $\begin{array}{l}\text { Attitude 'long-term consequences': } \\
-6 \text { (neg) - } 6 \text { (pos) }\end{array}$ & $0.92^{*}$ & $(0.85-1.00)$ & & & & \\
\hline Self-efficacy: -18 (neg) -18 (pos) & $0.96 * *$ & $(0.94-0.99)$ & & & & \\
\hline
\end{tabular}

Notes, ${ }^{*} \mathrm{p}<0.05,{ }^{* *} \mathrm{p}<0.01,{ }^{* * *} \mathrm{p}<0.001$; 'Neg' means negative towards non-smoking, 'pos' meand positive towards non-smoking

Table 5.4 presents the effects of the booster intervention with the odds ratios for the booster effects on smoking initiation at $\mathrm{T}_{4}$ and $\mathrm{T}_{5}$. Significant positive booster effects were found at $\mathrm{T}_{5}$ for smoking initiation, using the complete-case and the carried forward sample: students who received the boosters were less likely to start smoking at $\mathrm{T}_{5}$. The odds ratios were adjusted with significant covariates that are also listed in table 5.4. Only considered were those covariates that showed convincing significance $(\mathrm{p}<.01)$, to prevent type I errors due to multiple testing. It appeared that students with smoking people in their 'nuclear' environment (only at $\mathrm{T}_{4}$ ), students with lower self-efficacy expectations about their refusal skills $\left(\mathrm{T}_{4}\right.$ and $\mathrm{T}_{5}$ ), and students with a lower intention regarding non-smoking (only at $\mathrm{T}_{4}$ ) were more likely to initiate smoking. 
Table 5.5 Smoking continuation ( $1=$ yes, 0 -no) among pretest ever smokers: Booster effects using complete case analyses and intention to treat analyses (extreme case and carry forward), Odds ratios (OR), adjusted for pretest values of covariates, and $95 \%$ confidence intervals $(95 \% \mathrm{Cl})$

\begin{tabular}{|c|c|c|c|c|c|c|}
\hline & \multicolumn{2}{|c|}{$\begin{array}{l}\text { Complete case } \\
\text { analysis }\end{array}$} & \multicolumn{2}{|c|}{$\begin{array}{l}\text { Extreme case } \\
\text { analysis }\end{array}$} & \multicolumn{2}{|c|}{$\begin{array}{l}\text { Carry forward } \\
\text { analysis }\end{array}$} \\
\hline & OR & $95 \% \mathrm{CI}$ & OR & $95 \% \mathrm{Cl}$ & OR & $95 \% \mathrm{CI}$ \\
\hline \multicolumn{7}{|l|}{ POSTTEST $4\left(\mathrm{~T}_{4}\right)$} \\
\hline Booster: 1-yes, 0-no & 0.71 & $(0.38-1.35)$ & 0.98 & $(0.61-1.57)$ & 1.01 & $(0.56-1.81)$ \\
\hline Age, years & $1.90^{*}$ & $(1.07-3.55)$ & & & & \\
\hline $\begin{array}{l}\text { Attitude 'short-term consequences': } \\
11 \text { (neg) - } 55 \text { (pos) }\end{array}$ & $0.96^{\circ}$ & $(0.91-1.00)$ & & & & \\
\hline Modeling 'nuclear': - 8 (neg)- 0 (pos) & $0.76^{* \bullet}$ & $(0.63-0.92)$ & & & & \\
\hline Pressure: - 18 (neg) - 18 (pos) & $0.92 * \bullet$ & $(0.87-0.98)$ & & & & \\
\hline \multicolumn{7}{|l|}{ POSTTEST 5 ( $T_{5}$ ) } \\
\hline Booster: 1-yes, $0=$ no & $0.47^{*}$ & $(0.24-0.94)$ & 0.77 & $(0.49-1.20)$ & 0.79 & $(0.48-1.32)$ \\
\hline $\begin{array}{l}\text { Parents' origin: } 1=\text { one or two non- } \\
\text { Dutch parents, } 0=\text { two Dutch parents }\end{array}$ & $2.50^{*}$ & $(1.06-5.91)$ & & & & \\
\hline $\begin{array}{l}\text { Attitude 'short-term consequences': } \\
11 \text { (neg) - } 55 \text { (pos) }\end{array}$ & $0.95^{*}$ & $(0.91-1.00)$ & & & & \\
\hline Pressure: - 18 (neg) - 18 (pos) & $0.92 * *$ & $(0.87-0.99)$ & & & & \\
\hline
\end{tabular}

Notes, ${ }^{*} \mathrm{p}<0.05, * \mathrm{p}<0.01, \cdots * \mathrm{p}<0.001$; 'Neg' means negative towards non-smoking, 'pos' meand positive towards non-smoking

Table 5.5 presents the effects of the booster intervention with the odds ratios for the booster effects on smoking continuation at $T_{4}$, and $T_{5}$. Significant positive booster effects were found at $T_{5}$, using the complete-case analysis. Pretest ever smoking students who received the boosters were less likely to continue smoking at posttest-5. The odds ratios were adjusted with significant covariates $(\mathrm{p}<.01)$, which are also listed in table 5.5. It appeared that students with more smoking people in their 'nuclear' environment (only at $T_{4}$ ), and students who perceived less pressure $\left(T_{4}\right.$ and $T_{5}$ ) were more likely to continue smoking. 


\section{Process evaluation}

Table 5.6 compares the results of the process evaluations, carried out in February 1998 (out-of-school intervention) and February 2000 (booster intervention). The exposure to the boosters seemed to be improved when compared with the letters that were sent in the initial out-of-school intervention. Besides the boosters were evaluated slightly more positive than the out-of-school intervention, with the level of reading completeness and the evaluation of the personal relevance to be most conspicuous. On the other hand, fewer students shared the written information of the boosters with their parents and siblings, compared with the shared information of the letters that were sent during the out-of-school intervention.

Table 5.6 Process evaluation out-of-school program (February 1998) and booster intervention (February 2000), school-averages

\begin{tabular}{|c|c|c|}
\hline & February 1998 & February 2000 \\
\hline & 72 schools & 70 schools \\
\hline Exposure & $85 \%$ & $96 \%$ \\
\hline Number of times read & 1.3 times & 1.4 times \\
\hline Read almost completely & $70 \%$ & $91 \%$ \\
\hline Enjoyed reading & $51 \%$ & $53 \%$ \\
\hline Liked appearance & $48 \%$ & $50 \%$ \\
\hline Personal relevance & $59 \%$ & $68 \%$ \\
\hline \multicolumn{3}{|l|}{ Sharing information with: } \\
\hline - Mother & $58 \%$ & $45 \%$ \\
\hline - Father & $41 \%$ & $25 \%$ \\
\hline -Siblings & $12 \%$ & $9 \%$ \\
\hline - Friends & $6 \%$ & $10 \%$ \\
\hline
\end{tabular}

\section{Discussion}

This chapter describes the additional effects of tailored boosters on the earlier implemented out-of-school intervention. The results of complete case analyses only apply to those who were actually maintained in the study (relatively more girls and never smokers) and cannot be generalized to the total adolescent population. Therefore, besides complete case analyses, also intention to treat analyses (extreme case and 
carried forward analyses) were performed to control for dropout that occurred during follow-up.

Two main conclusions can be drawn from this chapter. The first is that when using extreme case analyses, where all missing values on smoking status are recoded by a smoking value, results in high initiation and continuation figures. These figures are probably much too high, taken into account the figures that were identified by the complete case and the carried forward analyses, the latter imputing the missing smoking status by the last observed smoking status. Complete case and carried forward methods resulted in reasonable similar figures, a finding that can probably be attributed to the fact that the changes in smoking behavior between the two posttests ( 30 and 36 months after pretest) were not extremely great. The second conclusion is that the effects of the booster intervention, implemented after the tailored out-of-school intervention, seem to be encouraging, considering the results of the complete case analyses and -in the case of smoking initiation- the confirmation by the carried forward analyses. It seemed that students who were engaged in the tailored out-of-school program and who had also received the booster letters were less likely to have initiated smoking than those who were only engaged in the tailored out-of-school program. Almost similar results were found for smoking continuation at posttest 5 , complete case analyses pointed at a booster effect, although these results were not confirmed by carried forward analyses. Besides, it seemed that ever smoking students from the out-of-school condition without boosters were the ones who mostly continued smoking, while ever smokers in the remaining conditions kept up with each other with respect to smoking continuation. The combined in- and out-of-school approach did not result in additional results. It appeared that increasing the amount of information provided at one time does not increase program effectiveness in the long-term.

The results of the booster intervention match the results of previous studies in which boosters were tested and in which it was demonstrated that providing students with ongoing intervention in the form of booster sessions can maintain and even enhance initial prevention effects (Botvin et al., 1995; M. Dijkstra et al., 1999; Rooney \& Murray, 1996; White \& Pitts, 1998).

The development of the out-of-school and booster interventions were based on an identical framework, although tailoring in the out-of-school intervention was based on sum scores while tailoring in the booster intervention was based on item scores. The latter resulted in a higher level of perceived personal approach. The process evaluation of the booster intervention confirmed that students indeed perceived the booster as a more personal approach. However selective dropout might also have influenced these scores. Process evaluation results of the booster intervention also indicated that there is room for implementation improvements and that the appeal of the out-of-school intervention could be further improved by refining its content and appearance.

At the start of our study, students were nested within schools, and schools were randomly assigned to treatment conditions. Since school influences are supposed to contribute to the unexplained variation, multilevel regression analyses were required, with schools as level-2 units and students as level-1 units. However, effect analyses at $\mathrm{T}_{4}$ and $\mathrm{T}_{5}$ did not reveal any intraclass correlation. This may have been caused by the fact that the students had left elementary schools more than a year before, and elementary schools' influence may have faded. In view of this lack of intraclass 
correlation, the analyses were performed with students, instead of schools, as the unit of analysis.

A limitation of the present study is that no validation of self-reported smoking behavior was used, because objective measurements for youngsters are unreliable and detect only very recent smoking, whereas most smokers in the age group selected for the present study are only experimenting with smoking. Furthermore, self-reports have been demonstrated to be more accurate when confidentiality is assured and an identification coding system is used (Akers et al., 1983; Botvin \& Botvin, 1992; Murray \& Perry, 1987; US Department of Health and Human Services, 1990). Precautions that were indeed taken in the present study.

In sum, the study described in this chapter has shown tailored out-of-school interventions offer affirmative promises in terms of smoking prevention programs. Firstly, positive short-term effects were found (Ausems et al., 2002). Secondly, although the long-term results of the out-of-school intervention (Ausems et al., submitted-a, submitted-b) do not differ from those of other research, in that adolescent smoking prevention efforts have mixed results (Aveyard et al., 2001; Lantz et al., 2000; Peterson et al., 2000) the effects of the tailored booster intervention seem promising, albeit the effects are most convincing for smoking initiation and the effects can not been generalized to the whole adolescent population. Thirdly, while the combined $\mathrm{I}+\mathrm{O}$ approach did not result in significant additional effects, the booster intervention showed that program effects, especially for never smokers, could be more fruitfully improved by extending the educational period in the form of tailored booster sessions than by increasing the amount of information provided at one time. More research however is needed about the ideal tuning of amount of information and the length of intervening. Finally, the three different strategies used in our study to handle with dropout resulted in quite similar conclusions for the complete case and carried forward analyses. The extreme case strategy resulted in high, and probably too high, estimations of smoking initiation and continuation percentages. It therefore seems not appropriate to use extreme case strategies in adolescence smoking prevention research. Anyhow, future research should concentrate on minimizing of attrition. 



\section{6}

\section{Effects of in-school and tailored out-of- school smoking prevention among Dutch vocational school students}

Manuscript accepted for publication as: Ausems, M., Mesters, I., van Breukelen, G., De Vries, H. 'Effects of in-school and tailored out-of-school smoking prevention among Dutch vocational school students' 


\begin{abstract}
This chapter evaluates a smoking prevention intervention aimed at vocational school students, consisting of an existing Dutch in-school program (three lessons each lasting 50 minutes), and a computer-based tailored out-of-school program (three tailored letters with smoking prevention messages mailed to students' homes). Nineteen schools that already participated in the in-school program were randomly assigned to the in-school or to the combined in-school and out-of-school condition. The remaining 17 schools were randomly assigned to the out-of-school condition or to the control group. Effect outcomes were assessed at 6,12 , and 18 months after a pretest, and were based on initiation among never-smokers and continuation among ever-smokers. Twelve months after the pretest (posttest 2), the in-school intervention was successful in preventing vocational school students from continuing to smoke, compared with students in the control condition (odds ratio $=0.49 ; 95 \%$ confidence interval $=0.29-0.84$ ). Eighteen months after the pretest (posttest 3), the tailored out-of-school intervention was successful in preventing smoking initiation, compared with students in the control condition (odds ratio $=0.42 ; 95 \%$ confidence interval $=0.18-0.96$ ). The effect of the combined approach was not larger than the sum of the effects of the in-school and the out-of-school effects.
\end{abstract}




\section{Introduction}

Smoking causes $85 \%$ of lung cancer mortality, while $33 \%$ of mortality from other cancers is also attributed to smoking. About half of all smokers will eventually be killed by their habit (Doll et al., 1994). Many authors state that smoking prevention programs should be aimed at preventing or delaying the start of tobacco use (Kelder et al., 1994), and that such programs might be especially indicated for high-risk populations. In the Netherlands separate secondary school types exist. Vocational schools prepare one third of the students (aged between 12-16 year) for specific vocations, while high schools (12-18 year olds) prepare the remaining students for follow-up education (CBS, 2002).

Smoking rates among vocational school students from 12 to 16 year olds are generally higher than among high school students (De Vries, 1995). In 1997, 66\% of the Dutch vocational school students (aged between 12 and 16 years) had tried cigarettes, $45 \%$ of them being occasional or daily smokers. In contrast, $50 \%$ triers and $26 \%$ occasional or daily smokers were found among high school students in the same age category (Stivoro, 1998). These findings imply the need for effective prevention programs targeted at first grade vocational school students aged 12-13 years old.

In the last decade, several smoking prevention programs have been developed, the most promising focusing on the development of social skills to resist social influences that encourage smoking (US Department of Health and Human Services, 2000). So far, most of these programs were run in school settings, which is an obvious choice, since school-based smoking prevention programs can reach wide audiences. However, a potential drawback of these programs is for example that their implementation depends on limited time and untrained personnel (Murray et al., 1992).

To overcome disadvantages of school-based interventions among (high-risk) vocational school students, an innovative computer-based out-of-school intervention was developed, consisting of personalized tailored letters mailed to the students' homes. The idea of personalized tailored letters originated in the US (Velicer et al., 1993), and has been further developed and tested for several years in the Netherlands (Dijkstra \& De Vries, 1999).

The goal of the present study was to compare the impacts on smoking rates of three programs: (1) a computer-based tailored out-of-school smoking prevention program; (2) a Dutch in-school smoking prevention program; and (3) a combined approach including the in-school and out-of-school intervention. The combined approach was included because research indicates that multiple prevention strategies produce better results in terms of the reduction of tobacco use (US Department of Health and Human Services, 2000). Smoking rates, based on both smoking initiation among never-smokers and smoking continuation among ever-smokers, were assessed at 6 months, 12 months, and 18 months after the pretest. 


\section{Methods}

\section{Design and procedure}

Table 6.1 presents a timeline following the sample from approach to the third posttest assessment. Springtime 1997, schools in the Netherlands were recruited with the assistance of six of the eight approached local health departments. All vocational schools within the six local health departments' regions received an introductory letter, followed by a telephone call to the student counselor of the lowest grade vocational students, to discuss participation in the project. It was also checked whether schools were already participating in the 'Healthy Schools and Stimulants Program', which was selected as the in-school activity (Trimbos Institute, 1996).

Table 6.1 Timeline from approach to posttest 3, number of schools and -between bracketsnumber of students

\begin{tabular}{|c|c|c|c|c|c|}
\hline Approach & Spring 1997 & & & & \\
\hline \multirow[t]{2}{*}{ Randomization } & June 1997 & I & o & $1+0$ & C \\
\hline & & 9 & 8 & 10 & 9 \\
\hline Pretest & Sept 1997 & $9(525)$ & $8(513)$ & $10(829)$ & $9(509)$ \\
\hline Intervention & Oct 1997- Feb 1998 & + & + & + & \\
\hline Posttest 1 & Feb 1998 & $9(432)$ & $7(446)$ & $10(703)$ & $8(335)$ \\
\hline Posttest 2 & Sept 1998 & $9(434)$ & $6(349)$ & $10(580)$ & $8(362)$ \\
\hline Posttest 3 & Feb 1999 & & $5(265)$ & $10(625)$ & $7(317)$ \\
\hline
\end{tabular}

Note, I, In-school; O, Out-of-school; I+O, In-school + Out-of-school; C, Control condition

A sample size of 36 schools was estimated to be sufficient to demonstrate an effect size with an odds ratio of 2.0 . Power calculation $(80 \%)$ assumed a significance level of $\alpha=0.05$ (two-sided), a cluster randomized control trial with 25 students on average per school, and between school variance of 0.30 , which implies an intraclass correlation of 0.08 (for binary data, intraclass correlation $=$ schoolvariance/ (schoolvariance $+\pi 2 / 3$ ) (Moerbeek, van Breukelen, Ausems, \& Berger, in press). Thirty-six schools agreed to participate, of which 19 were already working with the in-school materials, and as a consequence, had been trained in the use of the program by the Netherlands Institute of Mental Health and Addiction, the 'Trimbos Institute', who had designed the program.

In June 1997, the schools already participating in the 'Healthy Schools and Stimulants Program' were randomly assigned within regionally defined blocks to the inschool (I) or to the in-school and out-of-school condition $(\mathrm{I}+\mathrm{O})$. The remaining 17 schools were randomly assigned to the out-of-school $(\mathrm{O})$ or to the control group 
condition (C) in a similar manner. Schools participating in the $\mathrm{O}$ and $\mathrm{I}+\mathrm{O}$ conditions distributed consent forms to students' parents, as their children had been selected to receive educational materials sent to their home addresses. Forty out of $1342(3 \%)$ parents refused participation. In-school materials (which were made available free of charge for this project), pretest questionnaires and the assessment procedure were mailed to the schoolteacher who was responsible for this project. A letter with instructions on the assessment procedure was included, telling schools to schedule one hour for completing the pretest questionnaires in September 1997 in the presence of the teacher, to collect the questionnaires after completion in the classroom, put them in a postage-paid envelope and having sealed them- return the envelopes to the researchers.

Smoking behavior was assessed by means of self-reports. Objective smoking validation was not regarded as useful for this young age group because the available methods only detect very recent -at most weekly- smoking, while smoking family members may induce elevated readings (Sussman et al., 1995). Self-reported results are more accurate when confidentiality is assured and an identification coding system is used (US Department of Health and Human Services, 1990).

The interventions were implemented between October and early February 1998. Posttest 1 was in mid-February 1998. At the same time, students in the treatment conditions and teachers who implemented the in-school program completed a process evaluation questionnaire. Posttest 2 was in September 1998. The third posttest, February 1999, was restricted to long-term effects of the out-of-school intervention only, the inschool condition no longer being included in the sample at that time.

\section{Interventions}

The two interventions used in the present study were both based on essential components for successful social influence programs (Sussman et al., 1993). Topics included were the short-term physical and social consequences of smoking, pressure to smoke, other people's smoking behavior, and refusal skills.

The in-school intervention consisted of three lessons, each lasting about 50 minutes, for which student and teacher manuals were available. Each lesson comprised a general introduction by the teacher, a reading text in the workbook, a classroom discussion, a workbook task, and an additional task that summarized the main points of the lesson. The first lesson explained the ingredients of tobacco and the physical and mental reactions of smoking, while the second discussed norms concerning smoking and the third emphasized the pressures to smoke and the skills that are helpful in resisting cigarettes.

The out-of-school intervention consisted of three tailored letters with smoking prevention messages, which were sealed in envelopes and mailed to students' homes at three-week intervals. This procedure was used to ensure optimal confidentiality. The researchers signed the letters and telephone numbers were added. We deliberately did not disclose the students' pretest smoking behavior in the letters, to prevent arguments in the students' families. The contents of the letters, however, were tailored to individual characteristics. The pretest questionnaire on attitudes, social norms, selfefficacy, smoking intention, and smoking behavior was used to create a database file containing personal information. Pilot testing and revision of concepts resulted in the creation of a message file. A computer program combined the database file with the 
message file using decision rules that linked students' answers to personal messages. All messages thus selected were combined in a letter format. The letters were illustrated with a picture puzzle and several cartoons, and a competition was included in which students could win one of two CD vouchers. The first letter (eight versions) contained information regarding students' beliefs about smoking in general, and short-term and social consequences of smoking. The second letter ( 32 versions) discussed the influence of the social environment (with a description of the Dutch smoking prevalence) and intentions not to smoke in the future. Boys and girls received different messages and cartoons. The third letter (two versions) described refusal techniques and included an exercise about cigarette refusal. For instance, if students had indicated doubtful cigarette refusal capacities in the pretest questionnaire, the message selected by the computer program explained that they could improve their cigarette refusal capacity by doing a simulation exercise. The letter then described an exercise in which students were stimulated to practice cigarette-refusal step by step. Students already equipped with sufficient refusal capacities received a message reinforcing their capacities, followed by the simulation exercise and an explanation that cigarette refusal capacity might be improved even further through practice.

\section{Measurements}

\section{Process measurement for students}

The process evaluation assessed exposure and appreciation. Exposure to the in-school condition was measured by 15 questions on a two-point scale: 'yes' (1) or 'no' (0), assessing for each of the three lessons whether students had had the introductory talk, performed the reading assignment, engaged in the class discussion, and had done the workbook and additional task. Appreciation of each lesson had to be rated from 'very bad' ( 0 ) to 'excellent' (10). Exposure to the out-of-school condition was recorded by asking whether students had received each of the three letters, possible answers being 'yes' (1) or 'no' (0), and by asking to what extent they had read each letter: 'completely' (4) to 'not at all' (1). Students also indicated how many times they had read the letters. Appreciation of the letters was scored on a 4-point scale: 'liked reading it very much' (4) to 'not' (1) and students judged the visual appearance of the letters on a scale ranging from 'very attractive' (4) to 'unattractive' (1). To find out how students perceived the essence of tailoring, their impression of the degree of personal approach was assessed: 'completely personally directed' (4) to 'not personally directed' (1). Lastly, students could indicate which of their parents, siblings or friends they had allowed to read the letters.

\section{Process assessment for teachers}

The teachers' questionnaire assessed whether they had implemented the above five elements in the three lessons, using a two-point scale of 'yes' (1) or 'no' $(0)$. In addition, teachers indicated their appreciation of each lesson from 'very bad' (0) to 'excellent' (10). 
An updated version of the Attitude-Social influence-self Efficacy (ASE) questionnaire was used to assess the proximal factors of smoking: attitudinal beliefs, social influences, self-efficacy expectations, and intentions, as well as the outcome measures of smoking behavior (M. Dijkstra et al., 1999). Distal factors like age, gender, self-esteem, religion, family composition, pocket money and parents' jobs and origin were also included as predictors, although they are assumed to influence smoking via attitudes, social influences and self-efficacy expectations.

Factor analyses confirmed four attitude subscales:

- Disadvantages 'immediate': 8 items (Cronbach's $\alpha=80$ ) ranging from 'negative' (1) to 'very positive towards non-smoking' (5), reflecting immediate consequences (nausea, coughing, irritated eyes, breathing problems, unwise, bad for your health, disturbing others, and regret);

- Advantages 'adult': 4 items (Cronbach's $\alpha=.54$ ) ranging from 'positive' (1) to 'very negative towards non-smoking' (5), reflecting the perceptions of adult beliefs (growing up, relieving boredom, relieving tension, tasting good);

- Disadvantages 'long-term': 4 items (Cronbach's $\alpha=64$ ) ranging from 'very negative'(-3) to 'very positive' towards non-smoking (3), reflecting the long-term consequences (risks of cancer and heart diseases, disapproval of oneself, and bad smell);

- Advantages 'self-confidence': 8 items (Cronbach's $\alpha=.77$ ) ranging from 'very negative' $(-3)$ to 'very positive' towards non-smoking (3), reflecting consequences in terms of self-confidence (receiving attention from friends, acceptance by friends, making contacts, striking an attitude, feeling relaxed, being bullied, feeling cozy, and enjoying it).

Social influence was measured by four indices:

- Modeling 'nuclear network': 4 items ranging from 'smoking' (-2), 'absent' (-1), to 'not smoking' $(0)$, referring to perceived smoking behavior of the student's father, mother, brother/ sister and best friend.

- Modeling 'diffuse network': 4 items ranging from 'almost all' (-4) to, 'almost none are smokers' $(0)$, measuring the number of smoking friends, peers, teachers and family members.

- Social norms: 6 items ranging from 'very negative' $(-3)$ to 'very positive towards nonsmoking' (3), measuring the perceived beliefs of the student's father, mother, brother, sister, best friend and friends.

- Social pressure: 10 items ranging from 'very often' $(-5)$ to 'never' $(0)$, measuring the perceived pressure to smoke from the student's father, mother, brother, sister, best friend, friends, peers, teacher, family, and advertisements.

Self-efficacy: 5 items (Cronbach's $\alpha=89$ ) ranging from 'very uncertain' $(-3)$ to 'very certain' (3), each item referring to the students' expectations about refraining from smoking in different situations of increasing magnitude (when others smoke, when friends smoke, when a cigarette is offered by someone or by parents, or when you are called a coward).

Intention to smoke was measured by one item ranging from 'definitely do' (-3) to 'definitely do not intent to smoke' (3). 
Self-esteem questions were derived from questions originally developed by Harter (1985) and Minagawa and Charlton (1993). Factor analysis confirmed two self-esteem subscales:

- Self-esteem 'general': 7 items (Cronbach's $\alpha=.84$ ), ranging from 'very positive' (1) to 'very negative' (4), reflecting students' feelings about their general image (looking good, satisfaction with performance, appearance, or with oneself, opinion towards oneself as a person, personal affection, personal satisfaction).

- Self esteem 'physical': 4 items (Cronbach's $\alpha=.78$ ), ranging from 'very positive' (1) to 'very negative' (4), reflecting students' feelings about their physical appearance (satisfaction with height and weight, satisfaction with their own body, desiring a different appearance, satisfaction with face and hair).

Smoking behavior was based on self-reports, categorizing students as: (1) neversmokers: students who have never smoked even one cigarette or a puff of one; (2) noncurrent smokers: students who have smoked in the past, but not during the past month; and (3) current smokers: students who have smoked during the past month.

As treatment effects on (the outcome) smoking initiation, we assessed the percentage of pretest never-smoking students (category 1) who indicated to have started smoking at posttest 1, posttest 2 or posttest 3 (categories 2-3). As tratment effects on (the outcome) smoking continuation, we assessed the percentage of pretest ever-smokers (categories 23 ) who indicated at posttests 1-2-3 to have smoked during the past month (category 3).

\section{Analyses}

The results of the process measurements were first calculated for each student and teacher, averaging across letters and lessons respectively, and subsequently for each school, averaging across students and teachers respectively. Students were nested within schools, and schools were randomly assigned to treatment conditions. Since ignoring this nesting may lead to type I errors and too narrow confidence intervals for treatment effects (Flay et al., 1995), most analyses were carried out using multilevel regression modeling by the MIXREG (linear regression) program for continuous outcomes (Hedeker \& Gibbons, 1996b), and the MIXOR (logistic regression) program for dichotomous outcomes (Hedeker \& Gibbons, 1996a).

To check whether the randomization had been successful, the treatment conditions were compared for age, gender, pretest ever-smoking and pretest psychosocial variables. To check if those who dropped out differed from those who did not, we performed dropout analyses with attrition at posttests 1-2-3 as the outcome, and pretest demographics, pretest ever-smoking and psychosocial variables and treatment conditions as predictors.

As regards the program effects, in view of the two-way design of the study, the treatment factor was dummy-coded. The in-school intervention effects were tested by computing the in-school factor: both in-school conditions (1) versus both not in-school conditions $(0)$. The out-of-school intervention effects were tested by computing the outof-school factor: both out-of-school conditions (1) versus both not out-of-school conditions $(0)$. To test the possible moderating effect of the in-school intervention on the out-of-school intervention, the interaction term 'in $\mathrm{x}$ out-of-school' was included in the analyses. If a significant interaction 'in-school $x$ out-of-school' was found, the sample was stratified according to the scheme presented in Figure 6.1. 
All effect analyses were done separately for posttests 1-2-3. Since running large regression models with MIXOR might cause problems, model reduction was first applied, using SPSS 9.0 (SPSS Inc, 1999) to determine the final models containing significant covariates and interaction terms for the prediction of smoking at posttests 12-3. The strategy involved predicting smoking initiation as well as continuation at posttests 1-2-3 from treatment factors (in-school, out-of-school and their interaction). Subsequently, demographic and pretest psychosocial measures were entered as covariates, as previous research had shown that these were predictors of smoking (De Vries et al., 1994). Non-significant predictors and interactions were deleted in a stepwise procedure $(\alpha=0.05$ ), with the restriction that predictors were never removed from the models if they were involved in some interaction term in the model.

The two treatment factors (in-school, out-of-school) were never removed, as their effects were the focus of the study. The final models were entered in the multilevel analyses to test the intervention effects.

In-school factor

\begin{tabular}{l|l|l|}
\multicolumn{2}{l|}{ Out-of-school factor } & \\
\hline 0 & Control & Out-of-school \\
\hline 1 & In-school & Combined \\
\hline
\end{tabular}

'Out' factor=1; comparing combined with out-of-school

'Out' factor=0; comparing in-school with control

'In' factor=1; comparing combined with in-school

'In' factor=0; comparing out-of-school with control

Figure 6.1 Stratification scheme in case a significant 'in*out-of-school' interaction was found

\section{Results}

\section{Sample characteristics and randomization}

Table 6.2 presents the sample characteristics (averaged at school level) of the pretest sample. Students in the out-of-school conditions were more often from one-parent families $(\mathrm{OR}=0.76 ; 95 \% \mathrm{CI}=0.67-0.97)$. Since the randomization check of age showed a significant in*out interaction, different models were tested to check the randomization in terms of age (figure 6.1). Students in the out-of-school condition were found to be older than those in the control condition $(\mathrm{OR}=1.27 ; 95 \% \mathrm{CI}=1.03-1.57)$. 
chapter 6

Table 6.2 Pretest sample (school averages): smoking behavior, distal and proximal factors

\begin{tabular}{|c|c|c|c|c|}
\hline \multicolumn{5}{|l|}{ Smoking behavior } \\
\hline Ever smoking (\%) & 59.7 & & & \\
\hline Current smoking (\%) & 19.5 & & & \\
\hline Distal factors & Mean & SD & $\#$ Items & Range \\
\hline Age (years) & 13.1 & 0.3 & & \\
\hline Gender $(\%$, male $)$ & 52.1 & & & \\
\hline Origin (\%, with both parents Dutch) & 73.0 & & & \\
\hline Religious (\%, adhering to a religion) & 61.4 & & & \\
\hline Family composition (\%, with two parents) & 82.1 & & & \\
\hline Father's occupation (\%, paid job) & 68.7 & & & \\
\hline Pocket money $(\%,>6.8 €)$ & 23.5 & & & \\
\hline Self-esteem 'general' & 12.2 & 0.9 & 7 & 7 (pos) - 28 (neg) \\
\hline Self-esteem 'physical' & 8.7 & 0.7 & 4 & 4 (pos) - 16 (neg) \\
\hline Proximal factors & Mean & SD & \# Items & Range \\
\hline Disadvantages 'immediate' & 23.5 & 1.9 & 8 & 8 (neg) - 40 (pos) \\
\hline Advantages 'adult' & 8.6 & 0.6 & 4 & 4 (pos) - 20 (neg) \\
\hline Disadvantages 'long-term' & 5.1 & 0.9 & 4 & -12 (neg) -12 (pos) \\
\hline Advantages 'confidence' & -1.1 & 0.9 & 8 & -24 (neg) -24 (pos) \\
\hline Modeling 'nuclear' & -3.5 & 0.6 & 4 & -8 (neg) -0 (pos) \\
\hline Modeling 'diffuse' & -7.3 & 0.9 & 4 & -16 (neg) -0 (pos) \\
\hline Social norms & 9.3 & 1.3 & 6 & -18 (neg) - 18 (pos) \\
\hline Pressure & -5.3 & 1.4 & 10 & -50 (neg)- 0 (pos) \\
\hline Self-efficacy & 8.0 & 1.3 & 5 & -15 (neg) -15 (pos) \\
\hline Intention & 1.3 & 0.3 & 1 & -3 (neg) -3 (pos) \\
\hline
\end{tabular}

Notes, $\mathrm{SD}=$ standard deviation; 'Neg' means negative towards non-smoking, 'pos' means positive towards non-smoking

\section{Attrition}

Attrition at school level was $5.6 \%$ (two schools) at the first posttest, and $8.3 \%$ (three schools) at posttest 2 . At posttest 3 , schools from the in-school condition were no longer participating in the study and were therefore excluded from the calculation of posttest 3 attrition analyses. At posttest 3, attrition was $18.5 \%$ (five schools out of 27 , excluding the in-schools).

Absenteeism and difficulties in matching pretest and posttest data mainly caused attrition at student level. We calculated the attrition rates (student level) without the 
dropout schools, because we assumed that the students in these schools were not personally responsible for their dropout. Attrition at student level was $17.3 \%$ at posttest $1,25.4 \%$ at posttest 2 , and $24.6 \%$ at posttest 3 .

Logistic regression analysis with posttest 1 attrition as the dependent variable suggested that dropout students were older $(\mathrm{OR}=1.29 ; 95 \% \mathrm{Cl}=1.10-1.51)$, and less likely to have participated in the out-of-school program $(\mathrm{OR}=0.39 ; 95 \% \mathrm{CI}=0.18-0.86)$.

Posttest 2 attrition was less likely for students living with two parents instead of one $(\mathrm{OR}=0.63 ; 95 \% \mathrm{Cl}=0.44-0.89)$ and for students who were relatively less 'diffusely' surrounded by smokers $(\mathrm{OR}=0.93 ; 95 \% \mathrm{CI}=0.91-0.95)$.

Posttest 3 attrition was less likely for students living with two instead of one parent $(\mathrm{OR}=0.53 ; 95 \% \mathrm{Cl}=0.37-0.77)$, for students with two Dutch parents $(\mathrm{OR}=0.63 ; 95 \%$ $\mathrm{CI}=0.47-0.84)$, and for students who were relatively less 'diffusely' surrounded by smokers $(\mathrm{OR}=0.87 ; 95 \% \mathrm{CI}=0.84-0.90)$. Students in the combined condition were less likely to drop out than those in the out-of-school condition $(\mathrm{OR}=0.37 ; 95 \% \mathrm{Cl}=0.23$ 0.59 ).

\section{Process evaluation}

Fifty-eight percent of the intervention schools $(\mathrm{N}=11)$ returned the teacher process questionnaires. Response rates to the students' process questionnaire were identical to those of the outcome measurement posttest 1 questionnaire, as data collection was combined.

As regards the in-school exposure, all the teachers $(100 \%)$ gave the introductory talk and implemented the reading part and workbook task in all three lessons. The class discussion was used by $94 \%$ of the teachers, while the additional task was completed by $64 \%$ of the teachers. The students generally reported lower rates of exposure than the teachers' rates of completing the lesson tasks. Teachers evaluated the three lessons as $7.5(95 \% \mathrm{CI}, 6.9-8.1)$ on a scale from bad $(0)$ to excellent $(10)$, while students rated them as $6.6(95 \% \mathrm{CI}, 6.3-6.9)$.

As regards the out-of-school exposure, $65 \%$ of the students received the letters, and read them an average of 1.1 times, while $63 \%$ read them (almost) completely, $54 \%$ liked reading the letters and $54 \%$ liked the appearance of the letters. Forty-seven percent of the students felt more or less personally addressed by the letters. Forty-seven percent of students' mothers, $38 \%$ of students' fathers, $13 \%$ of students' siblings, and $7 \%$ of the friends had read the letters. Twenty percent of the students sent back their answers for the competition.

\section{Program effects}

Table 6.3 presents the percentages of smoking initiation among pretest never-smokers and the percentages of smoking continuation among pretest ever-smokers at posttests 12-3. Posttest 1 showed that smoking initiation among pretest never-smokers was lowest in the out-of-school condition (16.8\%) and highest in the in-school condition $(27.4 \%)$. In the pretest ever-smoking sample, the lowest level of smoking continuation was found in the in-and out-of-school condition (26.8\%) and the highest in the in-school condition $(34.6 \%)$. 
Table 6.3 Smoking initiation (school average \%) among pretest never-smokers, and smoking continuation (school average \%) among pretest ever-smokers, at posttests 1-2-3, with $95 \%$ confidence intervals by treatment condition

\begin{tabular}{lllll}
\hline & I & O & 1+O & C \\
\hline Pretest - posttest 1 & 9 schools & $\mathbf{7}$ schools & $\mathbf{1 0}$ schools & $\mathbf{8}$ schools \\
Initiation & $27.4(15.4-39.4)$ & $16.8(4.9-28.7)$ & $17.5(8.1-26.9)$ & $24.0(6.8-41.1)$ \\
Continuation & $34.6(18.8-48.3)$ & $33.8(25.2-42.3)$ & $26.8(17.1-36.6)$ & $29.9(14.4-45.4)$ \\
Pretest - posttest 2 & $\mathbf{9}$ schools & $\mathbf{6}$ schools & $\mathbf{1 0}$ schools & $\mathbf{8}$ schools \\
Initiation & $28.0(18.6-37.4)$ & $25.0(13.6-36.6)$ & $29.4(20.3-38.5)$ & $40.9(24.8-56.9)$ \\
Continuation & $29.4(16.9-42.0)$ & $37.0(21.3-52.6)$ & $45.0(37.0-53.1)$ & $42.2(35.2-49.2)$ \\
Pretest - posttest 3 & & $\mathbf{5 ~ s c h o o l s ~}$ & $\mathbf{1 0}$ schools & $\mathbf{7}$ schools \\
Initiation & & $27.2(8.8-53.5)$ & $40.0(29.4-50.6)$ & $47.9(29.1-66.6)$ \\
Continuation & & $37.0(22.3-51.7)$ & $40.4(34.0-46.9)$ & $46.9(33.7-60.1)$ \\
\hline
\end{tabular}

Note, I, In-school; O, Out-of-school; I+O, In + Out-of-school; C, Control condition

At posttest 2, smoking initiation among pretest never-smokers was lowest in the out-ofschool smoking sample (25\%) and highest in the control condition $(40.9 \%)$. The lowest level of smoking continuation was found in the in-school condition $(29.4 \%)$, while the highest continuation level occurred in the in+out condition $(45.0 \%)$.

At posttest 3, smoking initiation among pretest never-smokers was lowest in the outof-school condition $(27.2 \%)$ and highest in the control condition $(47.9 \%)$. In the pretest ever-smoking sample, the lowest level of smoking continuation was found in the out-of school condition $(37.0 \%)$ and the highest in the control group $(46.9 \%)$.

The results of the MIXOR analyses of posttest 1 are presented in table 6.4. Interactions between the in-school and out-of-school factors were found neither for smoking initiation nor for continuation, implying that the effect of in*out was not larger than the sum of the effects of the in-school and the out-of-school program. The in-school and the out-of-school programs did not show a significant effect on neither smoking initiation nor continuation. 
Table 6.4 Program effects at posttest 1: Odds ratios (OR) with $95 \%$ confidence intervals $(\mathrm{CI})$; smoking initiation ( 1 =ever-smoking; 0 -never-smoking) and smoking continuation ( 1 =-smoking; 0 -not smoking)

\begin{tabular}{|c|c|c|c|c|}
\hline & \multicolumn{2}{|c|}{$\begin{array}{l}\text { Pretest never smokers } \\
\text { Smoking initiation } \\
\mathrm{N}_{\text {student }}=807, \mathrm{~N}_{\text {school }}=\mathbf{3 4}\end{array}$} & \multicolumn{2}{|c|}{$\begin{array}{l}\text { Pretest ever smokers } \\
\text { Smoking continuation } \\
\mathrm{N}_{\text {student }}=1103, \mathrm{~N}_{\text {schoot }}=34\end{array}$} \\
\hline & OR & Cl & OR & Cl \\
\hline In-school: $1=$ yes, $0=$ no & 1.27 & $0.73-2.20$ & 0.89 & $0.47-1.70$ \\
\hline Out-of-school: $1=y e s, 0=$ no & 0.70 & $0.40-1.23$ & 0.68 & $0.37-1.26$ \\
\hline Age, years & & & $1.69 * \bullet$ & $1.21-2.46$ \\
\hline Self-esteem 'physical': 4 (pos) -16 (neg) & & & $1.08^{*}$ & $1.01-1.15$ \\
\hline $\begin{array}{l}\text { Disadvantages 'immediate': } \\
8 \text { (neg) - } 40 \text { (pos) }\end{array}$ & & & $0.92 * \bullet$ & $0.88-0.96$ \\
\hline Modeling 'nuclear': -8 (neg) - 0 (pos) & & & $0.88^{\bullet}$ & $0.81-0.95$ \\
\hline Pressure: - 50 (neg) - 0 (pos) & & & $0.96 * *$ & $0.94-0.98$ \\
\hline Intention: -3 (neg) - 3 (pos) & $0.67 * * *$ & $0.58-0.78$ & $0.67 * * *$ & $0.56-0.80$ \\
\hline
\end{tabular}

Notes, ${ }^{*} \mathrm{p}<0.05,{ }^{* *} \mathrm{p}<0.01,{ }^{* * *} \mathrm{p}<0.001$; 'Neg' means negative towards non-smoking, 'pos' means positive towards non-smoking

The intraclass correlation at posttest 1 , as obtained with the regression models in table 6.4 , was 0.08 for smoking initiation, and 0.06 for smoking continuation.

At posttest 2 (see table 6.5), significant 'in*out' interactions were found, so four pairwise comparisons were tested (figure 6.1). Since MIXOR failed to run some of the models (probably because of the reduced sample size), these specific models were run with the SPSS program (i.e., without random effects). As regards smoking initiation, no significant treatment effects were found. As regards smoking continuation, positive inschool effects were found: pretest ever-smoking students in the in-school condition were less likely to have continued smoking at posttest 2 than students in the control condition.

The intraclass correlation at posttest 2 , as obtained with the regression models in table 6.5, ranged from 0.001 to 0.04 for smoking initiation, and from 0.01 to 0.09 for smoking continuation. 
Table 6.5 Program effects at posttest 2: Odds ratios (OR) with $95 \%$ confidence intervals (CI); smoking initiation $(0=$ never-smoking, $1=$ ever-smoking $)$ and smoking continuation $(0=$ not smoking, 1=smoking)

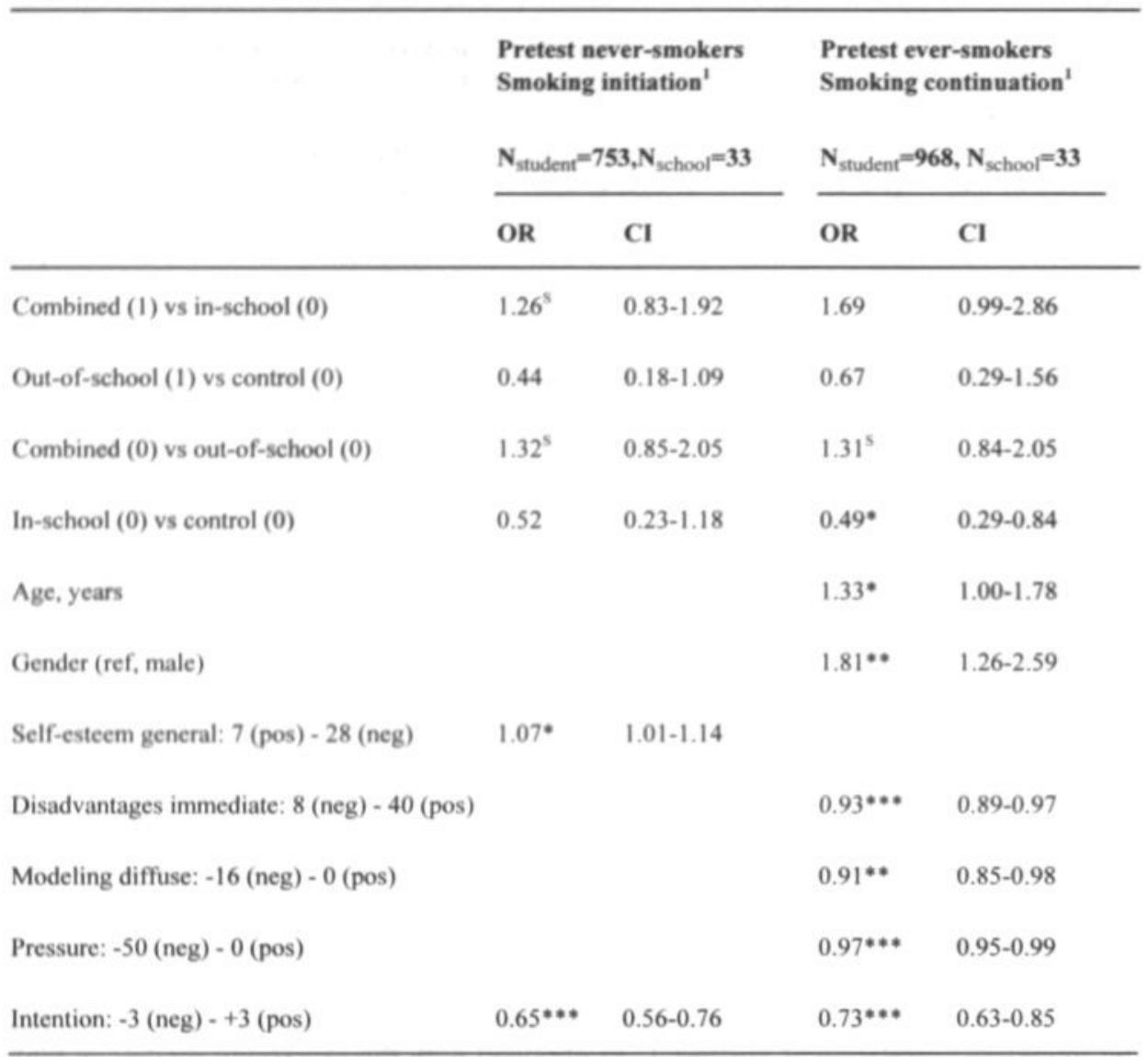

Notes, " $\mathrm{p}<0.05, \cdots p<0.01, \cdots * \mathrm{p}<0.001$; 'Because a significant 'in-school $\mathrm{x}$ out-of-school' interaction was found, treatment effects are based on four pairwise comparisons (fig 1), including the covariates age $\rightarrow$ intention. Effects of age $\rightarrow$ intention are based on the model for the total sample, including the 'inschool ${ }^{*}$ out-of-school' interaction. ${ }^{\text {s }}$ Model was tested without random effect, because MIXOR failed to run. 'Neg' means negative towards non-smoking, 'pos' means positive towards non-smoking

Table 6.6 presents the results of posttest 3. Data collection for the in-school population was not continued after posttest 2 , therefore only three of the four treatments groups were observed at posttest 3 and so the regression model contained only two dummies for treatments: Out ( $=1$ for Out and $\mathrm{I}+\mathrm{O}$, but 0 for Control), and In $(=1$ for $\mathrm{I}+\mathrm{O}$, but 0 for Out and Control). Their two regression weights estimate the difference between Out and Control, and between $\mathrm{I}+\mathrm{O}$ and Out, respectively. As regards smoking initiation, students in the out-of-school condition were less likely to have initiated smoking at posttest 3 than students in the control condition. As regards smoking continuation, no significant out-of-school effects were found. At posttest 3 the intraclass correlation for smoking initiation was 0.07 , for smoking continuation it was 0.05 . 
During all three posttests, intention (students with a negative intention towards nonsmoking being at higher risk) turned up as a consistent predictor for smoking initiation (tables 6.4-6.6). Age (older students being at higher risk), intention (students with a negative intention towards non-smoking being at higher risk), disadvantages 'immediate' (students perceiving fewer disadvantages being at higher risk), modeling 'nuclear' (students with more smokers in their immediate environment being at higher risk), modeling 'diffuse' (students with more smokers in their extended environment tending to be at higher risk), and pressure (students perceiving more pressure to smoke being at higher risk) were fairly consistent predictors for smoking continuation (tables 6.4-6.6).

Table 6.6 Program effects at posttest-3: Odds ratios (OR) with $95 \%$ confidence intervals (CI); smoking initiation ( 0 -never-smoking, $1=$ ever-smoking) and smoking continuation ( 0 -not smoking, 1=smoking)

\begin{tabular}{|c|c|c|c|c|}
\hline & \multirow{2}{*}{\multicolumn{2}{|c|}{$\begin{array}{l}\text { Pretest never smokers } \\
\text { Smoking initiation } \\
\mathrm{N}_{\text {student }}=523, \mathrm{~N}_{\text {school }}=22\end{array}$}} & \multirow{2}{*}{\multicolumn{2}{|c|}{$\begin{array}{l}\text { Pretest ever smokers } \\
\text { Smoking continuation } \\
\mathrm{N}_{\text {student }}=676, \mathrm{~N}_{\text {school }}=22\end{array}$}} \\
\hline & & & & \\
\hline & OR & CI & OR & CI \\
\hline Combined ( 1 ) vs out-of-school ( 0$)$ & 1.85 & $0.71-4.83$ & 1.08 & $0.42-2.75$ \\
\hline Out-of-school (1) vs control ( 0 ) & $0.42 *$ & $0.18-0.96$ & 0.60 & $0.23-1.53$ \\
\hline Self-esteem 'general': 7 (pos) - 28 (neg) & & & 1.07 & $1.00-1.15$ \\
\hline Modeling 'nuclear': -8 (neg) -0 (pos) & 0.86 & $0.73-1.01$ & $0.89^{*}$ & $0.81-0.99$ \\
\hline Modeling 'diffuse': - 16 (neg) - 0 (pos) & & & 0.90 & $0.81-1.01$ \\
\hline Pressure: -50 (neg) -0 (pos) & 0.96 & $0.92-1.01$ & & \\
\hline Intention: -3 (neg) -+3 (pos) & $0.68 * *$ & $0.56-0.76$ & $0.71 * * *$ & $0.61-0.82$ \\
\hline
\end{tabular}

Note, " $\mathrm{p}<0.05,{ }^{* *} \mathrm{p}<0.01,{ }^{* * *} \mathrm{p}<0.001$; 'Neg' means negative towards non-smoking, 'pos' means positive towards non-smoking

Because attrition at posttests could be predicted by several proximal and distal pretest characteristics and possibly also by treatment, selective dropout might have influenced the results. To check for this effect, analyses were repeated in two ways (Heyting et al., 1992). First, missing data of dropouts were replaced by their previous observation, the so-called 'last observation carried forward' analysis. Second, dropouts were treated as smokers, the so-called 'extreme case' analysis. Both analyses were performed for all students and 'extreme case' analyses yielded some divergent results compared with the 
effect analyses presented above. As regards the first posttest, the 'extreme case' analyses in the never-smoking sample resulted in significant positive effects of the outof-school program. For posttest 2, the extreme case analysis for the never-smoking sample showed that students in the combined condition were more likely to start smoking than students in the in-school condition. As regards posttest 3 , the positive effects of the out-of-school program (compared with the control condition) disappeared in the 'extreme case' analysis.

\section{Discussion and conclusions}

Compared were the effects on smoking prevention among Dutch first grade vocational schoolchildren of a newly developed computer-tailored out-of-school program, an existing in-school program and a combined approach including both the in-school and out-of-school programs. The two treatments were not effective immediately after the implementation of the programs. However, at 12 months after pretest, students in the inschool program were better able to discontinue smoking, compared with those in the control condition. Students in the out-of-school program tended to be more successful in not having initiated smoking after 18 months, compared with those in the control condition. In contrast to what was expected, the effect of a combined approach (in+out) was not larger than the sum of the effects of the in-school and the out-of-school program. Apparently, comprehensiveness does not mean doing everything at the same time or doing everything (Bell, Hilson, \& Chauvin, 1999). Simultaneous combination of interventions might cause an overload of information, which might produce back to the front effects.

To our knowledge, there have been two more or less comparable out-of-school smoking prevention interventions based on the Transtheoretical Model (TTM), targeting secondary school students. Pallonen and colleagues (1998) implemented a computerbased smoking prevention and cessation intervention in a vocational school sample (mean age 16.5 years) and reported six-month follow-up findings. Unfortunately, their sample size was too small to test the efficacy of the intervention. Aveyard and colleagues (2001) used an expert system computer program in a larger sample of 13-14 year-old British schoolchildren, and reported one- and two-year follow-up findings. No evidence of effectiveness for smoking prevention was found. An explanation of the promising effects of our tailored program might be the use of a different theory (ASE versus TTM) and or the use of the out-of-school context. Unfortunately, we could not single out whether the positive effects resulted from the presentation of the information in a letter format, or from the fact that the letters were delivered by mail.

Previous evaluation of the in-school program reported positive short-term results (ResCon, 1999). The results of the 1999 in-school study and our in-school evaluation can hardly be compared, however, because smoking was defined in the 1999 report as 'smoking once in a while', which did not correspond with our definitions of 'eversmoking' and 'smoking in the past month'. There were also differences in the research samples: secondary school students in general versus high-risk vocational school students. 
Results comparable to those of our in-school program have also been found in an earlier Dutch study by De Vries and colleagues (1994) about the implementation of a smoking prevention program for Dutch vocational school students based on social influence ('No smoking, your choice'). This program resulted in a decrease in regular smoking, but no effects on experimental smoking were found.

Process evaluation results of both our in-school and out-of-school programs indicated that there is room for implementation improvements. Firstly, about $65 \%$ of the students indicated that they had received the letters. It was unclear whether the remaining $35 \%$ had really not received the letters. The students had been asked to fill in their names and addresses at the pretest questionnaire, and in some cases these were not clearly written. An improved registration system might increase the exposure to the outof-school intervention. Secondly, almost half of the students felt personally addressed by the letters. The degree of perceived personalization would undoubtedly have been improved if the information in the letters could have been tailored to students' smoking behavior. However, this option was not used in the present study, to prevent arguments in the students' families. And lastly, the attractiveness of the out-of-school intervention in terms of content and appearance can be further refined.

Attrition in the present study roughly equals that in similar Dutch studies (De Vries et al., 1994; M. Dijkstra et al., 1999). Analyses including all dropouts, either as posttest smokers or using their pretest smoking scores, resulted in adjustment of some effects. Analyses including all dropouts as smokers ('extreme case') resulted in positive effects of the out-of-school program on smoking initiation and continuation at posttest 1, but the posttest 3 out-of-school effects disappeared. These results are in line with the attrition analyses; lower attrition rates are related with positive extreme cases results.

In conclusion, tailored out-of-school interventions offer protection to smoking initiation among vocational school students. Special attention should be paid to the registration system, to the improvement of personal relevance and attractiveness in terms of content and appearance, and to dropout prevention. By contrast, in-school interventions are recommended to prevent vocational school students from continuing to smoke. Furthermore, it is not necessary to implement in-school and out-of-school programs simultaneously.

In view of the development of smoking behavior, it is recommended to leave a sufficient interval between the out-of-school smoking prevention and the in-school smoking prevention. Booster interventions may be needed for long-term success. 



\section{Do Dutch 11-12 years olds who never smoke, smoke experimentally or smoke regularly have different demographic backgrounds and perceptions of smoking?}

Published as: Ausems, M., Mesters, I., van Breukelen, G., De Vries, H. (2003). Do Dutch 11-12 years olds who never smoke, smoke experimentally or smoke regularly have different demographic backgrounds and perceptions of smoking? European Journal of Public Health, 13, 160-168 


\begin{abstract}
Background: Most adolescent smokers start smoking before the age of twelve. Little is known about the behavioural smoking determinants of Dutch primary school children. Methods: A cross-sectional study was carried out in a sample of students from the final year of 143 Dutch primary schools. A total of 3700 students (mean age $=11.6$ years) completed a questionnaire based on the ASE model, measuring the attitude, social influences and self-efficacy expectations concerning smoking.

Results: Students were categorized as never smokers (64.3\%), experimental smokers $(28.0 \%)$, and regular smokers $(7.8 \%)$. Multinomial logistic regression analyses showed that never smokers were younger and were more often female, religious and from twoparent families than experimental smokers. Never smokers perceived more disadvantages, long-term physical consequences, more negative social norms and less pressure regarding smoking, higher self-efficacy expectations towards non-smoking, and had fewer parents, siblings or best friends who smoked. Looking at differences between experimental and regular smokers showed that experimental smokers received less pocket money. They also perceived more disadvantages, fewer advantages, more negative social norms and less pressure towards smoking, higher self-efficacy expectations towards non-smoking, and were less likely to be surrounded by friends, peers, family or teachers who smoked. Generally, the low scores for physical consequences and risk perception regarding addiction were striking.

Conclusions: Smoking prevention aimed at primary schoolchildren should consider the different smoking categories, with their specific motives and influences. For instance, the influences on smoking initiation of parents, siblings and best friends suggest more comprehensive programmes aimed at the entire family. Youngsters' ignorance of addiction needs more attention.
\end{abstract}


never, experimental, and regular smokers

\section{Introduction}

During the last decade, the number of Dutch youngsters who started smoking has been relatively stable. Lifetime prevalence has been found to increase with increasing age (De Zwart et al., 1997). In 1997, half of Dutch youngsters aged 10-19 years had smoked at some time (Stivoro, 1997). Most daily smokers in this age group were those who had started at the age of 12 or even earlier (De Zwart et al., 1997). Thus, the younger the age of initiation, the greater the risk that the youngster will be sentenced to a lifetime of heavy smoking, with its associated morbidity and mortality (US Department of Health and Human Services, 1994). Cigarette smoking also acts as a gateway drug, being a powerful predictor of alcohol and drug use (Torabi et al., 1993). Therefore, the choice of primary schoolchildren as the target population for the development of effective smoking prevention programmes seems justified.

Educational programmes tend to be more effective if they are theory-based (Bartholomew et al., 1998). Furthermore, a thorough problem analysis should precede programme development and, while attuning educational efforts to the appropriate determinants, enhances the effects (Green \& Kreuter, 1999). In the Netherlands, determinant and evaluation studies have been conducted on secondary schoolchildren (De Vries et al., 1994; M. Dijkstra et al., 1999). These secondary school studies were based on the Attitude - Social Influence - Self-Efficacy model (ASE) (De Vries \& Backbier, 1994), which is an extension of the Theory of Planned Behaviour (TPB) (Ajzen, 1991). The ASE model assumes that behaviour can be explained by behavioural intention, which in turn is determined by psychosocial determinants: attitudes, perceived social influences, and self-efficacy expectations. External variables such as demographic factors are assumed to influence behaviour via the three psychosocial determinants. A person's attitude is determined by evaluation of the salient beliefs concerning a particular behaviour. With respect to social influences, three independent influences are assumed to play a role (De Vries et al., 1995). The first is that of the perceived norms of important others concerning the behaviour. The second is the support or pressure a person experiences from their direct environment. The third social influence, modelling, involves using the behaviour of important others as an example (Bandura, 1986). Self-efficacy refers to a person's expectations regarding their capability to perform the desired behaviour. ASE has evolved as a separate model with several differences, predominantly of a methodological nature (De Vries et al., 1998).

Little is known about the behavioural smoking determinants of primary school children in the Netherlands. The present study used the ASE model to identify modifiable risk factors for early tobacco use in the period before transition to the secondary school system.

Three categories of smokers were identified: (1) never smokers, (2) experimental smokers and (3) regular smokers. Flay (Flay, d'Avernas, Best, Kersell, \& Ryan, 1983) claimed that becoming a smoker is a process rather than an instantaneous decision, with never smoking as the point of departure and regular smoking at the end. Not all beginners reach the final stage; some of them do not continue smoking. Various motives and influences apply while the subject passes through the smoking stages (Mayhew et al., 2000). Because smoking initiation takes place during primary schooling, the smoking process and its associated stages are expected to be encountered during these latter stages of primary schooling. 
The aim of the present study was to describe the differences in smoking perceptions and demographic variables between never smokers and experimental smokers, and between experimental smokers and regular smokers. These contrasts allow the identification of variables that are either relevant to only one comparison or are relevant during the whole phase of smoking onset. It is generally hypothesized that never smokers have the most negative perception of smoking, while regular smokers' perceptions of smoking are most positive, with experimental smokers in an intermediate position. In order to obtain comprehensive insights into the behavioural determinants of the three smoking categories, results will be described both at scale and at item level.

\section{Methods}

\section{Procedure}

All students in the final year of 156 primary schools from southern, eastern and central parts of the Netherlands were recruited in this study. Permission was sought from school principals in the spring of 1997. After their approval had been obtained, the teachers of the school classes involved received oral or written information about the assessment procedure. Teachers were instructed to schedule one hour for the questionnaire during September 1997, to collect the questionnaires after students had completed them at class level, put them in a pre-paid envelope and return the envelope to the researchers. Biochemical validation could not be applied to this young age group because available methods detect only very recent smoking (Sussman et al., 1995). Self-reports have been demonstrated to be accurate when confidentiality is assured (Botvin \& Botvin, 1992; De Vries et al., 1994). The front page of the questionnaire explained that only the researchers would have access to the files and only for research purposes.

\section{Questionnaire}

The questionnaire used in this study was developed on the basis of the ASE model. Two factor analyses with oblique rotation (Tabachnick \& Fidell, 2000) were applied for the construction of attitude scales. Table 7.3 presents an overview of the attitude items that were included in the factor analyses. The first factor analysis included the items consisting of five-point scales and resulted in two factors $(\mathrm{r}=-.04)$ :

Disadvantages (Cronbach's $\alpha=.79$ ), eleven items averaged: 1 (unfavourable); 2 (do not know); 3 (slightly favourable); 4 (favourable); 5 (very favourable towards nonsmoking).

Advantages ( $\alpha=.63$ ), five items averaged: 1 (favourable); 2 (do not know); 3 (slightly unfavourable); 4 (unfavourable); 5 (very unfavourable towards non-smoking).

The second factor analysis included the attitude items with 7-point scales, and resulted in two factors $(\mathrm{r}=.12)$ :

Social consequences, $(\alpha=.75)$, three items averaged, minus 3 (very unfavourable); minus 2 (unfavourable); minus 1 (slightly unfavourable); 0 (do not know); 1 (slightly favourable); 2 (favourable); 3 (very favourable towards non-smoking).

Long-term physical consequences, two items averaged ( $r=.57)$, with identical answer categories as the social consequences scale. 
As regards social influences, items in four domains were assessed. Table 7.4 shows the items that were summed and averaged, resulting in four social influence indices:

Modeling 'nuclear', four items: minus 2 (person concerned is a smoker); minus 1 (do not know/not applicable); 0 (person concerned is a non-smoker).

Modeling 'diffuse', four items: minus 4 (very many persons smoke); minus 3 (many); minus 2 (half /do not know); minus 1 (few); 0 (hardly anybody smokes).

Social norms, six items: minus 3 (very unfavourable); minus 2 (unfavourable); minus 1 (slightly unfavourable); 0 (do not know); 1 (slightly favourable); 2 (favourable); 3 (very favourable towards non-smoking).

Social pressure, ten items: minus 5 (very often); minus 4 (often); minus 3 (sometimes); minus 2 (rarely); minus 1 (very rarely); 0 (never experience pressure towards smoking). As regards the six self-efficacy items (table 7.5), factor analysis with oblique rotation confirmed one factor:

Self-efficacy expectations, six items averaged $(\alpha=.91)$, minus 3 (very uncertain); minus 2 (uncertain); minus 1 (slightly uncertain); 0 (do not know); 1 (slightly certain); 2 (certain); 3 (very certain to resist smoking).

Smoking behaviour was based on self-reports, categorizing students as: 1, never smoker (someone who has never smoked even one puff of a cigarette); 2, experimental smoker (someone who has tried smoking once or several times but is not currently a smoker and has not smoked during the last month); or 3, regular smoker (someone who has tried smoking, or smokes occasionally, or smokes daily and who has smoked during the last month).

Demographic variables included age, gender, religion, family composition, country of origin, occupation of parents, and amount of pocket money received.

\section{Analyses}

To test the differences in perceptions of smoking and demographic variables between never, experimental and regular smokers, multinomial logistic regression analyses were performed using SPSS 9.00 (SPSS Inc, 1999). As a result two odds ratios are obtained for each predictor of smoking, one for the odds of being a never versus an experimental smoker and one for the odds of being a regular versus an experimental smoker. The odds ratios indicated an increase in the likelihood of being, for instance, a never instead of an experimental smoker when the predictor value increased by one unit. The predictor variables (both dummy-coded categorical and continuous variables) were entered in one step in the analyses.

Demographic differences between never, experimental and regular smokers were tested with chi-square analyses for discrete variables. If the overall chi-square test showed a $\mathrm{p}<.05$, post-hoc pairwise comparisons with Bonferroni correction $\alpha=.05 / 3=.017$ were applied (Tabachnick \& Fidell, 2000). For continuous variables univariate analyses of variance were used. Differences between group means at item level with respect to the ASE determinants were also analysed with univariate analysis of variance. If the overall $\mathrm{F}$ test showed a $\mathrm{p}<.05$, the Tukey-HSD (honestly significant difference) method was employed for post-hoc pairwise comparisons (SPSS Inc, 1999). 


\section{chapter 7}

\section{Results}

\section{Demographic features of the sample}

Youngsters $(\mathrm{N}=3734$, mean age $=11.6)$ from 143 schools completed the questionnaire. Since 34 students' failed to indicate their smoking status, analyses were performed on 3700 subjects. Table 7.1 shows the demographics of the smoking categories: 2379 students $(64.3 \%)$ had never smoked, 1034 students $(28.0 \%)$ were experimental smokers, and 287 students $(7.8 \%)$ were regular smokers.

Table 7.1 Demographics of never smokers $(\mathrm{N})$, experimental smokers (E) and regular smokers (R)

\begin{tabular}{|c|c|c|c|c|c|}
\hline & $\begin{array}{l}N \\
(N=2379)\end{array}$ & $\begin{array}{l}E \\
(N=1034)\end{array}$ & $\begin{array}{l}R \\
(N=287)\end{array}$ & $\begin{array}{l}\text { Total } \\
(\mathrm{N}=3700)\end{array}$ & Significance \\
\hline Age (years) & 11.5 & 11.7 & 11.7 & 11.6 & $N<E, R ; p<0.001$ \\
\hline Gender (\%): Female & 54.6 & 43.2 & 46.0 & 50.8 & $\mathrm{~N}>\mathrm{E}, \mathrm{R} ; \mathrm{p}<0.01$ \\
\hline Religion (\%): Religious & 65.1 & 59.4 & 62.4 & 63.3 & $\mathrm{~N}>\mathrm{E} ; \mathrm{p}<0.01$ \\
\hline Origin (\%): Both parents Dutch & 83.4 & 80.8 & 77.0 & 82.2 & $\mathrm{~N}>\mathrm{R} ; \mathrm{p}<0.01$ \\
\hline Family composition (\%): Two parents & 91.2 & 83.8 & 81.5 & 88.4 & $N>E, R ; p<0.001$ \\
\hline \multicolumn{6}{|l|}{ Mother's occupational status (\%): } \\
\hline - Full-time & 13.5 & 16.4 & 19.5 & 14.8 & $\mathrm{~N}<\mathrm{R} ; \mathrm{p}<0.01$ \\
\hline - Part-time & 37.1 & 38.2 & 33.8 & 37.1 & \\
\hline - At home & 30.8 & 24.5 & 28.9 & 28.9 & $\mathrm{~N}>\mathrm{E} ; \mathrm{p}<0.001$ \\
\hline - Other & 18.7 & 20.9 & 17.8 & 19.2 & \\
\hline \multicolumn{6}{|l|}{ Father's occupational status (\%): } \\
\hline - Full-time & 67.4 & 63.6 & 63.1 & 66.0 & $\chi^{2}(6)=9.76 ; p=0.135$ \\
\hline - Part-time & 10.4 & 12.0 & 11.8 & 11.0 & \\
\hline - At home & 1.3 & 0.1 & 1.7 & 1.2 & \\
\hline - Other & 20.8 & 23.7 & 23.3 & 21.8 & \\
\hline Pocket money $(\%):<6.8$ euro & 93.2 & 92.4 & 79.8 & 93.2 & $\mathrm{~N}>\mathrm{E}>\mathrm{R} ; \mathrm{p}<0.001$ \\
\hline
\end{tabular}


Never smokers were younger, more often female and more likely to come from twoparent families than experimental and regular smokers. Never smokers were more likely than experimental smokers to have a registered religion, and never smokers were more likely than regular smokers to have Dutch parents. Never smokers were less likely than regular smokers to have a mother working full-time. Never smokers were more likely to have a mother who does not go out to work than experimental smokers. There were no differences between smoking categories in terms of the father's occupation. Never smokers were less likely than experimental smokers to receive more than 6.8 euros in pocket money each week, while experimental smokers in turn received less than regular smokers.

The upper part of table 7.2 shows the unique contributions of the variables (after correction for other predictor variables) to the explanation of the differences between smoking categories. The univariate findings of table 7.1 were confirmed.

\section{Differences in attitude}

The perception of disadvantages differed for all three groups (second part of table 7.2). Never smokers believed more strongly than experimental smokers that smoking has significant disadvantages. Table 7.3 shows that these disadvantages pertain to consequences such as nausea, shortness of breath, irritation of the eyes, passive smoking, unwise behaviour, expensive habits, poor health, annoying other people and addiction. All of these consequences, except for addiction, but including coughing and feelings of regret, also differentiated experimental from regular smokers. Furthermore, table 7.3 shows generally strikingly low scores for physical short-term consequences like nausea and shortness of breath among the disadvantages.

Table 7.2 indicates that perceived advantages scores differed between regular and experimental smokers, but not between never and experimental smokers, findings that are confirmed in table 7.3. Regular smokers were most strongly convinced that smoking gives them a tough image, that smoking tastes good and that it helps to counter nervousness and boredom. Except with regard to the tough image, never and experimental smokers shared similar opinions. Remarkably, all three groups' scores were close to the neutral score.

Never smokers were most strongly convinced of the long-term physical consequences in terms of increased risks of cancer and heart attacks (see table 7.2).

However, table 7.3 suggests that experimental and regular smokers also differed in their evaluations. The low risk perception of heart attack is remarkable. Table 7.2 suggests that social consequences scores did not differ between the groups, although the results shown in table 7.3 suggest that experimental and never smokers evaluated social consequences as more serious than regular smokers. 
Table 7.2 Multinominal logistic regression of contrasts 'never versus experimental' and 'regular versus experimental' smokers on demographic and ASE determinants; odds ratios (OR) with $95 \%$ confidence intervals $(95 \% \mathrm{CI})$

\begin{tabular}{|c|c|c|c|c|}
\hline \multirow[b]{2}{*}{ Demographic determinants } & \multicolumn{2}{|c|}{$\begin{array}{l}\text { Never versus } \\
\text { Experimental }\end{array}$} & \multicolumn{2}{|c|}{$\begin{array}{l}\text { Regular versus } \\
\text { Experimental }\end{array}$} \\
\hline & OR & $95 \% \mathrm{CI}$ & OR & $95 \% \mathrm{CI}$ \\
\hline Age, advancing years & $0.76 \bullet \bullet$ & $0.66-0.87$ & 0.84 & $0.66-1.02$ \\
\hline Gender, female= ref & $0.61 \bullet \bullet$ & $0.52-0.72$ & 0.84 & $0.63-1.12$ \\
\hline Religion, non-religious-ref & $1.24^{*}$ & $1.05-1.46$ & 1.14 & $0.85-1.54$ \\
\hline Origin, One/two parents non-Dutch-ref & 1.12 & $0.91-1.39$ & 0.92 & $0.64-1.31$ \\
\hline \multicolumn{5}{|l|}{ Mother's occupational status ('other'=ref) } \\
\hline - Full-time & 0.98 & $0.74-1.29$ & 1.23 & $0.76-2.05$ \\
\hline - Part-time & 0.95 & $0.76-1.20$ & 1.14 & $0.74-1.75$ \\
\hline - At home & 1.26 & $0.99-1.61$ & 1.46 & $0.93-2.27$ \\
\hline \multicolumn{5}{|l|}{ Father's occupational status ('other'=ref) } \\
\hline - Full-time & 0.97 & $0.79-1.20$ & 1.03 & $0.70-1.52$ \\
\hline - Part-time & 0.92 & $0.69-1.24$ & 0.94 & $0.56-1.58$ \\
\hline - At home & 1.66 & $0.72-3.81$ & 2.47 & $0.71-8.49$ \\
\hline Family composition, single-parent-ref & $1.41 * \bullet$ & $1.10-1.80$ & 0.98 & $0.66-1.47$ \\
\hline Pocket money, $\geq 6.8$ euros $=$ ref & 1.25 & $0.90-1.73$ & $0.38 * \bullet$ & $0.25-0.58$ \\
\hline $\begin{array}{l}\text { ASE determinants: } \\
\text { (composite variables in continuous form) }\end{array}$ & OR & $95 \% \mathrm{CI}$ & OR & $95 \% \mathrm{CI}$ \\
\hline Disadvantages $(1 \rightarrow 5)_{a}$ & $1.20 * *$ & $1.05-1.36$ & $0.51 * * *$ & $0.40-0.65$ \\
\hline Advantages $(1 \leftarrow 5)_{b}$ & 1.07 & $0.94-1.23$ & $1.38 * *$ & $1.10-1.73$ \\
\hline Long-term physical consequences $(-3 \rightarrow+3)_{a}$ & $1.13 * * *$ & $1.06-1.21$ & 1.06 & $0.95-1.19$ \\
\hline Social consequences $(-3 \rightarrow+3)_{a}$ & 1.04 & $0.96-1.13$ & 0.98 & $0.83-1.16$ \\
\hline Modeling 'nuclear' $(-2 \rightarrow 0)_{a}$ & $2.20 * * *$ & $1.85-2.62$ & 0.75 & $0.56-1.00$ \\
\hline Modeling 'diffuse' $(-4 \rightarrow 0)_{a}$ & 1.10 & $0.97-1.25$ & $0.68 * * *$ & $0.54-0.85$ \\
\hline Social norms $(-3 \rightarrow+3)_{a}$ & $1.19 * *$ & $1.06-1.33$ & $0.81^{*}$ & $0.66-0.98$ \\
\hline Pressure $(-5 \rightarrow 0)_{a}$ & $1.52 * \cdots$ & $1.28-1.79$ & $0.72 * *$ & $0.58-0.89$ \\
\hline$\underline{\text { Self-efficacy }(-3 \rightarrow+3)_{a}}$ & $1.14 * * *$ & $1.07-1.22$ & $0.79 * * *$ & $0.72-0.88$ \\
\hline
\end{tabular}

Notes, a Higher determinant score refers to answers more favourable towards non-smoking. A significant odds ratio $>1.0$ means that the determinant score is more favourable towards non-smoking in the non-reference group than in the reference group. $\mathrm{b}$ Lower determinant score refers to answers more favourable towards nonsmoking. A significant odds ratio $>1.0$ means that the determinant score is less favourable towards nonsmoking in the non-reference group than in the reference group. ${ }^{*} p \leq 0.05 ;{ }^{* *} p \leq 0.01 ;{ }^{* *} p \leq 0.001$ 
never, experimental, and regular smokers

Table 7.3 Means with standard deviations (in brackets) and significant differences (Tukey HSD, $\alpha=0.05$ ) of attitudinal scores of never $(N)$, experimental $(E)$, and regular smokers (R)

\begin{tabular}{|c|c|c|c|c|}
\hline Attitude items & $\mathrm{N}(\mathrm{N}=\mathbf{2 3 8 0})$ & $E(N=1035)$ & $R(N=285)$ & Tukey $\mathbf{H}$ \\
\hline \multicolumn{5}{|c|}{ Disadvantages: 0 (unfavourable) to 5 (very favourable towards non-smoking) } \\
\hline I will become nauseous & $2.75(1.23)$ & $2.46(1.30)$ & $1.85(1.16)$ & $N>E>R$ \\
\hline I will cough & $3.24(1.32)$ & $3.08(1.35)$ & $2.28(1.37)$ & $\mathrm{N}, \mathrm{E}>\mathbf{R}$ \\
\hline I sense shortness of breath & $2.81(1.21)$ & $2.44(1.25)$ & $1.92(1.21)$ & $N>E>R$ \\
\hline My eyes start to hurt & $2.56(1.13)$ & $2.29(1.20)$ & $1.90(1.13)$ & $N>E>R$ \\
\hline Others inhale my smoke & $3.53(1.21)$ & $3.25(1.21)$ & $2.85(1.35)$ & $N>B>R$ \\
\hline It is unwise of me & $3.81(1.34)$ & $3.61(1.29)$ & $3.07(1.35)$ & $N>E>R$ \\
\hline It is expensive & $4.10(1.17)$ & $3.87(1.31)$ & $3.57(1.47)$ & $N>B>R$ \\
\hline It is bad for my health & $4.52(0.89)$ & $4.38(0.90)$ & $4.14(0.94)$ & $N>E>R$ \\
\hline I annoy other people & $3.54(1.27)$ & $3.21(1.28)$ & $2.79(1.36)$ & $N>E>R$ \\
\hline I will become addicted & $3.18(1.29)$ & $2.98(1.29)$ & $2.83(1.36)$ & $\mathbf{N}>\mathbf{E}, \mathbf{R}$ \\
\hline I regret having started & $4.46(1.06)$ & $4.43(1.04)$ & $4.28(1.12)$ & $\mathrm{N}, \mathrm{E}>\mathbf{R}$ \\
\hline
\end{tabular}

Advantages: 0 (favourable) to 5 (very unfavourable towards non-smoking)

$\begin{array}{lllll}\text { It gives me a tough image } & 2.02(1.08) & 2.21(1.16) & 2.40(1.25) & \mathrm{N}<\mathrm{E}<\mathrm{R} \\ \text { It helps against nervousness } & 2.05(0.85) & 2.06(0.99) & 2.30(1.25) & \mathrm{N}, \mathrm{E}<\mathrm{R} \\ \text { It helps to relieve boredom } & 2.14(0.85) & 2.17(0.98) & 2.46(1.21) & \mathrm{N}, \mathrm{E}<\mathrm{R} \\ \text { I feel mature } & 2.14(1.04) & 2.18(1.12) & 2.24(1.19) & \\ \text { It tastes good } & 1.96(0.88) & 2.04(1.08) & 2.86(1.17) & \mathrm{N}, \mathrm{E}<\mathrm{R}\end{array}$

Social consequences: -3 (very unfavourable) to +3 (very favourable towards non-smoking)

Friends take more interest in me

$-0.06(1.23)$

$-0.40(1.19)$

$\mathrm{N}, \mathrm{E}>\mathrm{R}$

Friends accept me more easily

$0.21(1.40)$

$0.06(1.26)$

$-0.30(1.10)$

N, E $>$ R

I can make contacts more easily

$0.21(1.25)$

$0.05(1.09)$

$-0.13(1.14)$

$\mathrm{N}, \mathrm{E}>\mathrm{R}$

Long-term physical consequences: -3 (very unfavourable) to +3 (very favourable towards nonsmoking)

\begin{tabular}{lllll} 
I run a greater risk of getting cancer & $1.86(1.24)$ & $1.54(1.42)$ & $1.27(1.57)$ & $\mathrm{N}>\mathrm{E}>\mathrm{R}$ \\
$\begin{array}{l}\text { I run a greater risk of having a heart } \\
\text { attack }\end{array}$ & $1.05(1.50)$ & $0.58(1.63)$ & $0.32(1.73)$ & $\mathrm{N}>\mathrm{E}>\mathrm{R}$ \\
\hline
\end{tabular}


Table 7.4 Means with standard deviations (in brackets) and significant differences (Tukey HSD, $\alpha=0.05$ ) of scores regarding the social influences of ever $(\mathrm{N})$, experimental (E), and regular smokers (R)

Social influences

$\mathrm{N}(\mathrm{N}=\mathbf{2 3 8 0}) \quad \mathrm{E}(\mathrm{N}=1035)$

$\mathbf{R}(\mathbf{N}=\mathbf{2 8 5})$

Tukey HSD

Modeling 'nuclear', - 2 (all are smokers) to 0 (none are smokers)

$\begin{array}{lllll}\text { Father } & -0.72(0.94) & -1.06(0.97) & -1.08(0.96) & \mathrm{N}>\mathrm{R}, \mathrm{E} \\ \text { Mother } & -0.65(0.93) & -1.02(0.99) & -1.13(0.99) & \mathrm{N}>\mathrm{R}, \mathrm{E} \\ \text { Brother/sister } & -0.29(0.58) & -0.53(0.77) & -0.81(0.88) & \mathrm{N}>\mathrm{E}>\mathrm{R} \\ \text { Best friend } & -0.20(0.47) & -0.33(0.61) & -0.93(0.90) & \mathrm{N}>\mathrm{E}>\mathrm{R}\end{array}$

Modeling 'diffuse', -4 (almost all ) to 0 (hardly any are smokers)

$\begin{array}{lllll}\text { Family } & -1.60(1.23) & -2.11(1.26) & -2.38(1.36) & \text { N>E }>\text { R } \\ \text { Friends } & -0.86(1.00) & -0.95(1.07) & -1.66(1.40) & \text { N, E>R } \\ \text { Peers } & -0.96(0.99) & -1.03(1.02) & -1.60(1.15) & \text { N, E>R } \\ \text { Teachers } & -1.19(1.00) & -1.22(1.03) & -1.39(1.13) & \text { N, E>R }\end{array}$

Pressures towards smoking, - 5 (very often) to 0 (never)

$\begin{array}{lllll}\text { Father } & -0.21(0.84) & -0.32(0.97) & -0.60(1.32) & \mathrm{N}, \mathrm{E}>\mathrm{R} \\ \text { Mother } & -0.17(0.74) & -0.34(1.02) & -0.56(1.28) & \mathrm{N}, \mathrm{E}>\mathrm{R} \\ \text { Brother } & -0.07(0.47) & -0.14(0.62) & -0.40(1.07) & \mathrm{N}>\mathrm{E}>\mathrm{R} \\ \text { Sister } & -0.05(0.41) & -0.13(0.56) & -0.31(1.00) & \mathrm{N}>\mathrm{E}>\mathrm{R} \\ \text { Best friend } & -0.10(0.52) & -0.28(0.76) & -0.85(1.43) & \mathrm{N}>\mathrm{E}>\mathrm{R} \\ \text { Family } & -0.36(1.00) & -0.57(1.25) & -0.86(1.43) & \mathrm{N}>\mathrm{E}>\mathrm{R} \\ \text { Friends } & -0.14(0.58) & -0.43(0.93) & -0.95(1.47) & \mathrm{N}>\mathrm{E}>\mathrm{R} \\ \text { Peers } & -0.15(0.57) & -0.36(0.82) & -0.75(1.26) & \mathrm{N}>\mathrm{E}>\mathrm{R} \\ \text { Teachers } & -0.23(0.78) & -0.28(0.86) & -0.36(0.98) & \mathrm{N}>\mathrm{R} \\ \text { Commercials } & -0.11(0.50) & -0.32(0.86) & -0.74(1.25) & \mathrm{N}>\mathrm{E}>\mathrm{R}\end{array}$

Social norms, - 3 (very unfavourable) to 3 (very favourable towards non-smoking)

$\begin{array}{lllll}\text { Father } & 2.43(0.95) & 2.23(1.05) & 1.93(1.14) & \mathrm{N}>\mathrm{E}>\mathrm{R} \\ \text { Mother } & 2.54(0.83) & 2.32(0.97) & 2.05(1.15) & \mathrm{N}>\mathrm{E}>\mathrm{R} \\ \text { Brother } & 1.13(1.36) & 0.95(1.28) & 0.70(1.30) & \mathrm{N}, \mathrm{E}>\mathrm{R} \\ \text { Sister } & 1.19(1.35) & 1.02(1.31) & 0.71(1.24) & \mathrm{N}, \mathrm{E}>\mathrm{R} \\ \text { Best friend } & 1.89(1.31) & 1.53(1.40) & 0.81(1.38) & \mathrm{N}>\mathrm{E}>\mathrm{R} \\ \text { Friends } & 1.72(1.33) & 1.25(1.38) & 0.62(1.47) & \mathrm{N}>\mathrm{E}>\mathrm{R}\end{array}$


never, experimental, and regular smokers

\section{Differences in social influences}

Table 7.2 suggests that modeling 'nuclear' (by people in the immediate social environment) is an important explanatory factor for the differences between never and experimental smokers and the borderline differences between regular and experimental smokers. Never smokers had fewer smokers in their immediate social environment than experimental smokers. Likewise, experimental smokers had fewer smokers in their immediate social environment than regular smokers. Modeling 'diffuse' (by people in the extended social environment) is an important factor explaining the differences between regular and experimental smokers (table 7.2). Table 7.4 generally confirms these findings.

The perception of social norms and pressures differed for all three groups (table 7.2). Never smokers perceived more positive social norms towards non-smoking than experimental smokers, except for the social norms of siblings, which were equally perceived by never and experimental smokers (table 7.4). All perceptions of social influences differed between regular and experimental smokers. Never smokers perceived less pressure to smoke, although table 7.4 does not show significant differences in parental pressure between the never and experimental smokers.

\section{Differences in self-efficacy}

Table 7.2 shows that never smokers were most convinced of their ability to resist cigarettes, followed by experimental smokers, while regular smokers had the greatest doubts about their ability. Only in situations where others smoke were the self-efficacy expectations of never and experimental smokers comparable (table 7.5).

Table 7.5 Means with standard deviations (in brackets) and significant differences (Tukey HSD, $\alpha=0.05$ ) of scores regarding self-efficacy expectations of never $(N)$, experimental (E), and regular smokers $(\mathbf{R})$

\section{$\mathrm{N}(\mathrm{N}=2380) \quad E(\mathrm{~N}=1035) \quad \mathrm{R}(\mathrm{N}=285) \quad$ Tukey HSD}

Self-efficacy, ability to resist a cigarette: $-\mathbf{3}$ (very unfavourable) to 3 (very favourable towards nonsmoking)

$\begin{array}{lllll}\text { Others smoke } & 1.90(1.46) & 1.74(1.42) & 1.19(1.82) & \mathrm{N}, \mathrm{E}>\mathrm{R} \\ \text { Friends smoke } & 1.67(1.53) & 1.34(1.61) & 0.55(2.00) & \mathrm{N}>\mathrm{E}>\mathrm{R} \\ \text { Others offer you a cigarette } & 1.84(1.46) & 1.46(1.57) & 0.43(1.95) & \mathrm{N}>\mathrm{P}>\mathrm{R} \\ \text { Parents offer you a cigarette } & 1.86(1.57) & 1.45(1.72) & 0.62(2.14) & \mathrm{N}>\mathrm{E}>\mathrm{R} \\ \text { You are called a coward } & 1.52(1.58) & 1.22(1.65) & 0.72(1.93) & \mathrm{N}>\mathrm{E}>\mathrm{R}\end{array}$




\section{Discussion}

The aim of this study was to describe the differences in demographic background variables and in perceptions of smoking between never smokers, experimental smokers, and regular smokers from a primary school sample. The ASE model proved to be a useful tool for this purpose. Multinominal logistic regression analyses showed that never smokers were younger, and more often female, religious and from two-parent families than experimental and regular smokers. No obvious demographic differences between experimental and regular smokers were found, except that regular smokers received more pocket money. As hypothesized, never smokers had the most positive perception of the ASE determinants towards non-smoking, while regular smokers had the most negative perception. The perceptions of experimental smokers were generally between those of never and regular smokers.

With regard to attitudinal differences, the 'disadvantages' sub-scale showed a gradual rise going from never smokers to regular smokers. This finding could support the Cognitive Dissonance theory (Festinger, 1962), which holds that people adjust their opinion to suit their behaviour, in order to solve the contradictions between attitudes and behaviour. With regard to the 'advantages' sub-scale, regular smokers did indeed tend to adjust their attitude towards their behaviour. Experimental smokers seemed to maintain their opinion about smoking as if they were still never smokers. This finding is in agreement with the findings of Mc Neill and colleagues (1988), and may reflect the unreasoned or unplanned aspects of the first smoking experiences. Results on the 'longterm physical consequences' sub-scale show that the adjustment occurred mostly after the first experiences with cigarettes. The 'social consequences' sub-scale did not discriminate between the three smoking groups. However, univariate analyses showed that regular smokers evaluated the social consequences as being less serious than did experimental smokers, although all item scores were close to the 'do not know' score. Apparently, the social function of smoking was not (or not yet) important or recognized by all youngsters aged 11-12 years. According to Botvin and colleagues (1983), this social image of smoking increases as a function of age, which might apply to this study sample of primary school children.

Modeling 'nuclear' (by people who smoke in the immediate social environment) seems to differentiate between never and experimental smokers, and to account for the borderline difference between experimental and regular smokers. Earlier studies suggested that the availability of cigarettes, family members being users, and peer encouragement by best friends promote smoking (Mayhew et al., 2000). Smoking may also be encouraged by internalization of family norms, values or life-style (Engels, Knibbe, De Vries et al., 1999). Never and experimental smokers were comparable with respect to the number of smokers in their extended social environment (modeling 'diffuse': family, friends, peers and teachers), in contrast to experimental and regular smokers, who perceived different numbers of smokers. Establishing smoking behaviour seems to be related to the degree of smoking among peers, friends, family or teachers, who might facilitate the transition between experimental and regular smoking. However, the cross-sectional character of the present study does not explain whether the smoking environment results from or causes regular smoking.

As regards self-efficacy expectations, never smokers were more convinced of their ability to resist cigarettes than experimental smokers, who in turn were more convinced 
than regular smokers. As Bandura (1986) explained, self-efficacy expectations depend greatly on performance attainment. Youngsters with smoking experience demonstrate failure in refusing cigarettes and might therefore be equipped with lower self-efficacy expectations. This seems to apply even more to regular smokers.

Some striking results of the univariate analyses were the moderate scores (that is to say, 'do not know' answers) for short-term physical disadvantages (for example: nausea, coughing, shortness of breath, irritated eyes) and the long-term physical consequence of having a heart attack. The possibility of heart attacks may not have been taken very seriously, because primary school children rarely suffer from heart diseases, whereas childhood cancer is a disease all age groups might feel sensitive to. Low scores for short-term consequences could be due to the fact that children without tobacco experience were more inclined to choose the 'do not know' category. However, regular smokers seemed even less convinced about these consequences, probably because of the extinction of the physical effects through habituation to tobacco ingredients. A Dutch study among older schoolchildren (mean age 13.4 years) showed higher scores for these physical consequences (De Vries \& Kok, 1986), suggesting that the low scores in the present study were the consequence of the youth of the subjects. Another striking finding was that youngsters perceived little risk of becoming addicted, given the hesitant scores of never and experimental smokers and the even more hesitant scores of regular smokers. Similar results have been found for 13-year-old Dutch students (De Vries \& Kok, 1986). Youngsters might underestimate the probability and/or seriousness of tobacco addiction (Slovic, 1998).

The differences between the scores of regular and never smokers regarding smoking in the social environment were greatest for the perceived smoking behaviour of best friends. This may support the selection assumption, which states that smokers use smoking behaviour as a selection criterion in choosing their best friends (Engels, Knibbe, De Vries et al., 1999). Never smokers might use the same strategy, which would increase the level of polarization.

The low 'pressure' scores were also unexpected. In general, the youngsters hardly felt pressured towards smoking. Friedman and colleagues (1985) has already reported that adolescents do not always recognize or label the influence of peers as pressure.

The intention of this chapter was to present an outline of the smoking behaviour of Dutch primary schoolchildren and its corresponding psychosocial and demographic determinants. Though this study was limited by its cross-sectional nature, the description of the three smoking categories increases our understanding of the risk factors and motives of never smokers, experimental smokers and regular smokers. 


\section{Implications for smoking prevention}

The findings of this study have implications for smoking prevention addressing both parents and primary school children. First, the results of this study show that three categories of smokers can be distinguished, even in this primary school period. This implies that during the primary school period, never smokers are not the only important educational targets, but that experimental smokers also need special attention. Smoking prevention for primary schoolchildren should include information about disadvantages and social norms, and skills-increasing exercises in order to resist pressures and increase self-efficacy expectations about resisting cigarettes. When targeting experimental smokers to prevent their transition to regular smoking, special attention should be paid to advantages, influences of smoking peers, friends, family. Secondly, the strong parental, sibling and best friend influences on smoking initiation suggests that there should be more comprehensive family-directed programmes, in which smoking parents and siblings act as role models. Special attention could be paid to the amount of pocket money given to youngsters, as this was directly related to regular smoking. Thirdly, future prevention programmes should deal more extensively with youngsters' ignorance of addiction. 


\section{8}

\section{Prediction of smoking among Dutch elementary schoolchildren: Do girls need a specific prevention approach?}

Manuscript submitted for publication as: Ausems, M., Mesters, I., van Breukelen, G., De Vries, H. 'Prediction of smoking among Dutch elementary schoolchildren: Do girls need a specific prevention approach?' 


\section{chapter 8}

\section{Abstract}

This chapter describes predictors of smoking initiation and continuation among Dutch elementary schoolgirls and boys. Written questionnaires were used to collect longitudinal data on smoking. Concerning smoking initiation, girls and boys shared the following risk factors: increasing age, more smoking relatives and lower self-efficacy expectations. Gender specific features were parents' non-Dutch origin (girls), smoking siblings (girls) and high pressure (boys). Concerning smoking continuation, no predictive gender differences were found. More smoking siblings and best friends, lower perception of disadvantages of smoking and self-efficacy expectations predicted smoking. The findings of this study imply that self-efficacy and attitude information needs a prominent place in prevention programs. Separate elementary school programs for girls and boys seem unnecessary. Comprehensive family-directed programs are recommended. 
do girls need specific prevention?

\section{Introduction}

Smoking causes $85 \%$ of lung cancer mortality, while $33 \%$ of mortality from other cancers is also attributed to smoking. About half of all smokers will eventually be killed by their habit (Doll et al., 1994). In spite of this, cigarette smoking remains a major preventable cause of premature death and disability throughout the world (Ball, 1990; US Department of Health and Human services, 1994).

Adolescent girls and boys who start smoking at an early age are considerably more at risk of the disadvantageous consequences of smoking. like respiratory and coronary diseases, than late starters. Also, nicotine addiction among these early smokers is more severe than that among late starters (US Department of Health and Human Services, 1994).

Smoking prevalence rises sharply after students' transfer from elementary to secondary education. This finding does not apply exclusively to the Dutch situation, in which school transition occurs when students are 12 years old, but has also been identified by researchers in other countries (US Department of Health and Human Services, 1994). In 1996, the lifetime prevalence among 10-12 year-Old Dutch children was $19 \%$ for girls and $27 \%$ for boys. At the age of $13-14$, figures for girls $(47 \%)$ start to overtake those for boys ( $46 \%)$. Four percent of 10 -12 year-old girls and seven percent of 10-12 year-old boys indicate having smoked in the past four weeks, while at the age of $13-14,25 \%$ of the girls and $18 \%$ of the boys report having done so (Stivoro, 1998). The greater rate of smoking initiation by female adolescents has been found in many developed countries and is of great concern, in view of the implications of smoking for, e.g., reproductive functions (US Department of Health and Human Services, 1994). Recent research suggests that reasons for smoking need further examination, with special attention to girls (Soldz \& Cui, 2001).

The process of becoming a smoker comprises several distinct stages, starting with never smoking and ending with daily smoking. Flay and colleagues (1983) proposed a four-stage model of adolescent smoking: a preparatory stage (in which knowledge, beliefs, and expectations about smoking are formed), a trial stage (in which the first trial occurs, usually in the presence of friends), an experimental stage (involving repeated but irregular use over an extended period) and regular use (smoking on a regular basis, perhaps weekly). Given the smoking figures among Dutch adolescents, the first stages of the smoking process must already be manifest in the elementary school period. A cross-sectional study confirmed that about $35 \%$ of upper-grade elementary school pupils (mean age 11.6 years) were progressing in the smoking process (Ausems et al., 2003). Determinants of (non-) smoking vary for different smoking stages (Ary, 1988; Flay et al., 1983; Leventhal \& Cleary, 1980; Lloyd-Richardson, Papandonatos, Kazura, Stanton, \& Niaura, 2001; Mayhew et al., 2000), implying that specific preventive interventions are needed for each smoking stage. In other words, attuning educational efforts to the appropriate determinants enhances the effects (Green \& Kreuter, 1999).

In the Netherlands, the ASE model (Attitude -Social influence- self-Efficacy) has been used to assess the determinants of smoking and to evaluate smoking prevention programs for secondary school children (De Vries et al., 1995; M. Dijkstra et al., 1999). The ASE Model can be regarded as an integrated model for change, applying insights of the Theory of Reasoned Action (TRA) (Fishbein \& Ajzen, 1975) and its successor the Theory of Planned Behavior (TPB) (Ajzen, 1991), relevant aspects of Bandura's Social 
Learning Theory (1977) and Prochaska's Transtheoretical Model (1994). According to the ASE-model, behavior can be explained by behavioral intention, which in turn is determined by the psychosocial determinants, namely attitudes, perceived social influences, and self-efficacy expectations. External variables, such as demographic factors are assumed to influence behavior through the three psychosocial determinants. A person's attitude is determined by the evaluation of the salient beliefs concerning the behavior. With respect to social influences, three independent influences are assumed to play a role (De Vries et al., 1995). First, the perceived norms of important others concerning the behavior. Second, the support or pressure a person experiences from his direct environment. The third social influence appears when the behavior of important others is taken as an example: modeling (Bandura, 1986). Self-efficacy refers to a person's expectations regarding his or her capability to perform the desired behavior. ASE has evolved as a separate model with several differences, predominantly of a methodological nature (De Vries et al., 1998).

Smoking determinant studies in the Netherlands had until recently been conducted only among secondary schoolchildren (Chatrou, Maes, Dusseldorp, \& Seegers, 1999; De Vries et al., 1994; M. Dijkstra et al., 1999). Recently a cross-sectional study was conducted among elementary schoolchildren, which revealed a clear distinction between never, experimental, and regular smokers (Ausems et al., 2003). The distinction manifests itself in different backgrounds and motives of the youngsters. Cross-sectional research improves our insights into the relation between smoking behavior and its risk factors, but rules out causal relationships (Chassin, Presson, \& Sherman, 1995).

The goal of this study is to assess the risk factors for smoking initiation and continuation using a longitudinal design, and to assess as well whether these risk factors differ for girls and boys. In view of the higher rates of smoking initiation and smoking continuation by female adolescents aged 13-14, it was hypothesized that determinants of smoking initiation and continuation at the age of 11-12 year would also differ for the two genders.

\section{Methods}

\section{Design and procedure}

The present study used data from a study on Dutch upper-grade elementary school children $(\mathrm{N}=3775)$. These data were collected in 143 schools as part of a smoking prevention project, which used a longitudinal design with randomization of schools to in-school and out-of-school conditions, to a combined in-school and out-of-school condition and to a non-intervention control condition. Both in-school and out-of-school programs were based on essential components for successful social influence programs (Sussman et al., 1993). Topics included short-term physical and social consequences of smoking, pressure, other people's smoking behavior, and refusal skills. For a detailed description of both programs, see Ausems, Mesters, Van Breukelen, \& De Vries (2002). In 1997, Dutch school principals had the authority to approve in-school health courses, so that no consent procedure was required for the in-school intervention. Schools participating in the out-of-school program distributed consent forms to students' 
parents, as their children were selected to receive educational materials sent to the home addresses. Twenty-two parents refused to participate, so their children did not receive the out-of-school materials. The class teachers received oral and/or written instructions, after which they were asked to schedule three one-hour periods for completing the three questionnaires in class. Both in-school and out-of school interventions were administered between the pretest in September 1997 and the first posttest, in early February 1998. Short-term results of this posttest are described elsewhere (Ausems et al., 2002). The follow-up assessment, which results are described in this chapter, was in July 1998, nine months after the pretest.

\section{Questionnaire}

The survey was an updated version of the ASE questionnaire (Attitude-Social influenceself-Efficacy), which had been used in previous Dutch smoking prevention research (De Vries et al., 1994; M. Dijkstra et al., 1999). The ASE questionnaire assesses both the determinants of smoking (attitudinal beliefs, social influences, self-efficacy expectations and intentions) and the outcome measures (smoking initiation and continuation). Demographic variables like age, gender, religion, family composition, amount of pocket money and parents' jobs and origins were also included as predictors, although they were assumed to influence smoking via attitudes, social influences and self-efficacy expectations.

Factor analyses were used to form four attitude scales:

- Disadvantages of smoking (11 items, Cronbach's $\alpha=.80$ ) measured on a 5-point scale ranging from 'negative' (1) to 'very positive towards non-smoking' (5), referring to nausea, coughing, irritated eyes, breathing problems, unwise activity, expenses, bad for one's health, annoying others, causing passive smoking, regrets afterwards, and bad smell;

- Advantages of smoking ( 5 items, Cronbach's $\alpha=.63$ ) measured on a 5-point scale ranging from 'positive' (1) to 'very negative towards non-smoking' (5), referring to growing up, relieving boredom, relieving tension, tasting good, feeling tough;

- Social acceptability ( 3 items, Cronbach's $\alpha=.75$ ) measured on a 7-point scale ranging from 'very negative' $(-3)$ to 'very positive towards non-smoking' (3), referring to receiving attention from friends, acceptance by friends and making contacts;

- Long-term physical consequences (2 items, $r=.57$ ) measured on a 7-point scale ranging from 'very negative' (-3) to 'very positive towards non-smoking' (3), referring to risks of cancer and heart diseases.

Social influence was measured in four ways:

- Modeling 'nuclear network', 4 items measured on a 3-point scale: 'yes' (-2), 'absent' $(-1)$, and 'no' $(0)$, measuring the perceived smoking behavior of the student's father, mother, brother/sister and best friend;

- Modeling 'diffuse network', 4 items measured on a 5-point scale ranging from 'almost all are smokers' (-4) to, 'almost none are smokers' $(0)$, measuring the number of smoking friends, peers, teachers and relatives (e.g. aunts and uncles);

- Social norms, sum score of 6 items on 7-point scales ranging from 'very negative' (-3) to 'very positive towards non-smoking' (3), measuring the perceived beliefs of the student's father, mother, brother, sister, best friend and friends; 
- Social pressure, sum score of 10 items ranging from 'very often' (-5) to 'never' $(0)$, measuring the perceived pressure from the student's father, mother, brother, sister, best friend, friends, peers, teacher, relatives, and advertisements.

Self-efficacy expectations ( 6 items, Cronbach's $\alpha=.91$ ) measured on 7-point scales ranging from 'very uncertain' (-3) to 'very certain' (3), each item referring to the student's expectation about being able to refrain from smoking in different situations with increasing level of difficulty (when others or friends smoke, when a cigarette is offered by someone, by parents or by friends, or when you are called a coward).

Intention to smoke was measured by one item on a 7-point scale, ranging from 'definitely do' (-3) to 'definitely do not intent to smoke' (3).

Smoking behavior was based on self-reports, categorizing students as: a. never smokers, i.e., students who had never smoked one cigarette, not even a puff; b. noncurrent smokers, i.e., students who had smoked before, but not during the past month; and c. current smokers, i.e., students who had smoked before and also during the past month.

When a pretest never-smoking pupil (category a) indicated that he or she smoked (category b or c) at follow-up, this was categorized as smoking initiation. Smoking continuation was recorded when a pretest ever smoker (category b or c) indicated at follow-up to have smoked during the past month (category c).

Objective validation could not be used for this young age group, because available methods only detect very recent smoking, at most weekly smoking, and smoking family members can induce elevated readings (Murray et al., 1987; Sussman et al., 1995). Selfreports have been demonstrated to be accurate provided confidentiality is assured and an identification coding system is used (Akers et al., 1983; Botvin \& Botvin, 1992; De Vries et al., 1994; Murray \& Perry, 1987; US Department of Health and Human Services, 1994). Hence, the front page of the questionnaires provided information about confidentiality. An identification code was used in the datafile, with researchers replacing the names before the data were entered.

\section{Analyses}

Students were nested within schools, and this nesting has to be taken into account in the data analyses, as ignoring nesting may lead to type I errors and too narrow confidence intervals for treatment effects (Flay et al., 1995). Therefore, analyses were performed using multilevel regression modeling with the MIXREG (linear regression) program for continuous variables (Hedeker \& Gibbons, 1996b), and with MIXOR (logistic regression) for dichotomous variables (Hedeker \& Gibbons, 1996a).

To check randomization, the treatment conditions were compared for age, gender, baseline smoking and psychosocial variables of the participants. Randomization analyses (MIXREG, MIXOR) were performed using all features as outcome and treatment conditions and their interaction as predictor. Dropout rate was checked using logistic regression (MIXOR) with attrition at follow-up as the outcome and baseline demographics, baseline smoking and psychosocial variables, and treatment conditions and their interaction as predictors. Smoking percentages were calculated with schools as the units of analysis and the percentage of smokers per school as the outcome, using equal weighting for all schools.

Because running large regression models with MIXOR might cause problems, we started with model reduction using SPSS stepwise logistic regression analysis. Smoking 
initiation and continuation were each predicted from treatment dummy variables, which contain main effects of the in-school (both in-school [1] versus both no in-school conditions [0]) and out-of-school interventions (both out-of-school [1] versus both no out-of-school conditions [0]), and their interaction. Subsequently, the demographic variables were entered, and finally the psychosocial ASE variables were entered. Interactions with gender were tested simultaneously with the predictors. Interactions and main effects were deleted stepwise using a two-tailed alpha of 0.15 , excepting the main effects of treatment and of predictors involved in an interaction term in the model, which were maintained no matter their p-value. If a predictor was significant but did not interact with gender, the predictor was included in a multilevel analysis on the total sample. If the predictor interacted significantly with gender, the predictor was included in separate multilevel analyses for girls and boys with the same regression model excepting gender and its interactions with other predictors. The final model as obtained with SPSS was checked with MIXOR to prevent type I errors due to ignoring intraclass correlation, a measure for the interdepence of the students within schools.

\section{Results}

\section{Sample characteristics, randomization and attrition}

Table 8.1 presents the demographic and psychosocial characteristics of the pretest sample. To check the randomization, the four treatment conditions were compared on demographic, psychosocial and behavioral characteristics. Randomization analyses revealed no significant differences between the conditions.

Attrition at student level between the pretest and follow-up nine months later was $13.3 \%$. Seven schools did not return the questionnaires because of time constraints due to the end of term period and the students' preparations for secondary school. Questionnaires from one school were never received, even though the teacher assured us that they had been posted. Three-quarters of the dropout schools belonged to the inschool condition. Nevertheless, this condition is not held responsible for the attrition rates, since the in-school and combined conditions were implemented in the same way and attrition in the combined condition approximated the out-only and control conditions. We therefore assumed that the higher attrition rate in the in-school condition was a chance event, and we performed the attrition analyses without the eight drop out schools. Logistic regression analysis with attrition as the dependent variable suggested that younger children were more likely to drop out than older students $(O R=0.78 ; 95 \%$ $\mathrm{CI}=0.63-0.96)$ and that children from the in-school condition were less likely to drop out than children from the no in-school condition $(\mathrm{OR}=0.64 ; 95 \% \mathrm{CI}=0.42-0.96)$. Gender and pretest smoking was not related with drop out, therefore the following analyses were performed without those students who dropped out. 
Table 8.1 Demographic, psychosocial characteristics of the pretest sample, means or proportions (\%)

\begin{tabular}{|c|c|c|c|}
\hline & $\begin{array}{l}\text { Total sample } \\
\mathrm{N}=3734\end{array}$ & $\begin{array}{l}\text { Girls } \\
N=1887\end{array}$ & $\begin{array}{l}\text { Boys } \\
N=1841\end{array}$ \\
\hline Age & 11.62 & 11.59 & 11.66 \\
\hline Religious (\%) & 63.22 & 61.95 & 64.53 \\
\hline Family composition, 2-parent (\%) & 88.39 & 87.33 & 89.46 \\
\hline Origin, two Dutch parents (\%) & 84.60 & 84.38 & 84.63 \\
\hline Mother's occupational status, full- or part-time job (\%) & 51.80 & 52.52 & 51.06 \\
\hline Father's occupational status, full- or part-time job (\%) & 77.04 & 76.74 & 77.35 \\
\hline Pocket money < 6.8 Euro $(\%)$ & 90.77 & 94.48 & 88.00 \\
\hline Lifetime smoking (\%) & 35.41 & 30.68 & 40.25 \\
\hline Smoking in the past month (\%) & 7.70 & 7.05 & 8.37 \\
\hline Disadvantages: 11 (neg) - 55 (pos) & 36.22 & 36.70 & 35.72 \\
\hline Advantages: 5 (pos) - 25 (neg) & 10.55 & 10.39 & 10.71 \\
\hline Social acceptability: -9 (neg) -9 (pos) & 0.28 & 0.14 & 0.42 \\
\hline Long-term consequences: -6 (neg) -6 (pos) & 2.59 & 2.62 & 2.55 \\
\hline Modeling 'nuclear': -8 (neg) -0 (pos) & -2.33 & -2.33 & -2.31 \\
\hline - Mother smoking: -2 (neg) - 0 (pos) & -0.79 & -0.80 & -0.79 \\
\hline - Father smoking: -2 (neg) -0 (pos) & -0.84 & -0.85 & -0.83 \\
\hline - Brother/sister smoking: -2 (neg) -0 (pos) & -0.39 & -0.39 & -0.40 \\
\hline - Best friend smoking: -2 (neg) -0 (pos) & -0.30 & -0.30 & -0.30 \\
\hline Modeling 'diffuse': -16 (neg) - 0 (pos) & -5.03 & -5.03 & -5.02 \\
\hline - Friends smoking: -4 (neg) -0 (pos) & -0.96 & -0.95 & -0.96 \\
\hline - Peers smoking: -4 (neg) -0 (pos) & -1.03 & -1.04 & -1.03 \\
\hline - Relatives smoking: -4 (neg) -0 (pos) & -1.81 & -1.80 & -1.83 \\
\hline - Teacher smoking: -4 (neg) -0 (pos) & -1.22 & -1.24 & -1.21 \\
\hline Social norms: -18 (neg) -18 (pos) & 10.14 & 10.23 & 10.04 \\
\hline Pressure: -50 (neg) - 0 (pos) & -2.41 & -2.15 & -2.69 \\
\hline Self-efficacy: -18 (neg) - 18 (pos) & 9.39 & 9.30 & 9.47 \\
\hline
\end{tabular}

Note, 'Neg' means negative towards non-smoking, 'pos' means positive towards non-smoking 
Table 8.2 Smoking initiation and continuation for girls and boys from pretest to follow-up, nine months after pretest; percentages with $95 \%$ confidence intervals, schools as units of analysis, smoking percentages aggregated to the percentage of smokers per school.

\begin{tabular}{|c|c|c|c|c|c|}
\hline & & \multicolumn{2}{|r|}{ Pretest } & \multicolumn{2}{|c|}{ Follow-up } \\
\hline & & $\%$ & $95 \% \mathrm{Cl}$ & $\%$ & $95 \% \mathrm{Cl}$ \\
\hline \multicolumn{6}{|l|}{ GIRLS } \\
\hline $\begin{array}{l}\text { Total sample, } \\
\mathrm{N}_{\text {student }}=1633, \mathrm{~N}_{\text {school }}=135\end{array}$ & $\%$ ever smokers & 33.1 & 29.3-36.9 & 40.3 & $36.1-44.4$ \\
\hline $\begin{array}{l}\text { Pretest never smokers: } \\
\mathrm{N}_{\text {student }}=1126 \mathrm{~N}_{\text {school }}=133\end{array}$ & Initiation & & & 20.0 & $15.9-24.0$ \\
\hline $\begin{array}{l}\text { Pretest ever smokers: } \\
N_{\text {student }}=507, N_{\text {school }}=125\end{array}$ & Continuation & & & 18.6 & $13.6-23.7$ \\
\hline BOYs & & & & & \\
\hline $\begin{array}{l}\text { Total sample, } \\
\mathrm{N}_{\text {student }}=1576, \mathrm{~N}_{\text {school }}=135\end{array}$ & $\%$ ever smokers & 40.5 & $37.1-43.9$ & 46.2 & $42.7-49.7$ \\
\hline $\begin{array}{l}\text { Pretest never smokers: } \\
N_{\text {student }}=931, N_{\text {school }}=135\end{array}$ & Initiation & & & 20.0 & $16.4-23.6$ \\
\hline $\begin{array}{l}\text { Pretest ever smokers: } \\
N_{\text {student }}=645, \mathrm{Ns}_{\text {chool }}=135\end{array}$ & Continuation & & & 22.6 & $17.8-27.4$ \\
\hline
\end{tabular}

\section{Smoking initiation and continuation}

Table 8.2 presents smoking initiation at pretest, and smoking initiation and continuation at follow-up (nine months after the pretest) for girls and boys. The smoking percentages are based upon schools as the units of analysis, i.e. with smoking aggregated to the percentage of smokers per school. Considering the pretest samples, the percentage of ever-smoking boys was higher than for girls, both at pretest ( $40.5 \%$ vs $33.1 \%$ ) and at follow-up $(46.2 \%$ vs $40.3 \%)$. An equal percentage of girls and boys who had never smoked at pretest, namely $20 \%$, indicated at follow-up to have initiated smoking. More pretest ever-smoking boys than pretest ever-smoking girls indicated smoking continuation at follow-up $(22.6 \%$ vs. $18.6 \%)$.

\section{Predictors of smoking initiation}

Table 8.3 shows that neither in-school nor out-of-school interventions were effective anymore in the prevention of smoking initiation at follow-up (for more details see Ausems et al., submitted-a). Furthermore, table 8.3 shows that the percentage of smoking initiation increased with age. The presence during pretest of a smoking mother and smoking relatives like uncles and aunts also increased the risk for never smoking pupils to have smoked a cigarette at follow-up, nine months after pretest. 


\section{chapter 8}

Table 8.3 Predictors of smoking initiation $(1=y e s, 0=n o)$ at follow-up in the pretest never smoking sample: odds ratios (OR) with $95 \%$ confidence intervals $(95 \% \mathrm{CI})$

OR

$95 \% \mathrm{Cl}$

Never smokers, total (Nstudent $=2044$, Nschool=135)

In-school (1-yes, 0-no)

1.03

$0.78-1.35$

Out-of-school (1-yes, 0=no)

$0.70-1.23$

Age

$1.48 * * \cdot$

$1.17-1.86$

Self-efficacy: -18 (neg) -18 (pos)

$0.98^{*}$

$0.97-1.00$

Mother smoking: -2 (neg) -0 (pos)

$0.86^{*}$

$0.74-1.00$

Relatives smoking: -4 (neg) -0 (pos)

$0.84 * *$

0.75-0.95

Never smokers, female (Nstudent=1119, Nschool=133)

Origin, both parents Dutch, One/two parents non-Dutch=ref

$1.86^{*}$

$1.15-3.03$

Brother/sister smoking: -2 (neg)- 0 (pos)

$0.62 * * *$

$0.48-0.80$

Pressure: -50 (neg) -0 (pos)

1.00

$0.95-1.05$

\section{Never smokers, male (Nstudent=925, Nschool=135)}

Origin, both parents Dutch, One/two parents non-Dutch=ref

$0.46-1.34$

Brother/sister smoking: -2 (neg) -0 (pos)

Pressure: -50 (neg) - 0 (pos)

$0.95 * *$

$0.92-0.99$

Notes, Significance of predictors in the total never smoking sample is based upon the final regression model for the total pretest never smoking sample, including the relevant interactions with gender. Significance of predictors in the female and male never smoking samples is based upon the same final regression model, minus gender and its interactions with other predictors. 'Neg' means negative towards non-smoking, 'pos' means positive towards non-smoking. ${ }^{*} \mathrm{p}<0.05 ;{ }^{* *} \mathrm{p}<0.01 ;{ }^{* * *} \mathrm{p}<0.001$

At follow-up, interactions regarding smoking initiation were found between gender and parents' origin $(\mathrm{p}<0.05)$, between gender and smoking siblings $(\mathrm{p}<0.01)$, and between gender and pressure $(\mathrm{p}<0.1)$. The multilevel analyses conducted separately for girls and boys showed that pretest never smoking girls were less at risk of having started smoking nine months later if they had at least one or two parents of non-Dutch origin. A smoking sibling during the pretest assessment increased the risk for never smoking girls to have smoked at follow-up. Pretest never smoking boys were at higher risk of having started 
smoking nine months later if they perceived, at the time of the pretest assessment, more pressures to start smoking.

\section{Predictors of smoking continuation}

Table 8.4 shows that both the in-school and out-of-school interventions were ineffective in preventing smoking continuation. In addition, table 8.4 presents the results of multilevel analyses predicting smoking continuation among pretest ever smokers. Because no significant interactions with gender were found, the analyses on smoking continuation were performed for the total sample. Boys were at higher risk to continue smoking than girls. A smoking sibling and a smoking best friend during the pretest assessment increased the risk that ever-smoking pupils continued smoking nine months after the pretest. Finally, pupils with pretest smoking experiences and who perceived fewer disadvantages of smoking, and who perceived lower self-efficacy expectations towards non-smoking were at greater risk to continue smoking at follow-up.

Table 8.4 Predictors of smoking continuation (1-yes, 0 -no) at follow-up for the pretest ever smoking sample: odds ratios (OR) with $95 \%$ confidence intervals $(95 \% \mathrm{CI})$

\begin{tabular}{|c|c|c|}
\hline & OR & $95 \%$ CI \\
\hline \multicolumn{3}{|c|}{ Ever smokers, total (Nschool=133, Nstudent=1144, } \\
\hline In-school $(1=$ yes, $0=$ no $)$ & 0.90 & $0.61-1.33$ \\
\hline Out-of-school $(1=$ yes, $0=$ no $)$ & 0.81 & $0.54-1.17$ \\
\hline Age & 1.14 & $0.82 \cdot 1.58$ \\
\hline Gender (ref: male) & $0.68 * \bullet$ & $0.52-0.90$ \\
\hline Family composition (ref: single-parent) & 1.06 & $0.66-1.70$ \\
\hline Attitude 'cons': 11 (neg) - 55 (pos) & $0.97^{*}$ & $0.95-0.99$ \\
\hline Smoking brother/sister: -2 (neg) -0 (pos) & $0.67 \bullet \bullet \bullet$ & $0.54-0.82$ \\
\hline Smoking best friend: -2 (neg) -0 (pos) & $0.72 * \bullet$ & $0.57-0.90$ \\
\hline Smoking peers: -4 (neg) -0 (pos) & 0.89 & $0.77-1.04$ \\
\hline Self-efficacy: -18 (neg) -18 (pos) & $0.98 * \bullet$ & $0.96-0.99$ \\
\hline
\end{tabular}

Notes, Significance of predictors in the ever smoking sample is based upon the final regression model for the total pretest ever smoking sample. 'Neg' means negative towards non-smoking. 'pos' means positive towards non-smoking. " $p<0.05 ; * * p<0.01 ;{ }^{* * *} p<0.001$

The school intraclass correlation coefficient reflects the proportion of unexplained outcome variance accounted for by differences between the schools. As regards smoking initiation at follow-up, intraclass correlations were $2.8,1.5$ and $6.6 \%$ for the 
total, the female and the male samples, respectively. As regards smoking continuation, the intraclass correlation was $19.2 \%$.

\section{Discussion}

The rate of smoking initiation at follow-up was comparable for the girls and boys in our elementary school sample. Girls and boys shared a number of risk factors: age, smoking relatives (included a smoking mother) and self-efficacy expectations. This study confirms earlier findings, which suggested that the availability of cigarettes in the home and family members being users promote smoking initiation (Mayhew et al., 2000). Smoking may also be encouraged by internalisation of family norms, values or life-style (Engels, Knibbe, De Vries et al., 1999). At the same time, some gender-specific features were found. The risk of girls starting to smoke was lower for girls with at most one parent of non-Dutch origin than for girls with two Dutch parents, probably due to Islamic rules that do not allow women to smoke. The presence of smoking siblings increased the risk of smoking initiation nine months after pretest, but only for girls. This finding is consistent with those of other studies (Conrad et al., 1992; US Department of Health and Human Services, 1994; Van Roosmalen \& McDaniel, 1992), although the relation between sibling smoking and female smoking was not always confirmed there. Boys who perceived relatively more pressure towards smoking were more likely to start smoking at follow-up.

In general, in our sample of pretest ever smokers, elementary school boys were more at risk of continuing to smoke than girls. Despite the difference in continuation rate, there were no significant gender differences in the prediction of smoking continuation. The presence of smoking siblings was highly predictive of smoking continuation among these elementary school children. Besides, the presence of smoking best friends, lower perceptions of self-efficacy expectations with respect to the ability to refuse cigarettes, and lower perceptions of the disadvantages of smoking predicted smoking continuation nine months after the pretest assessment. Parental influences were no longer noticeable.

Leventhal and Clearly (1980) already mentioned the 'unreasoned' aspects of smoking initiation. The lack of attitudinal predictors of smoking initiation found in the present study supports this view. Elementary school children appear to encounter smoking haphazardly and smoking people in the child's environment seem to trigger this initiation without interference of attitudinal reasoning. With respect to smoking continuation, it seems that some level of reasoning is involved before the decision whether to continue smoking or not is made. However, advanced statistical analyses like Lisrel analyses are recommended to confirm these findings.

This study has limitations. No validation of self-reported smoking behavior was used in this study, because objective measurements among 11-12 year-olds are unreliable. These measurements can only detect very recent smoking, while most smokers in our selected age group were still experimenting with smoking. Furthermore, self-reports have been demonstrated to be accurate provided confidentiality is assured and an identification coding system is used (Akers et al., 1983; Botvin \& Botvin, 1992; Murray \& Perry, 1987; US Department of Health and Human Services, 1994), precautions that were indeed taken in the present study. 
The findings of this study have some implications for smoking prevention in elementary school settings. Firstly, self-efficacy with regard to the ability to refuse cigarettes should be given a prominent place in prevention programs, since low efficacy expectations predicted smoking initiation as well as continuation in girls and boys. Furthermore, high self-efficacy expectations can be protective since smoking mothers and relatives also seem to influence elementary schoolchildren to start smoking. Secondly, although developing a negative opinion about smoking may not seem to influence smoking initiation, it seems to be protective with regard to smoking continuation. Therefore, information about negative consequences of smoking should continue to be emphasized in smoking prevention programs. Thirdly, developing separate prevention programs for girls and boys seems unnecessary during the elementary school period, because any interactions of gender with other predictors are mainly grounded in environmental risk factors, like siblings' smoking behavior. A social influence approach seems adequate, since the main goal of this approach is to equip younger adolescents with specific skills and other resources that would help them to resist direct and indirect social influences to try cigarettes (US Department of Health and Human Services, 1994). Fourthly, it seems useful to incorporate smoke prevention efforts at elementary schools in comprehensive programs aimed at the entire family, in view of the strong influence of environmental risk factors like smoking mothers, siblings and relatives. More research on such programs is required. 

General discussion 


\section{Introduction}

This thesis deals with the evaluation of smoking prevention aimed at highest-grade elementary school students and first-grade Dutch vocational school students. The study initially started as part of a European smoking prevention project, in which the United Kingdom, Spain and the Netherlands participated. Different smoking prevention approaches were evaluated, including an in-school approach, an out-of-school approach and a combined in-school and out-of-school approach. The Dutch part of the study has paid attention to the contribution of computer tailoring, which was specially developed for and applied in the out-of-school approach, and to the contribution of booster sessions. It also examined the determinants of smoking initiation and continuation among highest-grade Dutch primary school students. This final chapter summarizes and integrates the Dutch results of the reported studies and discusses the contribution of the results to the field of smoking prevention among Dutch adolescents. In addition, it discusses the methodological strengths and limitations of the studies. The chapter ends with implications for further research and practice.

\section{Smoking prevention programs for elementary school students}

\section{The content of the smoking prevention programs for elementary schools}

The in-school program was an existing seven-lesson, social influence based school program that had not been evaluated before. It focused on short-term consequences, social norms and self-efficacy expectations. The out-of-school program made use of computer tailoring, and represented the first time that tailored messages were employed in prevention efforts among elementary school students. Students who participated in this out-of-school program received three tailored letters at their home addresses, consisting of individualized smoking prevention messages, which were also based on the social influence approach. Students participating in the combined in-school and outof-school approach received both programs.

The tailored out-of-school intervention for elementary school students was supplemented with three booster sessions. Like the out-of-school program, the boosters consisted of three tailored letters, although the booster letters had a higher level of individualization. Instead of dealing with, for instance, general attitudes (e.g. smoking is bad) or general social influences (e.g. influences deriving from an environment with many smokers) in the tailored letters, the booster letters dealt with specific beliefs (e.g. when I smoke, I will feel tough) and specific social influences (e.g. influences from smoking parents).

\section{Program results}

\section{Short-term results}

Chapter 2 outlines the effectiveness, six months after pretest, of the in-school, the outof-school, and the combined in-school and out-of-school smoking prevention programs that were implemented among elementary school students. The tailored out-of-school 
program resulted in positive short-term effects. It was found that $13 \%$ of the pretest ever smokers who had received the tailored letters continued to smoke, compared with $23 \%$ of the pretest ever smokers who had not received the tailored letters. Ten percent of the never smoking students who received the tailored letters initiated smoking. compared with $18 \%$ pretest never smokers who did not receive tailored letters. This eight percent difference was borderline significant. No significant effects were found for the in-school program, nor did the combined approach show stronger effects than the sum of the single-method approaches.

Process evaluation results of both the in-school and out-of-school programs indicated that implementation had not been optimal, and that the attractiveness of the tailored letters in terms of content and appearance could be improved.

\section{Follow-up results}

Chapter 3 reports on follow-up results, nine months after pretest, of the in-school, outof-school, and combined in-school and out-of-school smoking prevention programs that were implemented among elementary school students. The positive behavioral results of the out-of-school program at six months were no longer found nine months after pretest. The in-school program was still ineffective, and the combined approach did not result in additional effects either. Besides behavioral outcomes, chapter 3 also considers mediating outcomes. It was found that, irrespective of the prevention program, pretest ever as well as pretest never smoking students perceived more disadvantages of smoking after participating in the program. In addition, the tailored out-of-school program led to increased self-efficacy expectations about refusing cigarettes among pretest never smokers.

\section{Long-term results}

The study reported in chapter 4 assessed long-term behavioral results $(20,30$ and 36 months after the pretest) of the in-school, out-of-school, and combined smoking prevention programs that were implemented among elementary school students. Since the trial was confronted with considerable levels of dropout, the original random treatment allocation may have been violated (Hollis \& Campbell, 1999). Different strategies for handling missing data (complete-case, extreme-case, and carried-forward analyses) resulted in very similar conclusions for the complete-case and carried-forward analyses, showing that long-term effects were found for neither the in-school, nor the out-of-school, nor the combined in-school and out-of-school programs. The extremecase strategy resulted in very high, if not too high, estimations of smoking initiation and continuation percentages.

\section{Results of tailored boosters}

Chapter 5 describes the additional effects of tailored boosters, implemented 24 months after the above tailored out-of-school intervention. Like the long-term evaluation described above, this trial faced serious dropout. Therefore three analysis strategies, each dealing differently with missing data (complete-case, extreme-case, and carriedforward analyses) were applied to evaluate the booster effects. The effects of the boosters were encouraging. Thirty-six months after the pretest, students exposed to the tailored out-of-school program who had also received the booster letters were, according to the complete-case and carried-forward analyses, significantly less likely to have initiated smoking, compared with students who were engaged in the tailored out- 
of-school program but who did not receive booster letters (30\% vs $42 \%$ in the completecase analysis). A similar effect was found for smoking continuation (47\% vs $26 \%$ in the complete-case analyses), although this effect was only detected in the complete-case analysis, not in the carried-forward or extreme-case analyses. The extreme-case strategy resulted in high, and probably too high, estimations of smoking initiation and continuation percentages.

Process evaluation confirmed that the further fine-tuning of the messages in the boosters had indeed resulted in a higher degree of individualization than the earlier tailored letters. The process evaluation also showed that the appearance and content of the boosters could be further improved.

\section{Overall evaluation of elementary school smoking prevention}

In-school versus tailored out-of-school approach

Although the in-school and out-of-school programs were based on similar social influence principles, the in-school program did not result in positive effects, whereas the out-of-school program provided positive short-term results. Three explanations might be suggested for this out-of-school effect:

- The tailored letters that were used in the out-of-school program contained information that was fine-tuned to individual students' attitudes, social influences, self-efficacy expectations and intentions concerning smoking. This fine-tuning mav have resulted in a more direct personal approach. This finding is in line with the suggestion by Azjen and Fishbein that if proper individually based instructions are included in educational sessions, a greater level of success may be expected (Ajzen, 1985; Ajzen \& Fishbein, 1980).

- The out-of-school aspect of the tailored letters, implying that students received the letters at their home addresses, may have resulted in increased involvement with the messages and, as a consequence, a stronger attitude-behavior relationship (Petty \& Caccioppo, 1986).

- The tailored out-of-school program may have stimulated parental involvement, as the process evaluation indicated that some of the parents were allowed to read the letters. This parental involvement may have stimulated discussions at home about smoking or not smoking. At the age of 11-12 years, parental influence is still more dominant than among older children, where peers are more influential (Chassin, Presson, Montello, Sherman, \& McGrew, 1986; US Department of Health and Human Services, 1994).

\section{Combined approach}

The combined in-school and out-of-school program did not result in extra intervention effects in the elementary school population. One explanation may be that merely increasing the amount of information and time spent on prevention does not increase prevention effects. While earlier studies have suggested that tobacco use prevention programs for high-risk youths should use a variety of intervention approaches, rather than depending on any one approach (Glynn, 1993; Glynn et al., 1991; US Department of Health and Human Services, 2000), the combination of our in-school and out-ofschool programs did not result in additional effects. It must be remembered, however, that the in-school approach alone did not result in any significant effects, making an additional effect of the combined approach unlikely. 


\section{Boosters}

As discussed above, the single tailored out-of-school program delayed smoking in the short term among elementary school students, but these protective influences were no longer found in the longer term. Such long-term dissipation of effects has also been observed by other researchers (Best et al., 1988; Donaldson et al., 1994; Flay, 1985; Lantz et al., 2000; NHS, 1999; US Department of Health and Human Services, 1994, 2000). It has been suggested that dissipation of effects might be attributable to the lack of boosters (Elder, Wildey et al., 1993; Lantz et al., 2000; Murray et al., 1989). The study outlined in chapter 5 confirmed this suggestion, finding positive results of boosters. Our positive booster results matched the results of previous studies, which tested different kinds of booster and demonstrated that providing students with ongoing information in the form of booster interventions can maintain and even enhance initial smoking prevention effects (Botvin et al., 1995; M. Dijkstra et al., 1999; Rooney \& Murray, 1996; White \& Pitts, 1998).

\section{Smoking prevention programs for vocational school students}

\section{The content of the vocational school smoking prevention programs}

An existing in-school program based on social influence (three lessons on tobacco use) and a newly developed computer-based out-of-school program (three tailored letters with smoking prevention messages mailed to students' homes) were implemented among first-grade vocational school students, together with a combined approach in which students were exposed to both programs.

\section{Program results}

Chapter 6 summarizes the results of the smoking prevention intervention for vocational schools. The in-school program showed positive results 12 months after pretest: $29 \%$ of the pretest ever smoking students participating in the in-school program continued to smoke, compared with $42 \%$ of the pretest ever smokers in the control condition. The out-of-school program was successful 18 months after pretest, in that $27 \%$ of the pretest never smokers who had received the tailored letters initiated smoking compared with $48 \%$ of the never smokers in the control condition.

Process evaluation results showed that exposure to the letters was rather disappointing. A significant percentage of students (35\%) indicated not to have received them, partly due to incorrectly registered addresses.

\section{Overall evaluation of vocational school smoking prevention}

\section{In-school versus tailored out-of-school approach}

The in-school program was effective in the prevention of smoking continuation among pretest ever smoking vocational school students, while the tailored out-of-school program was effective in the prevention of smoking initiation among pretest never smoking vocational school students.

The in-school program implemented in this study was an existing program, which had been favorably evaluated before (ResCon, 1999). Hence, the present study can be 
regarded as a confirmation of the earlier ResCon program evaluation. Apart from our intervention, there have been no other smoking prevention programs among Dutch vocational school students using a tailored approach. Comparisons with existing tailoring initiatives in other countries in the field of smoking prevention for vocational students can hardly be made, apart from two international smoking prevention studies targeting secondary school students, based on the Transtheoretical Model (TTM) (Prochaska \& DiClemente, 1983). Briefly, the TTM suggests that behavior can change via an series of motivational stages, implying that participants in smoking prevention programs need tailored information depending on the stage in which they are situated. Pallonen and colleagues (1998) implemented a computer-based smoking prevention and cessation intervention in a vocational school sample (mean age 16.5 years), but unfortunately their sample was too small to test the efficacy of the staged intervention. Aveyard and colleagues (2001) used an expert system computer program, also allowing personal fine-tuning, in a larger sample of 13-to 14-year-old British schoolchildren, and reported follow-up findings up to two years. They found no evidence of the effectiveness of fine-tuned smoking prevention. Aveyard and his colleagues argued that the unreliable measurement of TTM stages might have led to inappropriate stagematched interventions. In other words, the algorithm used in their study might not properly represent either the behavioral or the cognitive stages of smoking acquisition (Aveyard, Lancashire, Almond, \& Cheng, 2002). In our tailored out-of-school intervention, the smoking prevention messages were not linked to behavioral stages, but to the cognitions derived from the ASE model (De Vries, Dijkstra, \& Kuhlman, 1988; De Vries \& Mudde, 1998). Respondents received feedback based on scale scores relating to ASE determinants that had been collected by written questionnaires. Ignoring behavioral stages and focusing on cognitions may have prevented inappropriately stagematched tailoring. Another possible explanation of the effects of our tailored letters relates to the importance of the out-of-school setting. Pallonen and Aveyard both implemented their interventions in a school setting, using computer sessions that were part of the school lessons. If students harbored any negative feelings about school, this setting may have reduced their motivation to process the program information. In our study, students were allowed to read the letters that were sent to their homes of their own free will, at any time and any place, and the relation with school was less obvious, which may have increased students' attention and motivation.

\section{Combined approach}

The effects of the combined approach did not exceed the sum of the effects of the single in-school and single out-of-school programs. Apparently, comprehensiveness does not mean doing everything at the same time (Bell et al., 1999). Simultaneous application of interventions may cause an overload of information, which might even produce the opposite effect.

\section{Factors associated with smoking initiation and continuation among elementary school students}

At the start of the project, our understanding of the reasons for elementary smoking initiation and continuation was limited. The few existing smoking prevention programs for elementary school students had been primarily developed as a blueprint of secondary 
school programs. Furthermore, it was unclear whether smoking prevention programs for elementary school students should pay attention to the distinction between initiation and continuation, or whether girls and boys should be treated separately. In order to increase our understanding of the reasons for smoking, we conducted a cross-sectional study (described in chapter 7) to examine differences between never smokers, experimental smokers and regular smokers. The effect studies outlined in chapters 2, 3, and 4 provided longitudinal data sets, which supplied us with additional information about longitudinal predictors of smoking initiation and continuation. Finally, chapter 8 discusses longitudinal predictors of smoking initiation and continuation, taking into account the differences between girls and boys in the elementary school setting.

\section{Cross-sectional findings}

Chapter 7 discusses three categories of highest-grade elementary school students in terms of smoking behavior: never smokers, experimental smokers, and regular smokers. Never smokers, representing $64 \%$ of the total sample, were those students who had never smoked, not even one cigarette or a puff. Experimental smokers, $28 \%$ of the total sample, were those students who reported smoking initiation but not having smoked in the past four weeks, while regular smokers, $8 \%$ of the total sample, reported smoking initiation as well as having smoked in the past four weeks. These three smoking categories were compared in terms of demographic and psychosocial determinants, using the ASE model (De Vries, Dijkstra, \& Kuhlman, 1988; De Vries \& Mudde, 1998).

As regards demographic determinants, never smokers discriminated from experimental smokers in that they were younger, more often female, more often religious and more often from two-parent families. Experimental smokers received less pocket money than regular smokers.

As regards psychosocial determinants, never smokers had the most positive perception of the ASE determinants for nonsmoking, while regular smokers had the most negative perceptions. Perceptions of experimental smokers were generally between those of the never and those of the regular smokers. Exceptions to this generalization were that, compared with experimental and regular smokers, never smokers perceived more long-term physical drawbacks of smoking and perceived less smoking among parents, siblings and best friends. Furthermore, never and experimental smokers perceived fewer advantages of smoking and encountered less smoking among friends, peers, family, or teachers than regular smokers. Finally, all students had low scores on the items relating to perceived physical consequences and risk perception regarding addiction, aspects which may have been too complex, too abstract, or too long-term.

The findings of this study were based on cross-sectional data, and although they gave further insights into the determinants of smoking among elementary school students, we are only able to evaluate the relations in terms of associations and not in terms of causation.

\section{Longitudinal findings}

Chapters 2, 3, and 4 provide information on longitudinal prediction of smoking. Before discussing the outcomes, we want to outline two methodological issues of our longitudinal design. 
Firstly, more than two-thirds of the research sample was lost during the assessment period (from September 1997 to September 2000). Attrition analyses demonstrated that dropouts differed in some respects from those who remained in the study. In general, boys and pretest smokers were more likely to have dropped out during the last three assessments. Since high levels of attrition may compromise predictive relationships, the outcomes of the analyses may have been subject to this bias, and the interpretation of the results should take this problem into account.

Secondly, in order to obtain a detailed overview of psychosocial factors associated with smoking, intention was not included in the analyses of the study described in chapter 7. According to the ASE model, behavior can primarily be explained by behavioral intention, which is a summary of influences by psychosocial ASE determinants (i.e., attitudes, social influences and self-efficacy expectations). Analyses were performed in a stepwise manner, including demographic and ASE variables in successive steps. Including intention in the analyses would cause part of the explained variance to be absorbed by intention, leading to underestimation of the ASE determinants. The studies described in chapters 2,3 , and 4 also used stepwise analyses including, successively, demographic and ASE variables, and adding intention in the last step. The main purpose of these studies, however, was to test program effects using final models that include important covariates, which was supposed to increase the power of the models. Testing predictors of smoking was a secondary goal. These different approaches complicate comparisons between the cross-sectional and longitudinal studies.

Tables 9.1 and 9.2 provide an overview of the predictive determinants measured at the pretest, derived from studies that were described in chapters 2,3, and 4 . Table 9.1 shows that, in terms of smoking initiation among pretest never smokers, older students were more at risk, but this finding only refers to initiation in the short term. Smoking initiation seemed to be predicted by smokers in the immediate environment ('modeling nuclear') during pretest and the pretest intention to smoke. Attitudinal predictors were not found (and are not included in table 9.1), either before or after entering intention into the regression analyses.

Table 9.2 shows that smoking continuation among pretest ever smokers was predicted by low pretest perceptions of the short-term disadvantages of smoking and by 'modeling nuclear' (i.e., people smoking in their immediate social environment), although the latter was only predictive for posttests 2 and 3 . 


\section{discussion}

Table 9.1 Prediction of smoking initiation by pretest variables among pretest never smokers

\begin{tabular}{|c|c|c|c|c|c|}
\hline Smoking Initiation & Posttest 1 & Posttest 2 & Posttest 3 & Posttest 4 & Posttest 5 \\
\hline & Feb 1998 & June 1998 & May 1999 & Feb 2000 & Sept 2000 \\
\hline Gender & & • & & & \\
\hline Age & $\cdots$ & $\bullet$ & • & & \\
\hline Disadvantages, long-term & & & & & - \\
\hline Modeling, nuclear & & $\cdots$ & $\bullet$ & $\cdots$ & $\bullet \bullet$ \\
\hline Modeling, diffuse & & • & & & \\
\hline Pressure & $\bullet$ & & & & • \\
\hline Self-efficacy & & & & • & $\bullet$ \\
\hline Intention & $\cdots$ & $\cdots$ & • & $\bullet \bullet$ & \\
\hline
\end{tabular}

Note, ${ }^{*} \mathrm{p}<.05,{ }^{* *} \mathrm{p}<.01,{ }^{* *} \mathrm{p}<.001$

Table 9.2 Prediction of smoking continuation by pretest variables among pretest ever smokers

\begin{tabular}{|c|c|c|c|c|c|}
\hline \multirow{2}{*}{ Smoking Continuation } & Posttest 1 & Posttest 2 & Posttest 3 & Posttest 4 & Posttest 5 \\
\hline & Feb 1998 & June 1998 & May 1999 & Feb 2000 & Sept 2000 \\
\hline Gender & & & & $\bullet$ & - \\
\hline Age & & - & • & $\bullet$ & \\
\hline Disadvantages, short-term & & $\bullet$ & $\bullet$ & - & $\bullet$ \\
\hline Advantages & - & & & & \\
\hline Modeling, nuclear & & $\cdots$ & $\cdots$ & - & \\
\hline Pressure & & & & - & $\cdots$ \\
\hline Self-efficacy & & - & - & - & \\
\hline Intention & & - & & & \\
\hline
\end{tabular}

Note, ${ }^{*} \mathrm{p}<.05, * * \mathrm{p}<.01,{ }^{* * *} \mathrm{p}<.001$ 


\section{Differences in smoking determinants between girls and boys}

Since recent research has found a higher rate of smoking initiation among female adolescents in many developed countries (De Vries et al., accepted for publication; US Department of Health and Human Services, 1994, 2000), reasons for smoking need further examination, especially among girls (Soldz \& Cui, 2001). Such research might indicate whether gender-specific smoking prevention messages and/or programs are needed. The study described in chapter 8 assessed longitudinal determinants of smoking initiation and continuation among Dutch highest-grade elementary schoolgirls and boys, nine months after pretest (June 1998).

In our elementary school sample, the rate of smoking initiation at follow-up was equal for pretest never smoking girls and boys. Girls and boys shared the following risk factors for smoking initiation: increasing age, maternal smoking, smoking relatives and lower self-efficacy expectations. Gender-specific features in smoking initiation were having parents of Dutch origin (predictive only for girls), smoking siblings (predictive only for girls) and high perceived pressure (predictive only for boys). Within the group of pretest ever smokers, Dutch elementary schoolboys were generally more at risk of continuing to smoke than girls, but no predictive gender differences were found. More smoking siblings and best friends, less perception of disadvantages of smoking and lower self-efficacy expectations predicted smoking continuation in both girls and boys.

\section{Overall evaluation of smoking determinants among elementary school students}

Comparing the findings of our cross-sectional and longitudinal studies of smoking determinants reveals some differences. In going from cross-sectional associations to longitudinal predictors, several significant associations declined or disappeared, which is not an isolated finding. Strong associations between cognitions and behavior might reflect the effects of behavior on cognitions and vice versa (Engels, Knibbe, \& Drop, 1999). Furthermore, the lower predictability of longitudinal smoking might be explained by the long intervals between the successive assessments (De Vries et al., 1995; Engels, Knibbe \& Drop., 1999). After all, initiation of smoking mostly takes place during adolescence, which is characterized by a quick succession of personal and social changes.

Behavioral intention appeared to be a relatively strong predictor of smoking initiation (table 9.1), but the positive intention towards smoking did not appear to be based on cognitive reasoning, since no significant attitudinal predictors were found. This might explain why youngsters, in spite of their negative intention towards smoking, still start to smoke, easily putting aside their negative intention towards smoking.

Pretest perceptions of short-term consequences of smoking hardly protected against future smoking initiation, but according to table 9.2 they did protect to some extent against future smoking continuation. According to the Mode Model (Fazio \& TowlesSchwen, 1999), which distinguishes between spontaneous and deliberate attitudebehavior processes, smoking initiation might be a spontaneous reaction to the 
perception of an immediate situation, like being offered a cigarette, which might for instance be unconsciously affected by the number of smokers in one's immediate environment. In contrast, the decision to continue smoking might be the result of a more deliberate attitude-to-behavior process based on more effortful reasoning on the available knowledge about short-term physical consequences of smoking (chapters 2,3), a process that can be identified in table 9.2.

A similar line of reasoning underlies the inverse attitude-behavior relationship that occurs in low involvement conditions, according to Chaffee and Roser (1986). It is conceivable that elementary school students who have never smoked, and are mostly uninvolved with smoking behavior, might suddenly find themselves in a smoking situation and will try a cigarette without using much rational consideration, while their attitudes about smoking are not formed until after the smoking has occurred. It looks as if never and experimental smoking categories based on behavioral grounds do not correspond with never and experimental smoking categories based on motivational criteria. Recently, a Dutch study proposed a framework integrating motivational and behavioral stages, the Model of Unmotivated Smoking Initiation of Children and Adolescents (MUSICA) (Kremers, 2002). MUSICA showed that the first behavioral stages of initiation occur in an unmotivated state with regard to future smoking behavior: the unmotivated cycle. On the other hand, committed never smokers are unlikely to display smoking initiation. According to MUSICA, it is these unmotivated youngsters who are more likely to try cigarettes and experiment with them without having concrete plans to start smoking in the future.

As regards the social influences towards smoking, both cross-sectional (chapter 7) and longitudinal (chapters $3,4,8$ ) results confirm the strong influence of smokers in the students' immediate environment. Smoking siblings appear to be a strong predictor of smoking initiation among girls, and of smoking continuation for both girls and boys (chapter 8). The influence of smoking parents was confirmed in our cross-sectional study (chapter 7), but only the mother's smoking predicted smoking initiation in our longitudinal study (chapter 8). Engels, Knibbe \& Drop (1999) and Epstein and colleagues (1999) found similar maternal influence. According to Flay (1998), parental smoking can also be a strong predictor of the transition from experimental to regular smoking. The study reported in chapter 8 does not support Flay's finding. However, the special circumstances of our study population, who were in the period before school transition, may have caused feelings of maturity among the schoolchildren, which made them turn away from parental influence and towards the influence of their best friends' smoking behavior. In their review of psychosocial factors related to adolescent smoking, Tyas and Peterson (1998) also reported that the inconsistency in the reported influence of parental smoking on adolescent smoking may reflect whether peer smoking was also examined, as the effect of parental smoking may become nonsignificant after controlling for peer-smoking.

Best friends' smoking behavior was highly (cross-sectionally) associated with smoking initiation and continuation (chapter 7). Best friends' smoking behavior also appeared to be an important predictor of smoking continuation (chapter 8), though no longitudinal prediction of smoking initiation was found. These contrasting results may have been caused by a well-established principle called false consensus effect or projection, which is based on a distorted perception of peer smoking (Bauman \& Ennett, 1996; Engels, Knibbe \& Drop, 1999). Smoking adolescents tend to overestimate the 
smoking behavior of their friends and peers. When projection occurs, the behavior considered to be the friends' is the consequence rather than the cause of the adolescent's behavior. Another explanation for the lack of longitudinal prediction of smoking initiation by best friends' smoking behavior might be offered by the selection paradigm, which implies that adolescents decide to take up smoking and then choose like-minded friends (Cohen, Richardson, \& LaBree, 1994; De Vries, 1999; Ennett \& Bauman, 1994; Kandel, 1978). Adolescents' self-efficacy expectations about their abilities to resist cigarettes appeared to be associated with smoking initiation and continuation in the cross-sectional study (chapter 7), but in the longitudinal studies, self-efficacy expectations hardly predicted smoking initiation or continuation (chapters 2,3 , and 4 ).

\section{Methodological issues}

The studies reported on in this thesis had some limitations:

- Time and funding restrictions made it impossible to perform determinant studies prior to the development and evaluation of the effect studies that were carried out for the European project. In other words, the development of the out-of-school programs was based on empirical findings from the literature and on results of pilot testing. The messages in the tailored out-of-school programs were fine-tuned on determinants that were already known from the literature, but since determinants for elementary school students were not yet available, this implies that the fine-tuning of the elementary outof-school program was mainly performed on hypothetical grounds.

- The validity of self-reports on smoking could not be objectively checked. Objective validation was impossible for this young age group, because the available methods only detect very recent -at most weekly - smoking, and smoking family members induce elevated readings (Murray et al., 1987; Sussman et al., 1995). An option to increase the validity of self-reports is to assure confidentiality and to use an identification coding system (Akers et al., 1983; Botvin \& Botvin, 1992; Murray \& Perry, 1987; US Department of Health and Human Services, 1994). This procedure was used in our study. The front pages of both the pretest and posttest questionnaires provided information about confidentiality. An identification code was used in the data file and the researchers replaced students' names before data entry.

- During the study period, a large percentage of the elementary school sample was lost as students transferred to secondary education. In the studies on long-term and booster effects, most attrition was found after the renewal of the participation request. The separate grant was submitted and received in order to test long-term effects of the outof-school program and the impact of booster sessions. In the original informed consent, children had agreed to participate in the four-year European study. For the second study, we asked the students again whether they would like to participate. Fifty percent of the initial study population refused further participation in this project. In order to control for the substantial dropout, we used not only complete-case analyses but also intention-to-treat analyses. Complete-case analyses assume that dropouts do not differ from complete cases that have the same treatment, pretest smoking status, and covariate values, in terms of their smoking status at follow-up. Since we could not ascertain whether this assumption was correct, we also performed intention-to-treat 
analyses (extreme-case and last-observation-carried-forward analyses) by including all students who had originally been randomized to the treatments. Extreme-case analyses assume that all dropouts had initiated or continued smoking, whereas the lastobservation-carried-forward analysis assume that all dropouts had maintained their last observed smoking status. The use of these different methods might clarify the process of drawing final conclusions. However, in view of the results of the long-term and tailored booster evaluation, that is the quite similar conclusions of the complete-case and the carried-forward analyses versus the very high estimations of smoking in the extreme-case analyses, it seems inappropriate to use extreme-case strategies in adolescent smoking prevention research.

- Exposure to the tailored out-of-school intervention was reduced because the respondents did not always receive the letters. This was especially the case in the vocational school sample. It seems reasonable that the out-of-school effects were influenced by this lower exposure.

- The project applied boosters to the tailored out-of-school program for elementary school students, but not in the single in-school program. Therefore, we are not able to assess the effectiveness of boosters added to an in-school program.

- Results of an international smoking prevention study that included young people (mean age 13 years) from six European countries were recently reported (Kremers, De Vries, Mudde, \& Candel, in press). The study focused on the stage of never smoking, and identified three subgroups of never smokers, based on their susceptibility to smoking: committers (those who are sure to never start smoking), immotives (those not planning to start within the next five years), and progressives (those planning to start within the next five years, but not within the next six months). It appeared that these subgroups differed in terms of their cognitive motives. Recognition of three different groups with distinguishable cognitive profiles may improve the effectiveness of computer tailored approaches. However, since the predictive power of the cognitive motives for smoking initiation in our study was low, and we did not find many differences between predictors of initiation and continuation among our elementary school students, it is not certain that this improved fine-tuning might indeed lead to less smoking initiation or continuation in our young study population.

\section{Considerations for the future}

\section{Smoking prevention among elementary school students}

- The study described in chapter 7 suggests that the highest-grade elementary school population can be categorized into three types with regard to smoking (neverexperimental-regular). It is therefore recommended that smoking prevention aimed at elementary school acknowledges these different types. Hence, never smokers should not be the only important educational target group, but experimental and regular smokers also need attention. When targeting experimental and regular smokers, special attention should be paid to disadvantages, long-term physical consequences, social norms and pressures. In addition, it is important to increase the self-efficacy expectations of experimental and regular smokers. 
- The findings reported in chapter 7 indicate that smoking initiation and continuation were associated with different factors. By contrast, the studies described in chapters 2 , 3,4 and 8 showed that the predictors of smoking initiation and continuation were rather similar, but this may have been due to the fact that we did not measure the beliefs with regard to these separate behaviors. Hence, it appeared redundant to make a clear distinction between predictors of smoking initiation and continuation when developing smoking prevention programs for elementary school students.

- The strong parental, sibling and best friend influences on smoking initiation suggest that there should be more comprehensive family-directed programs, discussing the role models of smoking parents and siblings. Special attention could be paid to the amount of pocket money given to youngsters, as this was directly related to regular smoking.

- Developing gender-specific smoking prevention programs for elementary school students may not be necessary (chapter 8 ), because our study showed that gender differences were only found with respect to environmental conditions like the number of smokers in the youngsters' environment and perceived pressures. It is recommended to pay attention to declining self-efficacy, a variable that is associated with perceived pressures.

- Because of the short-term promising effects of the tailored out-of-school intervention (chapter 2), it is recommended to further explore the possibilities of tailored smoking prevention for elementary school children. Our research, for instance, showed that tailoring effects might be improved by further refining the attractiveness of the letters in terms of content and appearance. Besides, it seems usefull to include booster sessions in tailored smoking prevention programs for elementary school students, because our study showed that adding booster sessions might continue the positive short-term effects of tailored out-of-school programs (chapter 5).

- It also seemed to be more effective to 'booster' smoking prevention information instead of increasing the amount of information offered in a relatively short period, since our research showed that a combined in-school and out-of-school approach was no more effective than the single approaches.

\section{Smoking prevention for vocational school students}

- Our study showed that smoking prevention programs are useful to prevent smoking initiation and continuation among vocational school students (chapter 6). Different approaches resulted in different effects with respect to the various smoking categories. Simultaneous combination of approaches did not yield additional benefits. Hence, it is recommended to start smoking prevention for vocational school students with a tailored approach, in order to prevent smoking initiation, and subsequently continue it with in-school programs, in order to prevent smoking continuation.

- Our research indicated that the implementation of the tailored out-of-school program was marred by registration problems. These problems might be solved by modifying the tailored letter format into a digital tailored message format. The data input might be completed during health classes on a computer that might be connected to the Internet. The letters might subsequently be delivered by e-mail instead of the usual mail.

- In view of the positive booster results among elementary school students, vocational school program effects might also be improved by applying booster sessions. 
- By analogy with the elementary school intervention, vocational school program effects might be improved by further refining the attractiveness of the tailored letters in terms of content and appearance.

\section{Smoking prevention research}

- Our research showed that the prediction of smoking initiation and continuation among elementary school students was modest. In order to find out whether initiation is a spontaneous occurrence or can be predicted by other factors, a more refined set of proximal and distal factors is needed, as well as relatively short intervals between the studies to be able to detect rapid changes in cognitions and/or behaviors. One option is to study elementary school students in more detail in laboratory situations to detect whether behavioral changes at this age precede the development of cognitions or whether cognitions precede behavior.

- Another option to improve our knowledge of factors affecting smoking initiation is to use the three categories of never smoking based on susceptibility to smoking described in MUSICA (Kremers, 2002).

- Further research is needed to study how to maintain initial smoking prevention effects, since many studies have found this to be difficult. While our study revealed the impact of booster interventions, a strategy for the whole period of adolescence has not yet been explored students should or tested. It is conceivable that older adolescents may need different messages and methods.

- Since considerable numbers of youngsters do start and maintain smoking, research is needed to analyze how smoking cessation can be achieved among smoking youths, especially vocational school students.

- Research is needed to further identify how the framing of messages may impact on the efficacy of smoking prevention programs.

- Our research indicated that parents were involved in the out-of-school intervention, with some of the parents being allowed to read the letters, and we suggested that this parental involvement may have stimulated discussions at home about smoking or nonsmoking. More research is needed, firstly, to check whether such discussions really took place and, secondly, on ways how to stimulate this parental influence by smoking prevention programs. 



\section{References}

Ajzen, 1. (1985). From intentions to actions: A theory of planned behavior. In J. Kuhl \& J. Beckman (Eds.), Action control: From cognition to behavior. New York: Springer-Verlag.

Ajzen, 1. (1991). The theory of planned behavior. Organizational Behavior and Human Decision Processes, $50,179-211$.

Ajzen, I., \& Fishbein, M. (1980). Understanding attitudes and predicting social behavior. Englewood Cliffs, NJ: Prentice Hall.

Akers, R., Massey, J., Clarke, W., \& Lauer, R. (1983). Are self-reports of adolescent deviance valid? Biochemical measures, randomized response, and the bogus pipeline in smoking behavior. Social Forces, 62, 234-251.

American Psychiatric Association. (1987). Diagnostic and statistical mamual of mental disorders (3rd ed..). Washington, DC: American Psychiatric Association.

Andrews, J., \& Duncan, S. (1998). The effect of attitude on the development of adolescent cigarette use. Journal of Substance Abuse, 10, 1-7.

Ary, D. (1988). Longitudinal changes in adolescent cigarette smoking behavior: Onset and cessation. Journal of Behavioral Medicine, 14, 361-382.

Ary, D., Biglan, A., Glasgow, R., Zoref, L., Black, C., Ochs, L., Severson, H., Kelly, R., Weissman, W., Lichtenstein, E., Brozovsky, P., Wirt, R., \& James, L. (1990). The efficacy of social-influence prevention programs versus "standard care": Are new initiatives needed? Journal of Behavioral Medicine, 13, 281. 296.

Ausems, M., Mesters, I., van Breukelen, G., \& De Vries, H. (2002). Short-term effects of a randomized computer-based out-of-school smoking prevention trial aimed at elementary schoolchildren. Preventive Medicine, 34, 581-589.

Ausems, M., Mesters, 1., van Breukelen, G., \& De Vries, H. (2003). Do Dutch never, experimental and regular smoking youngsters, aged 11-12 years old, differ in their demographic backgrounds and perceptions of smoking? European Journal of Public Health, 13, 160-168.

Ausems, M., Mesters, I., van Breukelen, G., \& De Vries, H. (submitted-a). In-school and out-of-school smoking prevention aimed at Dutch elementary school children: Behavioral and mediating follow-up results of a randomized control trial.

Ausems, M., Mesters, I., van Breukelen, G., \& De Vries, H. (submitted-b). In-school and tailored out-ofschool smoking prevention: Long-term effects of a Dutch randomized-controlled trial using different strategies for handling missing data.

Aveyard, P., Lancashire, E., Almond, J., \& Cheng. K. (2002). Can the stages of change for smoking acquisition be measured reliably in adolescents? Preventive Medicine, 35, 407-414.

Aveyard, P., Sheratt, E., Almond, J., Lawrence, T., Lancashire, R., Griffin, C., \& Cheng, K. (2001). The change-in-stage and updated smoking status results from a cluster-randomized trial of smoking prevention and cessation using the Transtheoretical Model among British adolescents. Preventive Medicine, 33, 313-324.

Ball, K. (1990). Exporting death: Britain's malignant epidemic spreads to the developing world. British Journal of Addiction, 85, 313-314.

Bandura, A. (1977). Social Learning Theory. Englewood Cliffs, New York: Prentice Hall.

Bandura, A. (1986). Social foundations of thought and action: A social cognitive theory. Englewood Cliffs, New York: Prentice-Hall.

Bartholomew, L., Parcel, G., \& Kok, G. (1998). Intervention mapping: A proces for developing theory- and evidence-based health education programs. Health Education \& Behavior, 25, 545-563.

Bauman, K., \& Ennett, S. (1996). On the importance of peer influence for adolescent drug use: Commonly neglected considerations. Addiction, 91, 185-198.

Bell, B., Hilson, M., \& Chauvin, J. (1999). International consultation on tobacco and youth What in the world works? Singapore, September 28-30.

Bellamy, C. (1998). Tobacco undermines child rights, UNICEF says. Marketing world no-tobacco day, calls for concerted global action. New York.

Best, J., Thomson, S., Santi, S., Smith, E., \& Brown, K. (1988). Preventing cigarette smoking among school children. Anmual Review of Public Health, 9, 161-201.

Biglan, A., Ary, D., Smolkowski, K., Duncan, T., \& Black, C. (2000). A randomised controlled trial of a community intervention to prevent adolescent tobacco use. Tobacco Control, 9. 24-32. 


\section{references}

Biglan, A., Severson, H., Ary, D., Faller, C., Gallison, C., Thompson, R., Glasgow, R., \& Lichtenstein, E. (1987). Do smoking prevention programs really work? Attrition and the internal and external validity of an evaluation of a refusal skills training program. Journal of Behavioral Medicine, 10, 159-171.

Botvin, E., Botvin, G., \& Baker, E. (1983). Developmental changes in attitudes toward cigarette smokers during early adolescence. Psychological Reports, 53, 547-553.

Botvin, G. (1986). Substance abuse prevention research: Recent developments and future directions. Journal of School Health, 56, 369-374.

Botvin, G., Baker, E., Dusenbury, L., Botvin, E., \& Diaz, T. (1995). Long-term follow-up results of a randomized drug abuse prevention trial in a white middle-class population. Journal of the American Medical Association, 273, 1106-1112.

Botvin, G., Baker, E., Filazzola, A., \& Botvin, E. (1990). A cognitive-behavioral approach to substance abuse prevention: One-year follow-up. Addictive Behaviors, 15, 47-63.

Botvin, G., \& Botvin, E. (1992). Adolescent tobacco, alcohol, and drug abuse: Prevention strategies, empirical findings, and assessment issues. Journal of Developmental and Behavioral Pediatrics, 13, 290-301.

Brug, J., Campbell, M., \& Van Assema, P. (1999). The application and impact of computer-generated personalized nutrition education: A review of the literature. Patient Education and Counseling, 36, $145-$ 156.

Brug, J., Glanz, K., Van Assema, P., Kok, G., \& Van Breukelen, G. (1998). The impact of computer-tailored feedback and iterative feedback on fat, fruit, and vegetable intake. Health Education \& Behavior, 25, 517-531.

Brundtland, G. (1998). Pediatricians enlisted in flight against childhood killers (59): World Health Organization.

Bruvold, W. (1993). A meta-analysis of adolescent smoking prevention programs. American Journal of Public Health, 83, 872-880.

Bulloct A De Vries H I ond M Thomas H Charlion A (1996) Smokino nrevention and voung people: Using research to identify out-of-school intervention sites in three countries. Educational Review, 48, 143-152.

Bush, P., \& lannotti, R. (1993). Alcohol, cigarette, and marijuana use among fourth-grade urban schoolchildren in 1988/89 and 1990/91. American Journal of Public Health, 83, 111-114.

Cameron, R., Brown, K., Best, J., Pelkman, C., Madill, C., Manske, S., \& Payne, M. (1999). Effectiveness of a social influences smoking prevention program as a function of provider type, training method, and school risk. American Journal of Public Health, 89, 1827-1831.

Campbell, M., DeVellis, B., Strecher, V., Ammerman, A., DeVellis, R., \& Sandler, R. (1994). Improving dietary behavior: The effectiveness of tailored messages in primary care settings. American Journal of Public Health, 84, 783-787.

Centraal Bureau voor Statistiek (2002). Cijfers-kerncijfers-onderwijs. CBS. Retrieved 26 August 2003, from the World Wide Web (http://statline.cbs.nl/StatWeb/start. asp?lp=-Search/Search).

Chaffee, S., \& Roser, C. (1986). Involvement and the consistency of knowledge, attitudes and behaviour. Communication Research, 3, 373-99.

Charlton, A. (1986). Evaluation of a family-linked smoking programme in primary schools. Health Education Journal, 45, 140-144.

Chassin, L., Presson, C. Montello, D., Sherman, S., \& McGrew, J. (1986). Changes in peer and parent influence during adolescence: Longitudinal versus cross-sectional perspectives on smoking initiation. Developmental Psychology, 22, 327-334.

Chassin, L., Presson, C., \& Sherman, S. (1995). Social-psychological antecedents and consequences of adolescent tobacco use. In J. Wallender \& L. Siegel (Eds.), Advances in pediatric psychology. NewYork, US: The Guilford Press.

Chatrou, M. (1992). Determinants of smoking and smoking prevention in Dutch adolescents. Leiden: DSWO Press.

Chatrou, M., Maes, S., Dusseldorp, E., \& Seegers, G. (1999). Effects of the Brabant Smoking Prevention Programme: A replication of the Winconsin Programme. Psychology and Health, 14, 159-178.

Cohen. D., Richardson, J.. \& LaBree, L. (1994). Parenting behaviors and the onset of smoking and alcohol use: A longitudinal study. Pediatrics, 94, 368-375.

Colby, S., Tiffany, S., Shiffman, S., \& Niaura, R. (2000). Are adolescent smokers dependent on nicotine? A review of the evidence. Drug and Alcohol Dependence, 59 (Suppl.1), S83-S95. 
Conrad, K., Flay, B., \& Hill, D. (1992). Why children start smoking cigarettes: predictors of onset. British Journal of Addiction, 87, 1711-1724.

Cuijpers, P. (2002). Effective ingredients of school-based drug prevention programs. A systematic review. Addictive Behaviors, 27, 1009-1023.

De Nooijer, J., Lechner, L., \& De Vries, H. (2002). Tailored versus general information on early detection of cancer: a comparison of the reactions of Dutch adults and the impact on attitudes and behaviors. Health Education Reseanch, 17, 239-252.

De Vries, H. (1995). Socio-economic differences in smoking: Dutch adolescents' beliefs and behaviour. Social Science and Medicine, 41,419-424.

De Vries, H. (1999). Smoking and young people: The wider issues. Health Promotion Northern Ireland, 8 , 11-13.

De Vries, H. (2000). Smoking Prevention and Smoking Cessation. In N. Smelser \& P. Baltes (Eds.). The International Enceclopedia of the Social \& Behavioral Sciences. Oxford: Pergamon.

De Vries, H., \& Backbier, E. (1994). Self-efficacy as an important determinant of quitting among pregnant women who smoke: The O-pattem. Preventive Medicine, 23, 167-174.

De Vries, H., Backbier, E., Dijkstra, M., Van Breukelen, G., Parcel, G., \& Kok. G. (1994). A Dutch social influence smoking prevention approach for vocational school students. Health Education Research, 9. 365-374.

De Vries, H., Backbier, E., Kok, G., \& Dijkstra, M. (1995). The impact of social influences in the context of attitude, self-efficacy, intention and previous behaviour as predictors of smoking onset. Journal of Applied Social Psychology, 25, 237-257.

De Vries, H., \& Brug. J. (1999). Computer-tailored interventions motivating people to adopt health promoting behaviours: Introduction to a new approach. Patient Education and Counseling, 36, 99-105.

De Vries, H., Dijkstra, M., \& Kok, G. (1988). A Dutch smoking prevention programme: development. implementation and results. Elsevier Seience Publishers 591-595.

De Vries, H., Dijkstra, M., \& Kuhlman, P. (1988). Self-efficacy: The third factor besides attitude and subjective norm as a predictor of behavioural intentions. Health Education Research, 3, 273-282

De Vries, H., \& Kok, G. (1986). From determinants of smoking behaviour to the implications for a prevention programme. Health Education Research, 1, 85-94.

De Vries, H., \& Mudde, A. (1998). Predicting stage transitions for smoking cessation applying the attitudesocial influence-efficacy model. Psychology and Health, 13, 369-385.

De Vries, H., Mudde, A., Dijkstra, A., \& Willemsen, M. (1998). Differential beliefs, perceived social influences, and self-efficacy expectations among smokers in various motivational phases. Preventive Medicine, 27, 681-689.

De Vries, H., Mudde, A., Leijs, I., Charlton, A., Vartiainen, E., Buijs, G., Pais Clemente, M., Storm, H., Gonzales Navarro, A., Nebot, M., Prins, T., \& Kremers, S. (accepted for publication). The European Smoking Prevention Framework Approach (ESFA): An example of integral prevention. Health Education Research.

De Zwart, W., Stam, H., \& Kuipers, S. (1997). Jeugd en riskant gedrag 1996: Roken, drinken, drugsgebruik en gokken onder scholieren vanaf tien jaar [Youth and risk behaviour 1996: Smoking, drinking, drugs use and gambling among students aged ten years and older]. Utrecht: Trimbos Instituut.

Dijkstra, A., \& De Vries, H. (1999). The development of computer-generated tailored interventions. Patient Education and Counseling, 36, 193-203.

Dijkstra, A., De Vries, H., \& Roijackers, J. (1998). Long-term effectiveness of computer-generated tailored feedback in smoking cessation. Health Education Research, 13, 207-214.

Dijkstra, A., De Vries, H., \& Roijackers, J. (1999). Targeting smokers with low readiness to change with tailored and nontailored self-help materials. Preventive Medicine, 28, 203-211.

Dijkstra, A., De Vries, H., Roijackers, J., \& Van Breukelen, G. (1998). Tailored interventions to communicate stage-matched information to smokers in different motivational stages. Journal of Consulting and Clinical Psychology, 66, 549-557.

Dijkstra, A., De Vries, H., \& Roijackers, J. (1998). Computerized tailored feedback to change cognitive determinants of smoking: A Dutch field experiment. Health Education Research, 13, 197-206.

Dijkstra, M., Mesters, I., De Vries, H., van Breukelen, G., \& Parcel, G. (1999). Effectiveness of a social influence approach and boosters to smoking prevention. Health Education Research, 14, 791-802.

Doll, R., \& Hill, A. (1950). Smoking and carcinoma of the lung. Preliminary report. British Medical Journal 739.748. 
Doll, R., Peto, R., Wheatly, K., Gray, R., \& Sutherland, I. (1994). Mortality in relation to smoking: 40 years' observation on male British doctors. British Medical Journal, 309, 901-911.

Donaldson, S., Graham, J., \& Hansen, W. (1994). Testing the generalizability of intervening mechanism theories: Understanding the effects of adolescent drug use prevention interventions. Journal of Behavioral Medicine, 17, 195-216.

Elder, J., Perry, C., Stone, E., Johnson, C., Yang, M., Edmundson, E., Smyth, M., Galati, T., Feldman, H., Cribb, P., \& Parcel, G. (1996). Tobacco use measurement, prediction, and intervention in elementary schools in four states: The CATCH Study. Preventive Medicine, 25, 486-494.

Elder, J., Sallis, J., Woodruff, S., \& Wildey, M. (1993). Tobacco-refusal skills and tobacco use among highrisk adolescents. Journal of Behavioral Medicine, 16, 629-642.

Elder, J., Wildey, M., de Moor, C., Sallis, J. j., Eckhardt, L., Edwards, C., Erickson, A., Golbeck, A., Hovell, M., Johnston, D., Levitz, M., Molgaard, C., Young, R., Vito, D., \& Woodruff, S. (1993). The long-term prevention of tobaceo use among junior high school students: Classroom and telephone interventions. American Journal of Public Health, 83, 1239-1244.

Ellickson, P., \& Bell, R. (1990). Drug prevention in junior high: A multi-site longitudinal test. Science, 247. 1299-1305.

Ellickson, P., Bell, R., \& McGuigan, K. (1993). Preventing adolescent drug use: Long-term results of a junior high program. American Journal of Public Health, 83, 856-861.

Engels, R., Knibbe, R., De Vries, H., Drop, M., \& van Breukelen, G. (1999). Influences of parental and best friends' smoking and drinking on adolescent use: A longitudinal study. Journal of Applied Social Psychology, 29, 337-361.

Engels, R., Knibbe, R., \& Drop, M. (1999). Predictability of smoking in adolescence: between optimism and pessimism. Addiction, 94, 115-124.

Ennett, S., \& Bauman, K. (1994). The contribution of influence and selection to adolescent peer group homogeneity: The case of adolescent eigarette smoking. Journal of Personality and Social Psychology, 67, 653-663.

Epstein, J., Botvin, G., \& Diaz, T. (1999). Social influence and psychological determinants of smoking among inner-city adolescents. Journal of Child and Adolescent Substance Abuse, 8, 1-19.

Evans, M. (1991). The problem of analyzing multiplicative composites: Interactions revisited. American Psychologist, 46, 6-15.

Evans, R. (1980). Behavioral medicine: A new applied challenge to social psychologists. In L. Bickman (Ed.), Applied Social Psychology Annual (Vol. 1). Beverly Hills-London: Sage Publications.

Evans, R. (1983). Deterring smoking in adolescents: Evolution of a research program in applied social psychology. International Review of Applied Psychology, 32, 71-83.

Evans, R., Rozelle, R., Mittelmark, M., Hansen, A., Bane, A., \& Havis, J. (1978). Deterring the onset of smoking in children: Knowledge of immediate physiological effects and coping with peer pressure, media pressure, and parent modeling. Journal of Applied Social Psychology, 8, 126-135.

Fazio, R., \& Towles-Schwen, T. (1999). The MODE model of attitude-behavior processes. In: S. Chaiken \& Y. Trope (Eds.), Dual process theories in social psychology. New York: Academic press.

Festinger, L. (1962). A theory of cognitive dissonance. Standford CA: Standford University Press.

Fishbein, M., \& Ajzen, I. (1975). Belief, attitude, intention, and behavior: an introduction to theory and research. Reading, MA: Addison-Wesley.

Flay, B. (1985). Psychosocial approaches to smoking prevention: A review of findings. Health Psychology, 4, 449-488.

Flay, B., d'Avernas, J., Best, J., Kersell, M., \& Ryan, K. (1983). Cigarette smoking: why young people do it and ways of preventing it. In: P. McGrath \& P. Firestone (Eds.), Pediatric and adolescent behavioral medicine. New York: Springer-Verlag.

Flay, B., Koepke, D., Thomson, S., Santi, S., Best, J., \& Brown, K. (1989). Six-year follow-up of the first Waterloo school smoking prevention trial. American Journal of Public Health, 79, 1371-1376.

Flay, B., Miller, T., Hedeker, D., Siddiqui, O., Britton, C., Brannon, B., Anderson Johnson, C., Hansen, W., Sussman, S., \& Dent, C. (1995). The Television, School, and Family smoking prevention and cessation Project: VIII. Student outcomes and mediating variables. Preventive Medicine, 24, $29-40$.

Flay, B., \& Petraitis, J. (1994). The theory of triadic influence: A new theory of health behavior with implications for preventive interventions. Advances in Medical Sociology. 4, 19-44).

Flay, B., Phil, D., Hu, F., \& Richardson, J. (1998). Psychosocial predictors of different stages of cigarette smoking among high school students. Preventive Medicine, 27, A9-A18. 


\section{references}

Flay, B. R. (1993). Youth tobacco use: Risks, patterns, and control. In: C. Orleans \& J. Slade (Eds.), Nicotine addiction: Principles and management. New York: Oxford University Press.

Flynn, B., Worden, J. K., Secker-Walker, R., Bladger, G., \& Geller, B. (1995). Cigarette smoking prevention effects of mass media and school interventions targeted to gender and age groups. Journal of Health Education, 26, Suppl.-2, S45 -S51.

Friedman, L., Lichtenstein, E., \& Biglan, A. (1985). Smoking onset among teens: An empirical analysis of initial situations. Addictive Behaviors, 10, 1-13.

G8 ministers of the Environment. (1997). Declaration of the environment leaders of the G-eight on children's environmental health, Miami.

Glynn, T. (1989). Essential elements of school-based smoking prevention programs. Journal of School Health, 59, 181-188.

Glynn, T. (1993). Improving the health of U.S. children: The need for early interventions in tobacco use. Preventive Medicine, 22, 513-519.

Glynn, T., Greenwald, P., Mills, S., \& Manley, M. (1993). Youth tobacco use in the United States- Problem. progress, goals, and potential solutions. Preventive Medicine, 22, 568-575.

Glynn, T. J., Anderson, D. M., \& Schwarz, L. (1991). Tobacco-use reduction among high-risk youth: Recommendations of a National Cancer Institute Expert Advisory Panel. Preventive Medicine, 20, 279. 291.

Green, L., \& Kreuter, M. (1999). Health Promotion and planning: An educational and ecological approach. Mountain View, CA: Mayfield Publishing Company.

Hafstad, A., Stray-Pedersen, B., \& Langmark, F. (1997). Use of provocative emotional appeals in a mass media campaign designed to prevent smoking among adolescents. European Journal of Public Health. 7 , 122-127.

Hansen, W., \& Graham, J. (1991). Preventing alchohol, marijuana, and cigarette use among adolescents: peer pressure resistance training versus establishing conservative norms. Preventive Medicine, 20, 414-430.

Hedeker, D., \& Gibbons, R. (1996a). MIXOR: A computer program for mixed-effects ordinal regression analysis. Computer Methods and Programs in Biomedicine, 49, 157-176.

Hedeker, D., \& Gibbons, R. (1996b). MIXREG: A computer program for mixed-effects regression analysis with autocorrelated errors. Computer Methods and Programs in Biomedicine, 49, 229-252.

Heyting, A., Tolboom, J., \& Essers, J. (1992). Statistical handling of drop-outs in longitudinal clinical trials. Statistics in Medicine, 11, 2043-2061.

Hollis, S., \& Campbell, F. (1999). What is meant by intention to treat analysis? Survey of published randomised controlled trials. British Medical Journal, 319, 670-674.

Jessor, R., \& Jessor, S. (1977). Problem behavior and social development: A longitudinal study of youth. New York: Academic Press.

Kandel, D. (1978). Homophily, selection, and socialization in adolescent friendships. American Journal of Sociology, 84, 427-437.

Kandel, D., \& Faust, R. (1975). Sequence and stages in patterns of adolescent drug use. Archives of General Psychiatry, 32, 923-932.

Kaufman, J., Jason, L., Sawlski, L., \& Halpert, J. (1994). A comprehensive multi-media program to prevent smoking among black students. Journal of Drug Education, 24, 95-108.

Kelder, S., Perry, C., Klepp, K., \& Lytle, L. (1994). Longitudinal tracking of adolescent smoking, physical activity, and food choice behaviors. American Journal of Public Health, 84, 1121-1126.

Kremers, S. (2002). On your marks: Revising, testing and integrating stage models of smoking initiation. Maastricht University, Maastricht.

Kremers, S., De Vries, H., Mudde, A., \& Candel, M. (accepted for publication). Motivational stages of adolescent smoking initiation: predictive validity and predictors of transitions. Addictive Behaviors.

Kreuter, M., Farrell, D., Olevitch, L., \& Brennan, L. (2000). Tailoring health messages: Customizing communication with computer technology. Mahwah, New Jersey: Lawrence Erlbaum Associates.

KWF. (2001). Feiten en cijfers over roken en kanker [Facts and figures about smoking and cancer]. Retrieved 26 mai, 2003. from the World Wide Web: (http://www. kankerbestrijding.nl/content/pages/ Cijfers_over_roken_en_kanker.html" 3 ).

Lantz, P., Jacobson, J., Warner, K., Wasserman, J., Pollack, H., Berson, J., \& Ahlstrom, A. (2000). Investing in youth tobacco control: A review of smoking prevention and control strategies. Tobacco Control, 9, 47. 63. 


\section{references}

Leventhal, H., \& Cleary, P. (1980). The smoking problem: A review of the research and theory in behavioral risk modification. Psychological Bulletin, 88, 370-405.

Levin, M., Goldstein, H., \& Gerhardt, P. (1950). Cancer and tobacco smoking. Journal of the American Medical Association, 143, 336-338.

Lloyd-Richardson, E., Papandonatos, G., Kazura, A., Stanton, C., \& Niaura, R. (2002). Differentiating stages of smoking intensity among adolescents: Stage-specific psychological and social influences. Journal of Consulting and Clinical Psychology, 70, 998-1009.

Lynch, B., \& Bonnic, R. (1994). Growing up tobacco-free: Preventing nicotine addiction in children and youth. Washington DC: National Academic Press.

Mayhew, K., Flay, B., \& Mott, J. (2000). Stages in the development of adolescent smoking. Drug and Alcohol Dependence, 59( Suppl.-1), S61-S81.

McAlister, A., Perry, C., Killen, J., Slinkard, L., \& Maccoby, N. (1980). Pilot study of smoking, alcohol and drug abuse prevention. American Journal of Public Health, 70, 719-721.

McGuire, W. (1964). Inducing Resistance to persuasion, some contemporary approaches. In: L. Berkowitz \& M. Zanna (Eds.), Advances in experimental social psychology. San Diego CA: Academic Press.

McNeill, A., Jarvis, M., Stapleton, J., Russel, M., Eiser, J., Gammage, P., \& Gray, E. (1988). Prospective study of factors predicting uptake of smoking in adolescents. Journal of Epidemiology and Community Health, 43, 72-78.

Ministers responsible for youth. (1998). Lisbon Declaration. Paper presented at the First world conference of ministers responsible for youth, Lisbon, August 8-12.

Moerbeek, M., van Breukelen, G., Ausems, M., \& Berger, M. (in press). Optimal sample sizes in experimental designs with individuals nested within clusters. Understanding Statistics.

Murray, D., O'Connell, C., Schmid, L., \& Perry, C. (1987). The validity of smoking self-reports by adolescents: A reexamination of the bogus pipeline procedure. Addictive Behavior, 12, 7-15.

Murray, D., \& Perry, C. (1987). The measurement of substance use among adolescents: When is the "bogus pipeline" method needed? Addictive Behavior, 12, 225-233.

Murray, D., Perry, C., Griffin, G., Harty, K., Jacobs, D., Schmid, L., Daly, K., \& Pallonen, U. (1992). Results from a statewide approach to adolescent tobacco use prevention. Preventive Medicine, 21, 449-472.

Murray, D., Pirie, P., Leupker, R., \& Pallonen, U. (1989). Five- and six-year follow-up results from four seventh-grade smoking prevention strategies. Journal of Behavioral Medicine, 12, 207-218.

NHS. (1999). Preventing the uptake of smoking in young people. York: NHS, Centre for reviews and dissemination.

Nutbeam, D., Macaskill, P., Smith, C., Simpson, J., \& Catford, J. (1993). Evaluation of two school smoking education programmes under normal classroom conditions. British Medical Journal, 306, 102-107.

Pallonen, U., Velicer, W., Prochaska, J., Rossi, J., Bellis, J., Tsoh, J., Migneault, J., Smith, N., \& Prokhorov, A. (1998). Computer-based smoking cessation interventions in adolescents: Description, feasibility, and six-month follow-up findings. Substance Use and Misuse, 33, 935-965.

Pentz, M., Dwyer, J., Mackinnon, D., Flay, B., Hansen, W., Wang. E., \& Johnson, C. (1989). A multicommunity trial for primary prevention of adolescent drug abuse. Effects on drug use prevalence. Journal of the American Medical Association, 261, 3259-3266.

Perry, C., Kelder, S., \& Klepp, K. (1994). Community-wide cardiovascular disease prevention in young people: Long-term outcomes of the Class of 1989 Study. European Journal of Public Health, 4, 188-194.

Peterson, A., Kealey, K., Mann, S., Marek, P., \& Sarason, 1. (2000). Hutchinson Smoking Prevention Project: Long-term randomized trial in school-based tobacco use prevention - Results on Smoking. Journal of the National Cancer Institute, 92, 1979-1991.

Petraitis, J., Flay, B., \& Miller, T. (1995). Reviewing theories of adolescent substance use: Organizing pieces in the puzzle. Psychological Bulletin, 117, 67-86.

Petty, R., \& Caccioppo, J. (1986). Communication and persuasion, central and peripheral routes to attitude change. New York: Springer-Verlag

Petty, R., \& Cacioppo, J. (1986). The elaboration likelihood model of persuasion. In: L. Berkowitz (Ed.), Advances in Experimental Social Psychology (Vol. 19). London: Academic Press.

Pierce, J., \& Gilpin, E. (1996). How long will today's new adolescent smoker be addicted to cigarettes? American Journal of Public Health, 86, 253-256.

Price, J., Beach, P., Everett, S., Telljohann, S., \& Lewis, L. (1998). Evaluation of a three-year urban elementary school tobacco prevention program. Journal of School Health, 68, 26-31. 


\section{references}

Prochaska, J., \& DiClemente, C. (1983). Stages and processes of self-change of smoking: toward an integrative model of change. Journal of Consultancy and Clinical Psychology, 51, 390-395.

Prochaska, J., Norcross, J., \& DiClemente, C. (1994). Changing for good. New York: William Morrow and Company.

Public Health Service. (1964). Smoking and health. Report of the advisory committee to the Surgeon General of the Public Health Service. (PHS Publication, 1103): US Department of Health, Education, and Welfare, Public Health Service.

Redman, B. (1997). The practice of patient education. St Louis: Mosby.

ResCon. (1999). De gezonde school en genotmiddelen 1995-1998: Eindevaluatie /The healthy school and stimulants 1995-1998: Final evalution]. Haarlem: ResCon Research \& Consultancy.

Rimer, B., Orleans, C., Fleisher, L., Cristinzio, S., Resch, N., Telepchak, J., \& Keintz, M. (1994). Does tailoring matter? The impact of a tailored guide on ratings and short-term smoking-related outcomes for older smokers. Health Education Research, 9, 69-84.

Ringwalt, C., Ennett, S., \& Holt, K. (1991). An outcome evaluation of Project DARE (Drug Abuse Resistance Education). Health Education Research, 6, 327-337.

Rooney, B., \& Murray, D. (1996). A meta-analysis of smoking prevention programs after adjustment for errors in the unit of analysis. Health Education Quarterly, 23, 48-64.

Scheier, L., Botvin, G., \& Griffin, K. (2001). Preventive intervention effects on developmental progression in drug use: Structural equation modeling analyses using longitudinal data. Prevention Science, 2, 91-112.

Shadel, W., Shiffman, S., Niaura, R., Nichter, M., \& Abrams, D. (2000). Current models of nicotine dependence: What is known and what is needed to advance understanding of tobacco etiology among youth. Drug and Alcohol Dependence, 59(Suppl-1), S9-\$22.

Skinner, C., Siegfried, J., Kegler, M., \& Strecher, V. (1993). The potential of computers in patient education. Patient Education and Counseling, 22, 27-34.

Slovic, P. (1998). Do adolescents smokers know the risks? Duke Law Journal, 47, 1133-1141.

Soldz, S., \& Cui, X. (2001). A risk factor index predicting adolescent cigarette smoking: A 7-year longitudinal study. Psychology of Addictive Behaviors, 15, 33-41.

Sowden. A., Alblaster, L., \& Stead, L. (2003). Community interventions for preventing smoking in young people Cochrane Review). In: The Cochrane Library. Issue 3. Oxford: Update Software

Sowden A , Arblaster L. (2003) Mass media interventions for preventing smoking in young people (Cochrane Review). In: The Cochrane Library, Issue 3, Oxford: Update Software.

SPSS Inc. (1999). SPSS Base 9.0: User's Guide. Chicago: SPSS Inc.

Stead L, Lancaster T. (2003). Interventions for preventing tobacco sales to minors (Cochrane Review). In: The Cochrane Library, Issue 3, Oxford: Update Software.

Stead, M., Hastings, G., \& Tudor-Smith, C. (1996). Preventing adolescent smoking: A review of options. Health Education Journal, 55, 31-54.

Stivoro (1996). NIPO-enquete naar roken onder de jeugd, 1996 [NIPO-survey on youth smoking. 1996]. The Hague: Stichting Volksgezondheid en Roken: Dutch Foundation on Smoking and Health.

Stivoro (1997). Anmual report 1996. The Hague: Stichting Volksgezondheid en Roken: Dutch Foundation on Smoking and Health.

Stivoro. (1998). Roken de harde feiten: Jeugd 1997 [Smoking the firm facts. Youth 1997]. The Hague: Stichting Volksgezondheid en Roken: Dutch Foundation on Smoking and Health.

Stivoro (2001). 100.000 helden: Jaarverslag 2000 [100,000 heroes: Anmual report 2000]. The Hague: Stichting Volksgezondheid en Roken: Dutch Foundation on Tobacco and Health.

Sussman, S., Dent, C., Burton, D., Stacy, A., \& Flay, B. (1995). Developing school-based tobaceo use prevention and cessation programs. London: Sage.

Sussman, S., Dent, C., Stacy, A., \& Craig. S. (1998). One-year outcomes of project towards no drug abuse. Preventive Medicine, 27, 632-642.

Sussman, S., Dent, C., Stacy, A., Sun, P., Craig. S., Simon, T., Burton, D., \& Flay, B. (1993). Project towards no tobacco use: 1-year behavior outcomes. American Journal of Public Health, 83, 1245-1250.

Tabachnick, B., \& Fidell, L. (2000). Using multivariate statistics. Boston: Allyn \& Bacon.

Taioli, E., \& Wynder, E. (1991). Effect of the age at which smoking begins on frequency of smoking in adulthood. The New England Journal of Medicine, 325, 368-369.

Thomas R. (2003). School-based programmes for preventing smoking (Cochrane Review). In: The Cochrane Library, Issue 3, Oxford: Update Software. 


\section{references}

Thompson, E. (1978). Smoking education programs 1960-1976. American Journal of Public Health, 68, 250257.

Tobler, N., \& Stratton, H. (1997). Effectiveness of school-based drug prevention programs: A meta-analysis of the research. Journal of Primary Prevention, 18, 71-128.

Torabi, M., Bailey, W., \& Majd Jabbari, M. (1993). Cigarette smoking as a predictor of alcohol and other drug use by children and adolescents: Evidence of the 'gateway drug effect'. Journal of School Health, 63 , 302-306.

Tyas, S., \& Pederson, L. (1998). Psychosocial factors related to adolescent smoking: A critical review of the literature. Tobacco Control, 7, 409-420.

US Department of Health and Human Services. (1988). The health consequences of smoking: nicotine addiction. A report of the Surgeon General (DHHS Publication No. (CDC 88-8406). Washington, DC: U.S. Government Printing Office.

US Department of Health and Human Services.(1990). The Health benefits of smoking cessation: A report of the Surgeon General. (CDC 90-8416). Washington DC: U.S. Government Printing Office.

US Department of Health and Human Services. (1994). Morbidity and Mortality Weekly Report: Guidelines for School Health Programs to Prevent Tobacco Use and Addiction. Washington DC: U.S. Government Printing Office.

US Department of Health and Human Services. (1994). Preventing Tobacco use among young people: a report of the Surgeon General. Washington DC: U.S. Government Printing Office.

US Department of Health and Human Services. (2000). Reducing tobacco use: a report of the surgeon general. Washington DC: U.S. Government Printing Office: USDHHS.

Van Roosmalen, E. H., \& McDaniel, S. A. (1992). Adolescent smoking intentions: Gender differences in peer context. Adolescence, 27, 87-105.

Vartiainen, E., Paavola, M., McAlister, A., \& Puska, P. (1998). Fifteen-year follow-up of smoking prevention effects in the North Karelia Youth Project. American Journal of Public Health, 88, 81-85.

Velicer, W., Prochaska, J., Bellis, J., DiClemente, C., Rossi, J., Fava, J., \& Steiger, J. (1993). An expert system intervention for smoking cessation. Addictive Behaviors, 18, 269-290.

VWS. (2002, 25-4-2002). Tabakswet 2002 [Tobacco Law 2002]. Retrieved 26th of May, 2003, from the World Wide Web: (http://www.minvws.nl/documents/gzb/Wetstekst/Tabakwet-ek.pdf)

Warren, C., Riley, L., Asma, S., Eriksen, M., Green, L., Blanton, C., Loo, C., Batchelor, S., \& Yach, D. (2000). Tobacco use by youth: A surveillance report from the Global Youth Tobacco Survey project. Bulletin of the World Health Organization, 78, 868-876.

Wenter, D., Blackwell, S., Davis, K., \& Farrelly, M. (2002). First Look report 8: Using multiple strategies in tobacco use prevention education: American Legacy Foundation.

White, D., \& Pitts, M. (1998). Educating young people about drugs: a systematic review. Addiction, 93, 14751487.

Willemsen, M., \& De Vries, H. (1995). Evaluation of a smoking cessation intervention for Dutch employees consisting of self-help methods and a group program. Tobacco Control, 4, 351-354.

Willemsen, M., De Vries, H., Oldenburg, B., \& Van Breukelen, G. (1999). Impact of a comprehensive worksite smoking cessation programme on employees who do not take part in cessation activities. Psychology and Health, 14, 887-895.

Willemsen, M. C., \& de Zwart, W. M. (1999). The effectiveness of policy and health education strategies for reducing adolescent smoking: a review of the evidence. Journal of Adolescence, 22, 587-599.

World Health Organization (1998). Guidelines for controlling and monitoring the tobacco epidemic. Geneva: WHO monograph nr. WM $29098 \mathrm{GU}$

Yach, D., \& Ferguson, B. (1999). Can we stop children and adolescents from smoking? Social Science \& Medicine, 48, 757-758. 


\section{Summary}

Despite all prevention efforts, the prevalence of smoking among youngsters remains a cause for concern. Several areas of special attention related to smoking prevention have been identified. In this thesis several high priority areas were stressed: smoking prevention interventions for youngsters and for at-risk groups; smoking prevention in out-of-school settings; and smoking prevention supplemented with booster sessions.

This thesis starts in chapter 1 with an overview of the prevalence of smoking among youngsters, the health effects of smoking, the development and impact of of smoking prevention strategies, and the explanation of smoking onset. The first chapter ends with a description of the context and outline of the resarch project on which this thesis was built.

Chapters 2-6 report on the evaluation of different approaches of smoking prevention aimed at both elementary and vocational school students, namely in-school, tailored out-of-school, and combined in-school and out-of-school programs. The elementary and vocational in-school programs were existing social influence smoking prevention programs. The out-of-school programs made use of computer tailoring and consisted of personalized letters that were sent to the students' home addresses. The letters, for instance, informed the student about her/ his concerns considering smoking or about the social influences from smoking people in the student's environment, and were based on data gathered through the pretest questionnaire.

In chapter 2 the short-term effects, six months after pretest, of the elementary inschool, out-of-school and combined in- and out-of-school programs are discussed. Data analyses showed that the tailored out-of-school program was successful in preventing smoking continuation among pretest ever smokers. The in-school program and the combined approach did not show positive results.

Chapter 3 reports on follow-up results (nine months after pretest) of the in-school, out-of-school and combined smoking prevention programs for elementary school children. The positive six-month behavioral tailoring effects were no longer continued. The in-school program and the combined approach neither resulted in significant effects. Chapter 3 also considers intermediate outcomes. It was found that elementary school students perceived more disadvantages of smoking after participation of irrespective the in-school or out-of-school program. In addition, the tailored out-ofschool program led to increased self-efficacy expectations about refusing cigarettes among pretest never smokers.

Chapter 4 reports on long-term behavioral results (20,30,36 months after pretest) of the in-school, tailored out-of-school and combined smoking prevention programs for elementary school children. By then, the transition to secondary education had occured. Since the trial was confronted with considerable levels of dropout, different strategies for handling missing data were used: complete case, extreme-case and carried-forward analyses. Complete-case and carried-forward analyses resulted in highly similar conclusions, namely that long-term effects were found for neither the in-school, nor for the out-of-school and combined approach. The extreme-case strategy resulted in very high, probably too high, estimations of smoking initiation and continuation percentages. 
Therefore, the results of the extreme-case analyses should not be taken serious.

Because, the positive short-term results, and the long-term dissipation of effects of the tailored out-of-school program, a booster intervention was developed and implemented 24 months after the above mentioned tailored out-of-school intervention. This booster intervention, described in chapter 5 , was supposed to reinforce or renew the earlier presented tailored information about smoking. The booster intervention consisted of three personalized letters with information that was derived from a previous assessment. Like the long-term elementary school study, the booster intervention faced serious dropout. Therefore, again three strategies that deal missing data differently were applied to evaluate the booster effects. Thirty-six months after the pretest, students exposed to the tailored out-of-school program and who were assigned to the booster condition were, according to the complete-case and carried-forward analyses, less likely to have initiated smoking compared with students who were engaged in the tailored outof-school program but who did not receive the booster letters. A similar effect was found among pretest ever smokers for smoking continuation, although this effect was only detected in the complete-case analyses. Again, the extreme case strategy resulted in very high smoking percentages, and could therefore hardly be interpreted.

Chapter 6 summarizes the results of the vocational school smoking prevention intervention. The in-school program showed positive results 12 months after pretest as regards smoking continuation among pretest ever smokers, while the tailored out-ofschool program was successful 18 months after pretest as regards smoking initiation among pretest never smokers.

The second part of this thesis, the chapters 7 and 8 , deals with factors related to smoking initiation and continuation among elementary school students. Chapter 7 presents cross-sectional findings with respect to differences between never, experimental, and regular smoking elementary school students. These three smoking categories were compared on demographic and psychosocial ASE (Attitude- Social influence- self Efficacy) determinants. With respect to demographic determinants, never smokers discriminated from experimental smokers in that they were younger, more often female, more often religious and more often from two-parent families. Experimental smokers received less pocket money than the regular smokers. With respect to psychosocial determinants, never smokers were most positive regarding the ASE determinants, while regular smokers had the most negative perceptions. The scores of the experimental smokers were in general between those of the never and regualr smokers.

Another point of interest with respect to the understanding of reasons for elementary smoking initiation and continuation was whether elementary schoolgirls and -boys differ in their reasons, and should as a consequence be treated separately. Chapter 8 reports on these gender differences considering smoking. Girls and boys shared a number of risk factors for smoking initiation like higher age, maternal smoking and smoking relatives (more is worse), and higher self-efficacy expectations, but some differences also appeared. Predictive only for girls were parents' Dutch origin and the presence of smoking siblings, while predictive only for boys was a higher perception of pressures to smoke. Dutch elementary schoolboys were more at risk to continue to smoke than girls, but no predictive gender differences came out. The presence of smoking siblings and best friends, a lower perception of disadvantages of smoking and lower self-efficacy expectations predicted smoking continuation in both girls and boys. 
Chapter 9 is a general discussion of the results from the various studies on smoking prevention aimed at Dutch youngsters, followed by a review of methodological limitations and considerations for the future. Several conclusions can be drawn from the research in this thesis, with regard to smoking prevention for elementary school and vocational school students. The findings of the elementary school research indicate that tailored out-of-school programs might prevent smoking in the short-term but not in the long-term. Supplementary booster sessions to the smoking prevention programs gave mixed results making a reliable estimate of effects difficult. Further exploration of tailored smoking prevention for elementary schoolchildren seems recommended. The findings of the vocational school research indicate that smoking prevention for vocational school students might start with a tailored approach, in order to prevent smoking initiation, and could subsequently continue with in-school programs, in order to prevent smoking continuation.

Finally, cross-sectional data showed that the highest-grade elementary school population could be categorized into three types with regard to smoking: never, experimental, and regular smokers. Smoking prevention aimed at elementary school students should acknowledge these different types. Cross-sectional data increase the insights in factors associated with smoking initiation and continuation, but do not increase the insights in the process of smoking initiation. Longitudinal data that were collected in the studies described in the chapters 2-4, however suggest that risk factors of smoking initiation and continuation were rather similar. More research is needed to explore a more refined set of proximal and distal factors related with smoking. Finally, developing gender-specific smoking prevention programs for elementary school students seems not necessary. 



\section{Samenvatting}

Ondanks de inspanningen op het gebied van rookpreventie blijft de aanwezigheid van rokende jongeren een bron van zorg. Dit proefschrift richt zich op verschillende aspecten van rookpreventie: rookpreventie gericht op jongeren; rookpreventie gericht op risicogroepen; rookpreventie in de buitenschoolse setting; en rookpreventie aangevuld met boosters. Een booster is een herhaling van -of vernieuwde blootstelling aan- een eerdere voorlichtingsactiviteit.

Het eerste hoofdstuk van dit proefschrift geeft een overzicht van de prevalentie van roken door jongeren, van de mogelijke gevolgen van roken voor de gezondheid, van reeds bekende risicofactoren die samenhangen met roken, van de ontwikkelingen die de voorlichting over roken voor jongeren heeft doorlopen, en van de invloed van de verschillende voorlichtingsvormen. Het eerste hoofdstuk eindigt met een beschrijving van het onderzoeksproject dat de basis vormde voor dit proefschrift.

In de hoofdstukken 2 tot en met 6 worden de resultaten gepresenteerd van onderzoeken naar de effectiviteit van verschillende rookpreventieprogramma's: 1. Programma's uitgevoerd op school (schoolprogramma's); 2. Programma's uitgevoerd buiten de school om (buitenschoolse programma's); en 3. Een combinatie van schoolen buitenschoolse programma's. Deze programma's werden geïmplementeerd bij basisschoolleerlingen en bij leerlingen uit het voorbereidend beroepsonderwijs (VBO). De schoolprogramma's voor de basisschoolleerlingen en de VBO-leerlingen waren reeds bestaande programma's, die de invloed van de sociale omgeving als uitgangspunt hadden. De buitenschoolse programma's bestonden uit een drietal brieven met voorlichting op maat, die per post -met intervallen van ongeveer drie weken- naar de huisadressen van de jongeren zijn verzonden. De brieven waren met hulp van de computer samengesteld, en bevatten bijvoorbeeld informatie over de mening van de jongeren over roken en over de invloed die rokende mensen in de omgeving van de jongeren kunnen uitoefenen. De persoonlijke afstemming was mogelijk omdat, voorafgaande aan de interventie, de leerling een vragenlijst had ingevuld.

In het tweede hoofdstuk worden korte termijn effecten, zes maanden na de voormeting, beschreven van de basisschool interventie. De brieven met voorlichting op maat uit het buitenschoolse programma bleken effectief. Jongeren die al rookervaring hadden ten tijde van de voormeting, bleken in mindere mate hun rookgedrag te hebben gecontinueerd dan jongeren met rookervaring maar die geen brieven hadden ontvangen. Het schoolprogramma en de gecombineerde benadering bleken niet effectief.

Hoofdstuk 3 beschrijft de effecten van de basisschoolprogramma's negen maanden na de voormeting. De positieve korte termijn effecten van de brieven met voorlichting op maat uit buitenschool programma waren verdwenen. Het schoolprogramma en de gecombineerde aanpak resulteerden evenmin in positieve effecten. Op determinantenniveau werden wel effecten gevonden: Basisschool leerlingen bleken meer op de hoogte te zijn van de nadelen van roken, nadat ze deelgenomen hadden aan het schoolprogramma en/ of aan het buitenschoolse programma. Daarmaast hadden de studenten die de brieven hadden ontvangen (buitenschoolse programma), meer de indruk dat ze in staat waren om een sigaret te weigeren. Dit laatste gold enkel voor studenten die tijdens de voormeting nog nooit gerookt hadden.

Hoofdstuk 4 geeft een overzicht van de lange-termijn effecten, 20, 30 en 36 maanden na de voormeting, bij studenten die als basisschoolleerlingen deelgenomen 
hadden aan het schoolprogramma, het buitenschoolse programma of aan beiden. De toenmalige basisschoolleerlingen waren inmiddels overgestapt naar het voortgezet onderwijs. Helaas werd de studie tijdens de lange-termijn metingen geconfronteerd met flinke uitval, waardoor het noodzakelijk was om de effecten op verschillende manieren te meten. Allereerst werden alleen de gegevens van die studenten in de analyses opgenomen die daadwerkelijk aan de nameting hadden deelgenomen ('complete case' analyses). Vervolgens werden analyses uitgevoerd waarin de uitvallers als rokers werden beschouwd ('extreme case' analyses). Tenslotte werden analyses uitgevoerd waarin de ontbrekende waarden van de uitvallers werden vervangen door hun score op de voorlaatste meting ('carried forward' analyses). Wat lange-termijn effecten betreft, toonden de complete-case en carried forward analyses gelijke resultaten, namelijk het ontbreken van lange-termijn effecten van het schoolprogramma, van het buitenschoolse programma, en van de gecombineerde aanpak. De extreme case analyses resulteerden in zeer hoge schattingen van het rookgedrag van de studenten, waardoor deze laatste analyses niet betrouwbaar lijken.

Vanwege de positieve korte-termijn resultaten van het buitenschoolse programma (brieven met voorlichting op maat) en het ontbreken van follow-up effecten, werd besloten om een booster interventie te ontwikkelen en te implementeren 24 maanden nadat de studenten aan het eerder genoemde buitenschoolse programma hadden blootgestaan. De booster-interventie bestond wederom uit drie brieven met voorlichting op maat, gebaseerd op informatie verkregen uit een eerder ingevulde vragenlijst. De veronderstelling was dat boosters de eerder aangeboden voorlichting op maat zouden opfrissen en/ of bekrachtigen. De ontwikkeling, implementatie en evaluatie van de boosters staan beschreven in hoofdstuk 5 . Bij de booster interventie bleek sprake van flinke uitval. Wederom werden verschillende methoden gebruikt om de effecten vast te stellen. Uit de complete case en carried forward analyses bleek dat de boosters succesvol waren in het voorkomen dat jongeren hun eerste sigaret roken. De boosters leidden er ook toe dat jongeren die al eens gerookt hadden, in mindere mate doorgegaan zijn met roken. Dit laatste resultaat werd alleen door de complete case analyse aangetoond. De extreme case analyses leidden tot hoge -onrealistische- rookprevalentie cijfers, en waren derhalve weinig betrouwbaar.

De resultaten van de evaluaties van de VBO-interventie staan beschreven in hoofdstuk 6. Het schoolprogramma bleek een jaar na de pretest succesvol in het voorkomen dat VBO-studenten met rookervaring hun rookgedrag continueerden. Het buitenschoolse programma (brieven met voorlichting op maat) bleek succesvol in het voorkomen dat studenten zonder rookervaring ten tijde van de pretest, 18 maanden later zouden beginnen met roken.

Het tweede deel van dit proefschrift beschrijft de factoren die samenhangen met beginnen en doorgaan met roken bij leerlingen uit het basisonderwijs. Hoofdstuk 7 behandelt cross-sectionele data afkomstig van nooit rokers, experimentele rokers en regelmatig rokers. Deze drie categorieën werden vergeleken wat betreft demografische en psychosociale ASE-determinanten. Wat betreft de demografische determinanten bleek dat de nooit rokers in het algemeen jonger waren, vaker meisje, vaker gelovig en vaker afkomstig waren uit 2-ouder gezinnen dan de experimentele rokers. Vergeleken met regelmatig rokers bleken de experimentele rokers minder zakgeld te krijgen. Wat psychosociale determinanten betreft bleek dat de nooit rokers het meest positief scoorden op de ASE-determinanten ten aanzien van niet roken, terwijl de regelmatig 
rokers het meest negatief scoorden. De scores van de experimenteel rokers bevonden zich tussen die van de nooit en regelmatig rokers in.

Hoofdstuk 8 gaat in op de risicofactoren van roken bij basisschoolleerlingen en eventuele sexe-specifieke verschillen hierin. Het bleek dat meisjes en jongens een aantal risicofactoren deelden wat betreft beginnen met roken, zoals een hogere leeftijd, een rokende moeder en rokende familieleden, en een lagere inschatting van de verwachting om een sigaret te kunnen weigeren. Meisjes met twee Nederlandse ouders en meisjes met rokende zussen of broers bleken vaker te beginnen met roken, terwijl jongens die aangaven meer druk te ervaren om te roken ook meer geneigd waren om te beginnen met roken. In het algemeen waren jongens meer geneigd om door te gaan met roken, hoewel er wat betreft risicofactoren geen verschillen tussen meisjes en jongens werden gevonden. Meisjes en jongens met rokende broers, rokende zussen en/of rokende beste vrienden, meisjes en jongens die de nadelen van roken minder ernstig beoordeelden en meisjes en jongens die zichzelf minder goed in staat achtten om een sigaret te kunnen weigeren bleken vaker door te gaan met roken.

In hoofdstuk 9 worden de belangrijkste resultaten van het rookpreventie-onderzoek samengevat, bediscussieerd en worden aanbevelingen gedaan voor de praktijk en voor vervolg onderzoek. Uit de hier beschreven evaluatie-studies die betrekking hebben op de basisschool- en VBOleerlingen blijkt dat buitenschoolse rookpreventieprogramma's, in de vorm van voorlichting op maat, mogelijkheden bieden om roken bij jongeren terug te dringen. De effectiviteit van de voorlichting op maat bij de basisschoolleerlingen was echter van korte duur. Door gebruik te maken van boosters was het mogelijk om de duur van de effectiviteit te verlengen. De aanzienlijke uitval in deze fase van het onderzoek bemoeilijkte de interpretatie van de onderzoeksresultaten. Verder onderzoek dient zich, behalve op het voorkomen van uitval van de onderzoeksdeelnemers, te richten op het optimaliseren van voorlichting op maat bestemd voor basisschoolleerlingen. De resultaten van de VBO-studie lijken te wijzen op een gefaseerde aanpak van rookpreventie, te beginnen met voorlichting op maat, om beginnend rookgedrag te voorkomen, gevolgd door een schoolprogramma, om te voorkomen dat de jongere die al eens heeft gerookt doorgaat met roken.

Daarnaast is gebleken dat basisschoolleerlingen in drie categorieën opgedeeld kunnen worden: Nooit rokers, experimenteel rokers en regelmatig rokers. Rookpreventie op de basisschool dient met dit onderscheid rekening te houden. Cross-sectionele data vergroten het inzicht in de factoren die geassocieerd zijn met beginnen en doorgaan met roken, maar zeggen niet veel over het proces dat zich afspeelt tijdens deze beginfase van het rookproces. Longitudinale data, afkomstig van de evaluatiestudies uit hoofdstukken 2 , 3 , en 4 suggereren dat de risicofactoren van beginnen met roken en doorgaan met roken niet wezenlijk verschillen. Meer onderzoek wordt aanbevolen om een breder inzicht in proximale en distale factoren die samenhangen met roken te verkrijgen. Verder lijkt het ontwikkelen van aparte rookpreventieprogramma's voor meisjes en jongens overbodig. 


\section{Dankwoord}

Dit proefschrift is tot stand gekomen dankzij de adviezen, medewerking en vertrouwen van vele mensen.

Allereerst dank ik Hein de Vries en Ilse Mesters. Zij hebben als promotor en copromoter een belangrijke rol gespeeld in de begeleiding tijdens de afgelopen jaren. Hein op de cruciale momenten en Ilse vrijwel dagelijks. Gerard van Breukelen dank ik voor zijn onmisbare statistische ondersteuning.

I also would like to thank the project leaders and researcher Marie-Louisa Lopéz, Howell Thomas en Wolf Markham for their cooperation in the European project.

Stivoro en het Trimbos-instituut wil ik bedanken voor het ter beschikking stellen van de voorlichtingsmaterialen. De Europese Commissie en het Koning Wilhelmina Fonds dank ik voor de financiêle ondersteuning.

Medewerkers van de GGD-en, de vrijwilligers die trainingen voor de docenten hebben verzorgd, directeuren van het basis- en voortgezet onderwijs, onderwijzend personeel en alle deelnemende leerlingen bedankt voor jullie medewerking en inzet.

Jack Berben, Harold Dello en Leon Kolenburg, veel dank voor de hulp bij het tot stand komen van de computer programma's en/of de computer ondersteuning.

Marieke Banken en Lotte Steuten bedankt voor jullie -vaak ad hoc- assistentie.

Maastrichtse studenten, de afdeling Memic en het data-entry bureau 'Cendris' bedankt voor de prettige samenwerking.

Jan Klerkx bedankt voor de correcties en suggesties van de Engelstalige publicaties.

Collega's en oud-collega's van de capgroep GVO, dank voor de belangstelling en gezelligheid.

Verder dank ik mijn moeder voor haar stimulering, mijn vader die altijd in mij heeft geloofd, en mijn zus, broers en schoonfamilie voor hun belangstelling,. Tenslotte -last but not least- ben ik Kaspar, Janneke en Matthieu, Reinier en Jean-Pierre eeuwig dankbaar voor alle inspiratie, hulp en geduld in de afgelopen jaren. 


\section{Curriculum Vitae}

Marlein Ausems was born in Geleen on May 12, 1954. She received her VWO diploma in 1974 at the Michiel Lyceum in Geleen. In 1986 she started studying Health Sciences at the Universiteit Maastricht, she graduated in Health Education in 1991. She started working at the Department of Health Education and Promotion in 1992 as a researchassistant. In September 1997 she started working as a researcher on the European project entitled 'Smoking prevention and children', in April 1999 she continued her research on the project entitled 'Effectiveness of tailored out-of-school smoking prevention interventions among youngsters'. The outcome of this work has been written down in the present thesis. Since April 2002, she has been working as a lecturer in the field of communication and genetics at the Department of Health Education and Promotion, Universiteit Maastricht. 
